\title{
Azalides from Azithromycin to New Azalide Derivatives
}

\section{Stjepan Mutak}

Received: August 22, 2006 / Accepted: January 22, 2007

(C) Japan Antibiotics Research Association

\begin{abstract}
Azalides are semi-synthetic macrolides, in which a nitrogen atom is introduced into a macrolactone ring via a Beckmann rearrangement. Starting from erythromycin, oximes, depending on the reaction conditions lactams, or bicyclic-imino-ethers were formed, which were further reduced to aminolactones. The cyclic amine $9 \mathrm{a}-$ became the precursor for novel, significantly more active derivatives, especially for 9-dihydro-9-deoxo-9a-methyl-9a-aza-9ahomoerythromycin A with the generic name azithromycin. It showed a broad spectrum of antibacterial activity covering all significant bacteria causing respiratory tract infections. The greatest advantages of azithromycin are its unusual pharmacokinetics (high tissue distribution), metabolic stability and high tolerability. These properties have led in recent years to the widespread use of the azalide scaffold for the synthesis of new compounds with advantageous pharmacokinetics.

The azalide scaffold possesses an amino and several hydroxyl groups, which could be substituted or transformed to obtain new compounds. Different derivatives were obtained by substitution on the nitrogen but a large variety of derivatives, such as ethers, esters and carbamates, were made by reactions with various hydroxyl groups. Substitutions on both nitrogen and hydroxyl or two hydroxyl groups yielded new, bridged compounds. The 4"hydroxy group was oxidized to 4-oxo-, which was transformed via the oxime to 4-amino, or via epoxide to $4 "$-methylamino compounds. Cleavage of the cladinose sugar and further transformations gave 3-acyl or 3-oxo compounds, which were less active than 14-membered acylides or ketolides. Beckmann rearrangement of some 16-membered macrolide oximes yielded only 17-membered lactams, which were less active than starting macrolides, and could not be reduced to amines.

Intramolecular rearrangement of azalide imino-ethers yielded 13-membered azalides. Some new 11a-azalides were obtained after oxidative cleavage of some 16-membered macrolides and additional cyclisation.
\end{abstract}

Keywords azalides, azithromycin, 8a- and 9a-lactams, azalide- $N, O$-substituted derivatives, descladinosyl-azalides, ketoazalides, bicyclic-azalides

S. Mutak: Consultant for Medicinal Chemistry and Chemical Process Development, PLIVA Research Institute, ${ }^{\dagger} 10090$ Zagreb, Croatia, E-mail: stjepan.mutak@zg.t-com.hr

${ }^{\dagger}$ till March 2006 
1. Introduction

2. 15-Membered Azalides

2.1. 9a-Azalides

2.2. 8a-Azalides

2.3. $\quad \mathrm{N}$-Substituted Azalide Derivatives and Azithromycin

2.4. Other $\mathrm{N}$-Substituted Azalide Derivatives

2.5. $O$-Substituted Azalide Derivatives (Esters, Ethers and Carbamates)

2.6. $\quad \mathrm{N}, O$-Disubstituted Bicyclic Azalides

2.7. Substitution on C-4" Position

2.8. Substitution on C-3' Position

2.9. 3-Descladinosyl-3-substituted Azalides-Acylides, Ketolides

2.9.1. Acylides

2.9.2. Ketoazalides

3. Other Azalides

3.1. 13-Membered Azalides

3.2. Other 15-Membered Azalides

3.2.1. 11-Deoxy-9a-Aza 15-Membered Azalides

3.2.2. New 11a-Aza 15-Membered Azalides

3.3. 17-Membered Azalides

4. Intramolecular Rearrangements of Azalides

4.1. Hemiketals, Spiroketals and Iminoethers

4.2. Anhydrolides

4.3. Open Chain Analogs

5. References

This article is dedicated to the memory of Professor Vladimir Prelog and celebrates the 100th anniversary of his birth. The period Prelog spent in Zagreb (1935 1941) marked the beginning of the development of organic synthetic chemistry in the Zagreb University and, at the same time, the start of 70 years of organized research within the pharmaceutical company PLIVA. A major consequence of Prelog's influence on organic synthetic chemistry in Zagreb was the discovery of azithromycin.

Twenty five years after the first patent application for the synthesis and discovery of azithromycin and 20 years from the first publication of its antibacterial activity, azalide chemistry has expanded significantly and many new derivatives have been developed for other indications.

Azithromycin, the first 15-membered macrolide antibiotic on the market, is characterized by a basic nitrogen atom inserted into the macrocyclic ring. It was synthesized in 1980 by a team of researchers at PLIVA laboratories: Gabrijela Kobrehel, Gorjana Radobolja-Lazarevski, Zrinka Tamburasev and Slobodan Djokic. For their great contribution to chemistry, on August 21, 2000, Gabrijela Kobrehel and Slobodan Djokic received the medal of "Heroes of Chemistry", the higher honor that is bestowed by the American Chemical Society.

Once the excellent properties of the new azalide scaffold had been noticed, researchers from many companies started to work on it, never forgetting that PLIVA was the originator.

Following the discovery of azithromycin, PLIVA chemists and engineers developed an excellent production process which made the company the largest producers of the active substance. This was the basis for the broader synthesis of new biologically active chemical entities, in which a new generation of PLIVA chemists have played an important role. 

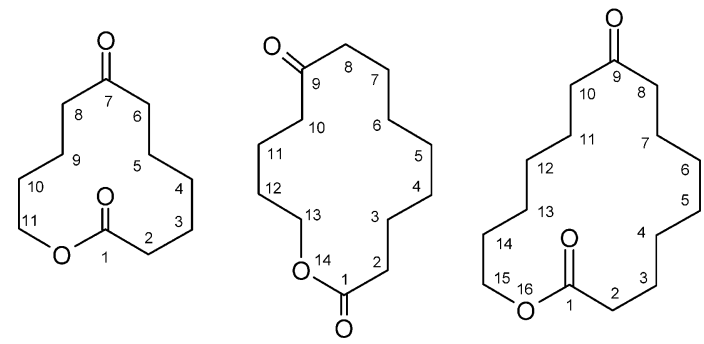

12, 14, 16-Membered lactone rings of macrolide antibiotics
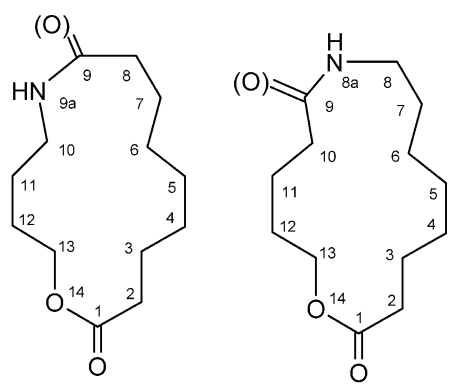

15-Membered lactone rings of 9aand 8 a-azalides or lactams

Fig. 1 Basic structures of macrolide lactones.

\section{Introduction}

Macrolides represent a well-known family of oral antibiotics. In 1952 the first and most widely used macrolide, erythromycin (1), was introduced to the market and medical practice. Medically important macrolide antibiotics were originally characterised by a 12-, 14- or 16-membered lactone to which amino-sugars and neutral sugars are attached. Macrolides express their antibacterial activity by binding to bacterial $50 \mathrm{~S}$ ribosomal subunits and inhibiting protein synthesis.

As a broader term, macrolides, isolated from natural sources, encompasses all macrocyclic lactones (Fig. 1) with larger than 8-membered rings varying in size up to 62 membered rings [1]. They consist not only of simple carboxylic monolactones but also of more complex lactones such as macropolydes and macrocyclic lactones that contain amino nitrogen, amide nitrogen, an oxazole ring, or thiazole ring in their skeleton. Macrolide-producing organisms are actinomycetes, myxobacteria, fungi, algae, plants and insects. Many macrolides have different biological activities, but the starting point of this overview will be azalides as semi-synthetic macrolides based on classical antibacterials.

The first and most important 14-membered erythromycin A (1) is active against Gram-positive and certain Gramnegative microorganisms and is still used to treat infections of the respiratory tract, skin and soft tissues and genital tract. After confirmation of the precise structure of the fermentation products (from Streptomyces erythreus, later reclassified as Saccharopolyspora erythrea) worldwide efforts in medicinal chemistry were undertaken to improve the biological profile (better activity, higher stability, and improved bioavailability). Macrolides have low toxicity and are well tolerated, but they are unstable in acidic media. $\mathbf{1}$ is metabolized in the acidic environment of the stomach to its inactive 8,9-anhydroerythromycin-6,9-hemiketal and anhydroerythromycin-6,9:9,12-spiroketal (Fig. 2). This reaction is the result of intramolecular interreaction between of the hydroxyls and the keto group.

To improve acidic stability and oral bioavailability of $\mathbf{1}$, the first generation of semisynthetic macrolides were prepared as $2^{\prime}$-esters and 11,12-cyclic carbonates and introduced to medical practice (as 2'-propionyl or erythromycin estolate, Ilosone ${ }^{\circledR}$-Eli Lilly and $2^{\prime}$-acetyl octadecanoate or erythromycin acistrate, Erasis, Orion Pharma).

Further modification at the 9-keto group of $\mathbf{1}$ was performed, including oximation or further reduction to amino group, which finally resulted in the synthesis of roxithromycin and dirithromycin. Alternatively, methylation at position 6 yielded the stable and highly active clarithromycin, which became the market leader among macrolide antibiotics during the final decade of the last century.

$\mathbf{1}$ is the most important starting substance for the preparation of 14-membered semisynthetic macrolide antibiotics. This approach has yielded various new chemical entities [2 6]. The key derivative $\mathbf{1}$ for this group of new derivatives (Fig. 3) was $9(E)$-erythromycin A oxime (2) prepared from 1 and hydroxylamine hydrochloride [7 9] in the presence of weak base or buffer (Scheme 1).

Suitable reaction conditions had to be sought for this sterically hindered keto-group which is unstable in acidic media. Later, it was found that under the chosen reaction conditions isomeric $9(Z)$-erythromycin A oxime (3) could be formed also $[7,8]$.

A qualitatively new group of macrolide antibiotics was discovered when a nitrogen atom was introduced into the aglycone ring, yielding a 15 -membered imino-ether by Beckmann rearrangement of 2 [10 13]. The compound was further reduced to an amino-lactone, thereby introducing a second amino group. This new class of 9-dihydro-9a-aza-9a-homoerythromycins was named 

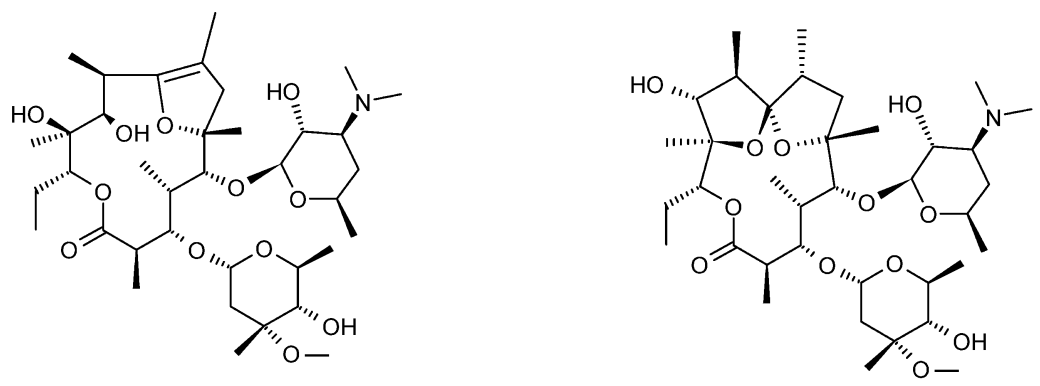

\section{8,9-Anhydroerythromycin-6,9-hemiketal Anhydroerythromycin-6,9;9,12-spiroketal}

Fig. 2 Structures of erythromycin acid rearrangement products.

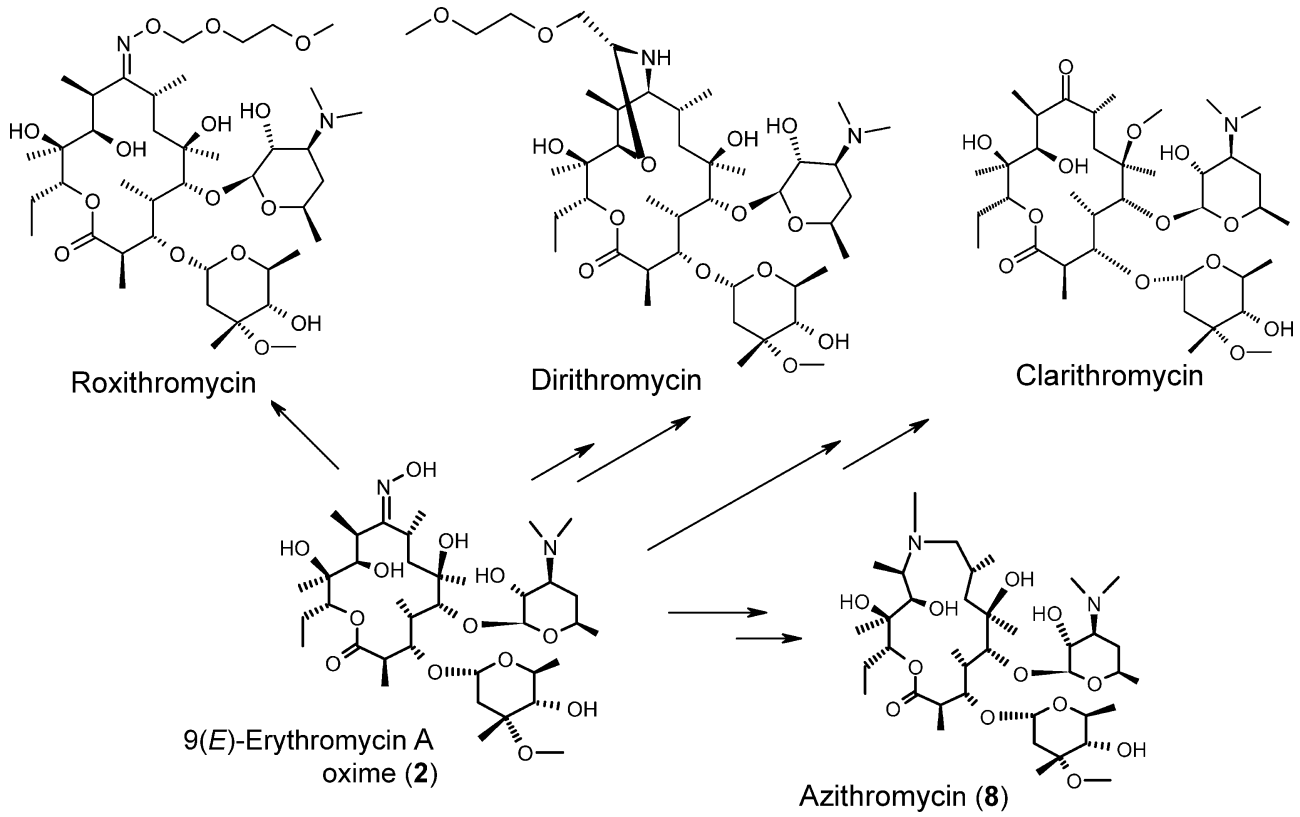

Fig. 3 Structures of semisynthetic macrolides obtained from erythromycin A and its oxime.

"azalides". The first azalide, azithromycin (8, 9a-methyl-9deoxo-9-dihydro-9a-aza-9a-homoerythromycin), was discovered in 1980 by PLIVA [10 14]. Its broad spectrum of activity covers all relevant bacteria causing respiratory tract infections, including Haemophilus influenzae and Moraxella catarrhalis.

The greatest advantages of $\mathbf{8}$ compared to other macrolide antibiotics are its unusual pharmacokinetics (high tissue distribution), metabolic stability and high tolerability. These properties have led in recent years to the widespread use of the azalide scaffold for synthesis of new compounds with advantageous pharmacokinetics, not only as antibacterials, but also for other indications. It is known that macrolides generally have anti-inflammatory and immunomodulatory activity $[15 \sim 18]$, but some have shown tuberculostatic, antimalarial, antiviral and antitumor activity [19]. To increase these activities, azalide scaffolds were combined with compounds with the desired actions to form new complex or hybrid molecules called "conjugates" and active compounds have been bonded to new compounds to generate improved bioavailability.

\section{15-Membered Azalides}

\subsection{9a-Azalides}

The key reaction in the formation of azalides was established during the synthesis of $O$-sulfonyl derivatives of oxime 2 [10 12]. It is well known that sulfonyl chlorides are catalysts for the Beckmann rearrangement to transform oximes to amides. However, this chemical derivatisation step was not applied previously to macrolactone scaffolds 


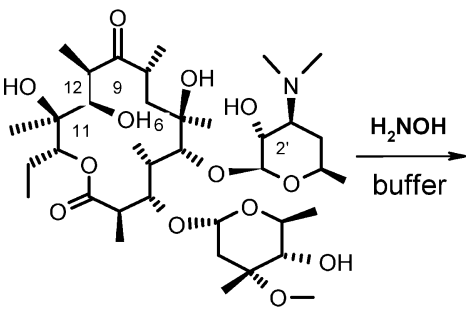

Erythromycin (1)

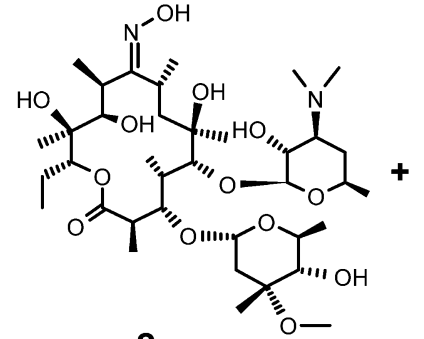

2

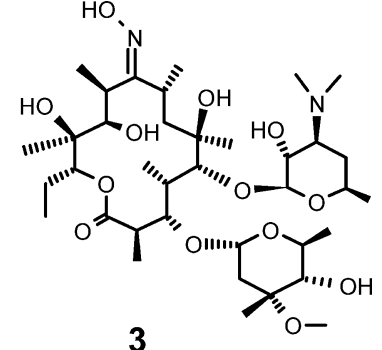

3

Scheme 1 Synthesis of erythromycin A 9-oximes (2 and $\mathbf{3}$ ).

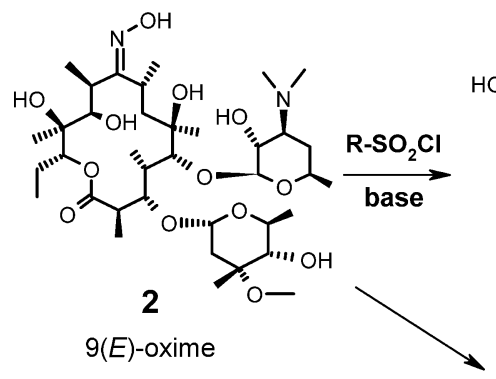

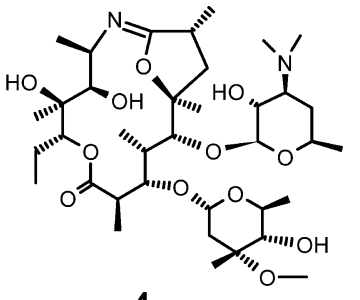

4

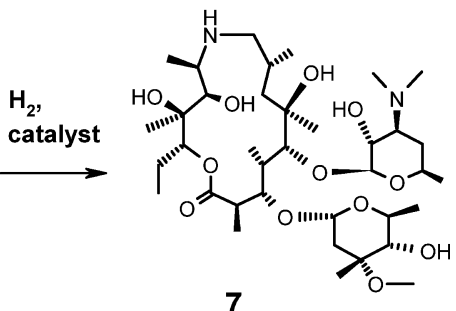

7

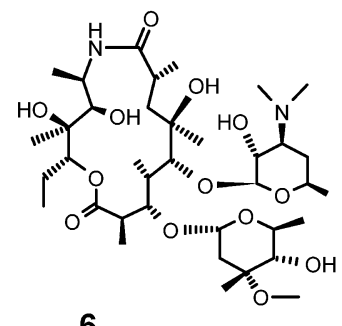

6

Scheme 2 Beckmann rearrangment of 9(E)-erythromycin A oxime.

[13]. Treatment of oxime $\mathbf{2}$ with benzenesulfonyl chloride in an acetone-water mixture with sodium bicarbonate yielded an unexpected product. Physico-chemical analysis indicated that in the assumed structure one water molecule was missing and that the compound exhibited a bicyclic structure. The presumed structure was erythromycin-6,9imino-ether (4), which was later confirmed by X-ray structural analysis [14]. The product had no antibacterial activity and was further transformed in various subsequent reactions. Further investigations provided evidence that $\mathbf{4}$, the main product of the first successful Beckmann rearrangement, was formed from readily available $\mathbf{2}[7,14]$.

When the Beckmann rearrangement was performed in ether (Scheme 2) in the presence of pyridine at $-45^{\circ} \mathrm{C}$, the mixture of $\mathbf{4}$ and 9,11-iminoether 5 was formed [8].

The same conditions and temperature $\left(0\right.$ to $\left.5^{\circ} \mathrm{C}\right)$ yielded the lactam 6 [8]. The bicyclic compound 4 was further reduced to an amino-lactone 7 , thereby introducing a second amino group. Catalytic hydrogenation in the presence of Pt-catalyst gave the cyclic amine 7, named 9-dihydro-9-deoxo-9a-aza-9a-homoerythromycin A, which was cited earlier as 10-dihydro-10-deoxo-11-azaerythromycin A according to the older nomenclature.

To this new class named azalides belongs also cyclic amide 9a-aza-9a-homoerythromycin (9a-lactam 6), which showed lower antibacterial activity than its corresponding cyclic amine 7. Lactam 6 could not be reduced to its amine 7 [13].

The structures of the imino-ether $\mathbf{4}$ and the 15 -membered amine 7 were determined by mass spectroscopy and ${ }^{1} \mathrm{H}$ and ${ }^{13} \mathrm{C}$ NMR analysis. Finally, the structures were confirmed by X-ray analysis of the respective aglycone derivatives prepared by removal of both sugars [13].

The antibacterial activity of $\mathbf{7}$ was close to that of $\mathbf{2}$ : similar activity against Gram-positive bacteria and better activity against Gram-negative bacteria than $\mathbf{1} .7$ become the main precursor for novel, significantly more active derivatives, especially for 9-dihydro-9-deoxo-9a-methyl-9aaza-9a-homoerythromycin A (8) with the generic name azithromycin (see section 2.3.). 
The azalide scaffold possesses a number of functional groups, which could be substituted or changed.

Figure 4 highlights positions for possible derivatization of the azalide scaffold, which will be described in the following chapters.

The intention was to get the review structured according to the site and type of substitution or derivatization, but they can not be totally separated, because frequent combinations of the various changes have been made.

\subsection{8a-Azalides}

Isomeric 9-dihydro-8a-aza-8a-homoerythromycins were prepared starting from 3, along with various $N$ - or $O$-alkyl or acyl substituted derivatives.

As mentioned above, 2 [7] is the main product of oximation of $\mathbf{1}$. After isolation of 3 [20] and basic isomerisation of the $E$ isomer into the $Z$ isomer, researchers

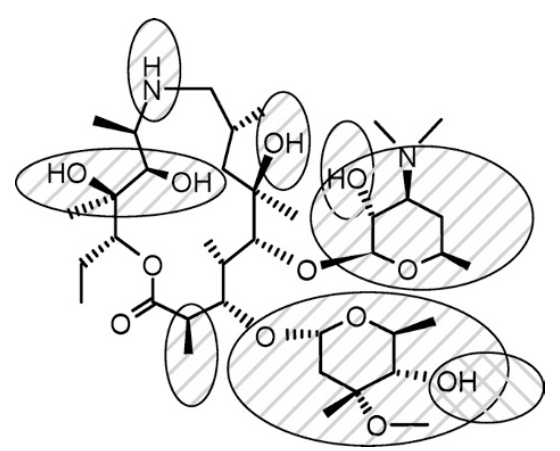

Fig. 4 Azalide structure modification and derivatisation. at Merck\&Co applied the Beckmann rearrangement and synthesized isomeric 8a-homoerythromycin-6,9-iminoether (9), 8a-homoerythromycin-9,12-iminoether (10) and isomeric 8a-lactam 11 [21, 22]. Under aqueous conditions, imino-ether $\mathbf{9}$ and lactam 11 were formed.

When anhydrous conditions were used, imino-ethers 9 and $\mathbf{1 0}$ were isolated. $\mathbf{1 0}$ was in equilibrium with its 10methyl epimer (Scheme 3). Conformational analysis and application of molecular modeling techniques to $\mathbf{4}$ and 9 were used to establish the predominant solution-state conformation [20,23] and to explain chemical reactivity. 9 and 10 were further reduced with hydrogen in the presence of Pt or with $\mathrm{NaBH}_{4}$ to the corresponding 9-dihydro-9deoxo-8a-aza-8a-homoerythromycin (12). The reduction rate of 9a-aza- and 8a-aza-6,9-imino-ethers $\mathbf{4}$ and $\mathbf{9}$, as well as 9a-aza-9,11-imino-ether $\mathbf{5}$, have been studied using molecular modeling techniques [23].

\section{3. $\quad \mathrm{N}$-Substituted Azalide Derivatives and}

\section{Azithromycin}

Starting from the first synthesized azalide, cyclic aminolacton 7, a number of derivatives have been produced. The best antibacterial activity was achieved with $\mathbf{8}$, which was prepared by reductive methylation (Scheme 4) with formaldehyde and formic acid [14]. The new product, 8, named azithromycin, showed broad antibacterial activity and strongly improved acid stability. The full chemical name, following Chemical Abstracts is [2R$\left.\left(2 R^{*}, 3 S^{*}, 4 R^{*}, 5 R^{*}, 8 R^{*}, 10 R^{*}, 11 R^{*}, 12 S^{*}, 13 S^{*}, 14 R^{*}\right)\right]-13-$ [(2,6-dideoxy-3-C-methyl-3- $O$-methyl- $\alpha$-L-ribo-hexapyra-

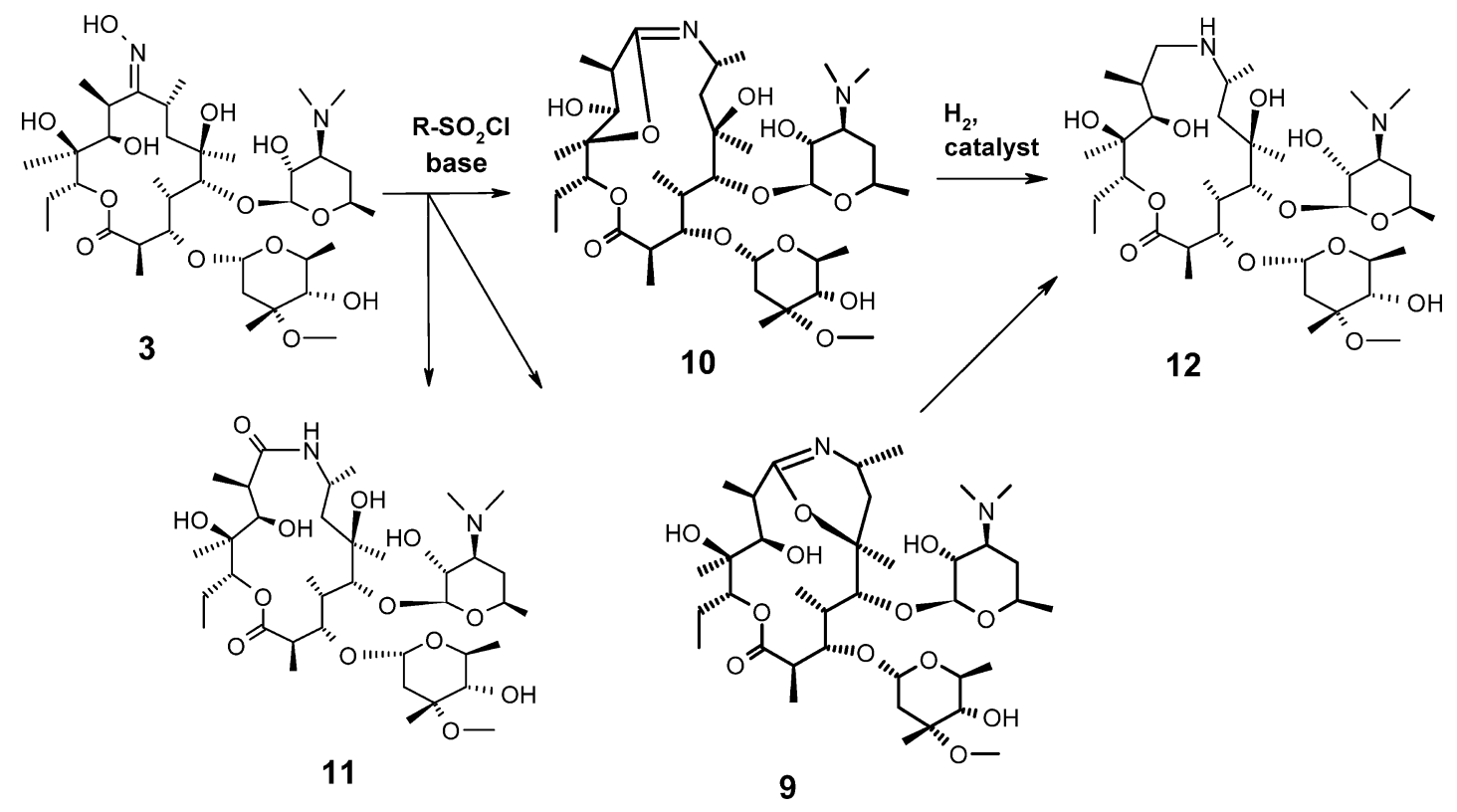

Scheme 3 Beckmann rearrangment of $9(Z)$-erythromycin A (3). 

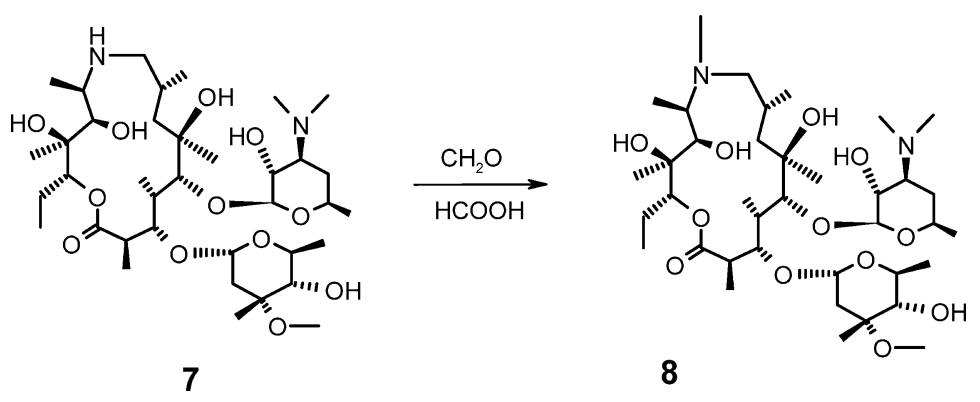

Scheme 4 Synthesis of azithromycin (8).

nosyl)oxy]-2-ethyl-3,4,10-trihydroxy-3,5,6,8,10,12,14heptamethyl-11-[[3,4,6-trideoxy-3-(dimethylamino)- $\beta$-Dxylo-hexapyranosyl]oxy]-1-oxa-6-aza-pentadekan-15-on.

8 is the first and presently the only 15 -membered macrolide antibiotic on the market with a basic nitrogen atom inserted into the macrocyclic ring. It was synthesized in 1980 by the researchers at PLIVA laboratories $[10,11]$.

In 1986 Pfizer, whose scientists also worked on this compound class [24, 25], decided to licence-in azithromycin from PLIVA for worldwide markets. During the process development, 8 was first isolated as the anhydrous substance [14]. Later various crystal forms were prepared [24, 26 29], and the most stable was found to be its dihydrate [26]. For intravenous application, water-soluble salts were prepared $[14,29]$, and some stable divalent metal ion complexes were formed [30] as possible oral dosage forms for treatment of stomach ulcers.

Further investigation of the biological properties of $\mathbf{8}$ revealed its high activity against some important Gramnegative microorganisms [31] such as Haemophilus influenzae, Neisseria gonorrhoeae and Moraxella catarrhalis. Preclinical investigations very soon showed its promising and favourable profile, such as stability in acid environment [32], high oral bioavailability compared to erythromycin [33] longer half-life and high tissue concentration [34]. This profile allowed a short dosing regimen, one of the key advantages of $\mathbf{8}$ compared to other antibacterials and macrolides [35].

In 19888 was introduced to the domestic (previous Yugoslavian) market in its dihydrate form by PLIVA under its brand name "Sumamed". Pfizer achieved market approval in its first markets in 1990 under the brand name "Zithromax". After 2000, 8 became the market leader of antibiotics for RTI.

The conformation of $\mathbf{8}$ in solution was determined by NMR spectroscopy and molecular modeling, and compared with its crystal structure and some derivatives 1 [36]. With the determination of the crystal structure of the bacterial ribosome various scientists tried to prepare binding complexes of ribosome and macrolide antibiotics. Analysis of the crystal structure of the large ribosomal subunit (50S) from Deinococcus radiodurans complexed with azithromycin, showed that azithromycin exerts its antimicrobial activity by blocking the protein exit tunnel, but in contrast to other macrolides, a second binding site was also recognized [37]. Nitrogen inserted into the lactone ring does not directly contribute to the binding of $\mathbf{8}$ to the ribosome. Is seems, that this modification alters the conformation of the lactone ring sufficiently to induce novel contacts. One molecule of $\mathbf{8}$ interacts with domains $\mathrm{IV}$ and $\mathrm{V}$ of $23 \mathrm{~S}$ rRNA, and second $\mathbf{8}$ interacts with ribosomal proteins L4 and L22 and domain II of $23 \mathrm{~S}$ rRNA. Furthermore, AZI-2 makes direct contact to AZI-1 through a hydrogen bond between its desosamine sugar and O1 in the lactone ring of AZI-1.

The introduction of the Beckman rearrangement opened a completely new derivatisation line and various attempts were undertaken to improve the properties of $\mathbf{8}$. Using the same method as for $\mathbf{8}$, isomeric 9-dihydro-9-deoxo8a-aza-8a-homoerythromycin (8a-azalide 12), subjected to reductive methylation (Scheme 5), yielded the corresponding 9-dihydro-9-deoxo-8a-methyl-8a-aza-8ahomoerythromycin (13).

Antibacterial activities of 8a-azalide $\mathbf{1 2}$ and its $N$-methyl derivative 13 were similar to those of 9a-azalide 7 and azithromycin (8) respectively [21]. The 11-deoxy 8aazalide retained the same in vitro antimicrobial potency [38].

\subsection{Other $N$-Substituted Azalide Derivatives}

The generation of the first azalide 7 permitted a derivatisation line at the 9a-nitrogen. Using reductive alkylation with formaldehyde or acetaldehyde, $\mathbf{8}$ or its 9 aethyl analogue were prepared. To avoid the formation of quaternary ammonium salt, some $N$-alkyl substituted derivatives were prepared by reaction (Scheme 6) of the corresponding halides and the $N$-hydroxy derivative $\mathbf{1 4}$ was generated from amine 7 [25]. 


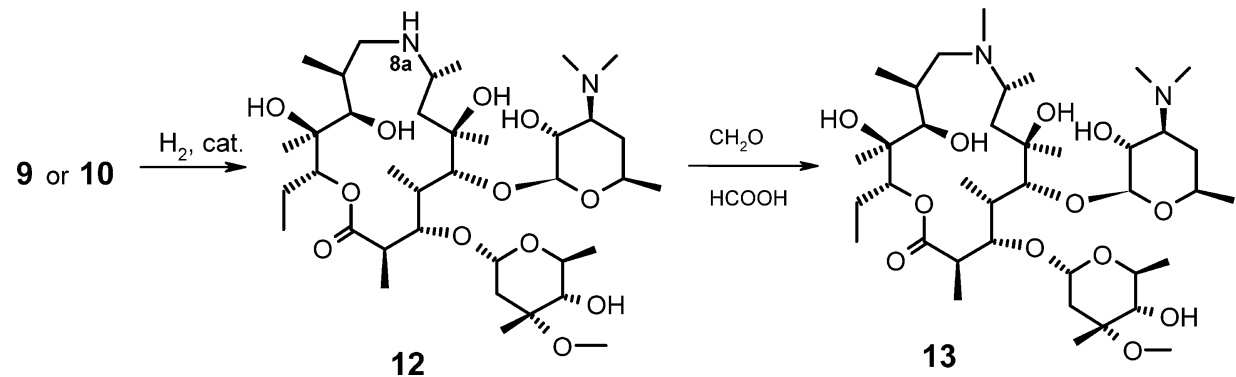

Scheme 5 Synthesis of 9-dihydro-9-deoxo-8a-methyl-8a-aza-8a-homoerythromycin (13).

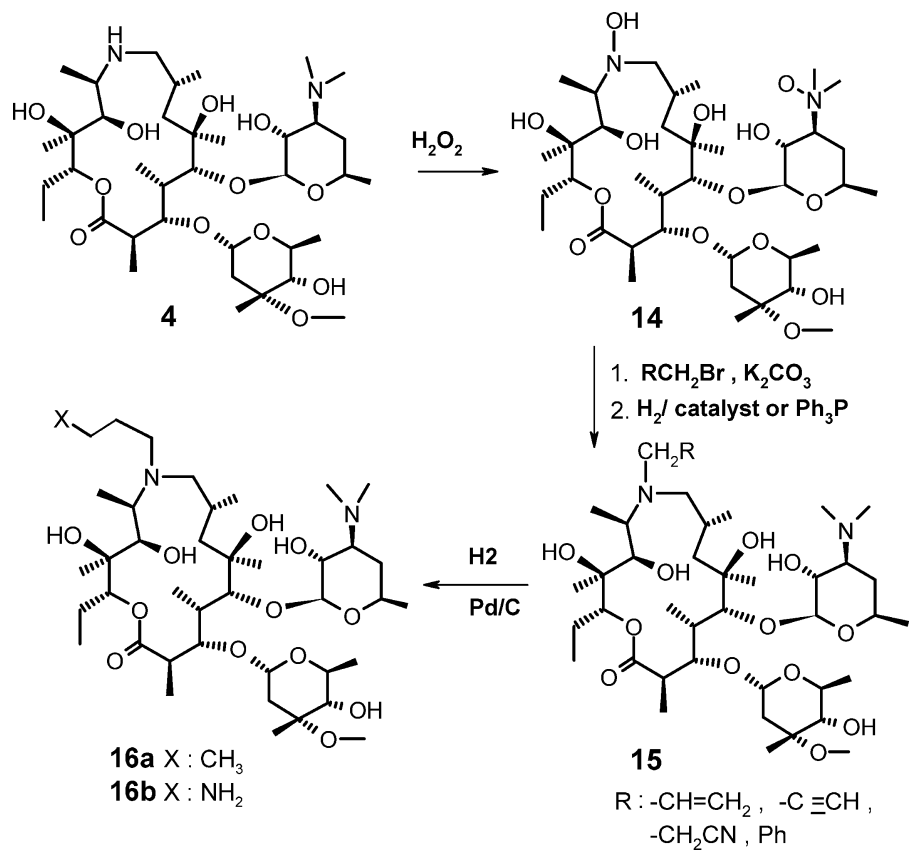

Scheme 6 Synthesis of 9a(M)-substituted-9-dihydro-9a-aza-9a-homoerythromycins.

These new derivatives, e.g. 15, were further transformed into their $N$-allyl derivatives, subsequently transformed by hydrogen and Pd catalyst to the $N$-propyl derivative 16, which was confirmed by X-ray analysis of its aglycone backbone [39]. The application of the reaction on acrylonitrile yielded new cyano-alkyl derivatives which were reduced with hydrogen in the presence of Raney Ni to corresponding amino-alkyl compounds. However, none of these derivatives showed better biological activity than $\mathbf{8}$. The $N$-aminopropyl derivative $\mathbf{1 6} \mathbf{b}$ was later used as an intermediate for various new $N$-substituted derivatives. Similar, $N$-substituted derivatives on isomeric $\mathbf{1 2}$ have been prepared by chemists at Merck [21, 22].

The lactam 11 was $N$-alkylated at position 8 a with alkyl halides and $\mathrm{NaH}$ with prior protection of the hydroxyl groups by TMS [21]. Another method for preparation of $N$ substituted lactams was based on the primary oxidation of imino-ethers $\mathbf{9}$ or $\mathbf{1 0}$ to the $N$-oxide of the sugar's dimethylamino group, followed by reaction with alkyl halides [21] and finally by hydrolysis to yield the lactam and deoxygenated product of the $\mathrm{N}$-oxide.

It is known that some macrolides and $\mathbf{8}$ itself have antiinflammatory properties [15 18]. Scientists from PLIVA working on the synthesis of new anti-inflammatory compounds have prepared a number of 9a-substituted azalides bound to known steroidal and non-steroidal anti-inflammatory agents (Fig. 5). Most derivatives were prepared starting from amine $\mathbf{1 6 b}$ or some longer amino-methylene chain, using 1-hydroxybenzotriazole and carbodiimide as condensation agents. The idea was to use azalide properties for improving cellular targeting to inflammatory cells [40 43].

Another $N$-derivatisation line of azalides was performed in PLIVA. Starting from 7, various 9a-carbamoyl and 

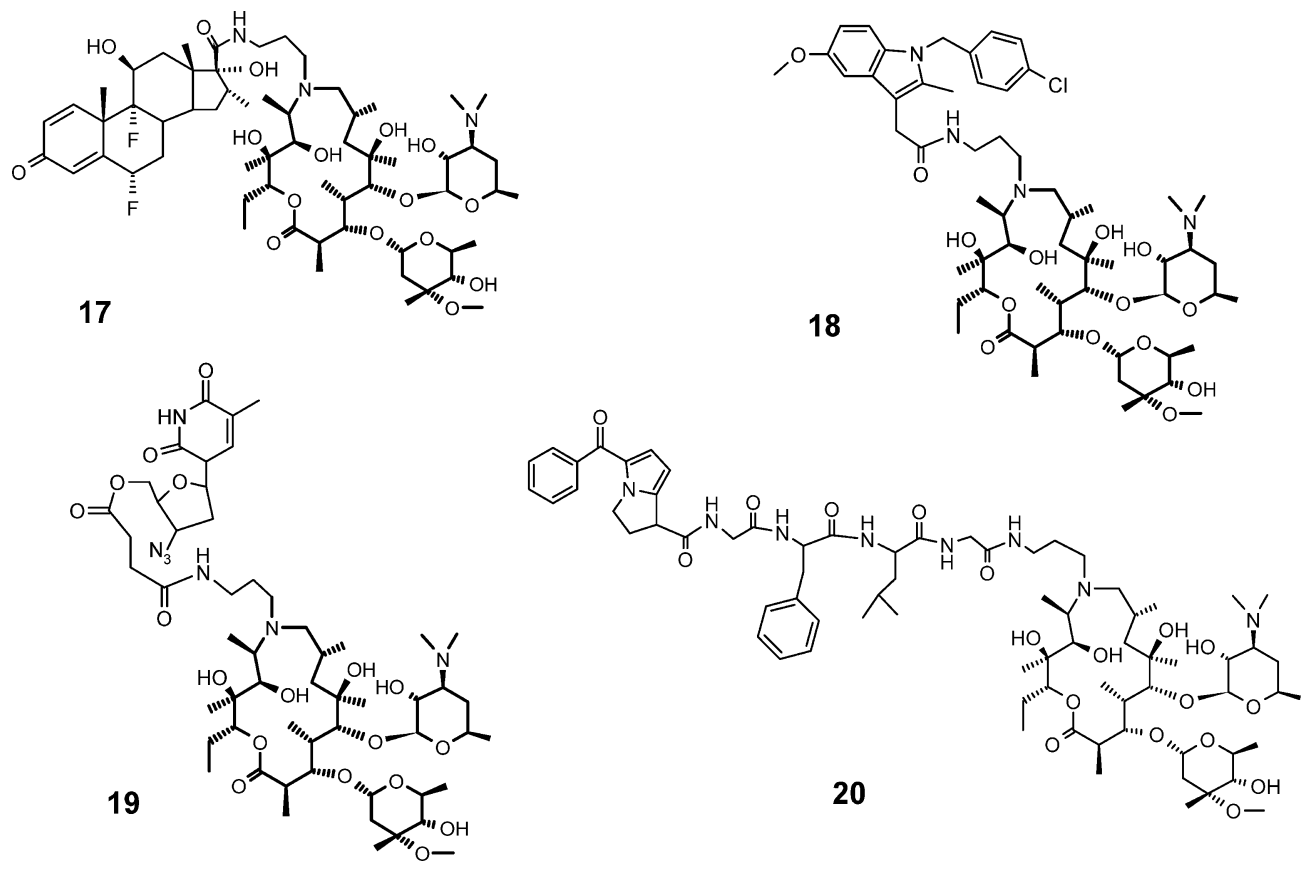

Fig. 5 Structures of $9 a, N$-substituted azalides with some biologically active scaffolds.

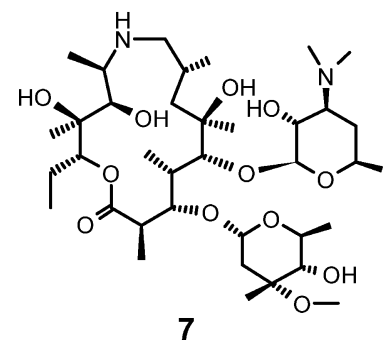

7

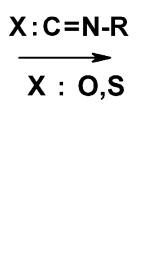

Scheme 7 Synthesis of 9a-carbamoyl- and thiocarbamoyl-9-dihydro-9a-aza-9a-homoerythromycins.

thiocarbamoyl derivatives 21 were prepared (Scheme 7) by reaction of 7 with corresponding isocyanates or isothiocyanates [44]. Reactions were usually conducted in toluene to achieve easily crystallisable $N^{\prime}$-alkyl or $N^{\prime}$-aryl substituted ureas. Structures of the $N^{\prime}$-isopropyl and $N^{\prime}$-(4pyridyl) derivatives were confirmed by X-ray analysis [45].

Representatives of various ureas included isopropyl-, 4methyl-5-oxazolyl-, 2-furyl-, 4-pyridyl-, phenyl-, benzyl-, and 1-naphthyl ureas, and $N^{\prime}$-benzyl-thiourea. In biological testing, only a few derivatives $\mathbf{2 1}$ showed moderate antibacterial activity. Additional halogen-aryl derivatives of $\mathbf{2 1}$ have been synthesized showing activity against resistant strains [46]. Later 9a-(4-aminosulfonyl)phenyl-carbamoyl derivatives of 9-deoxo-9-dihydro-9a-aza-9a-homoerythromycin 22 were prepared (Fig. 6) as compounds with antibacterial properties [47, 48]. Sulphonylureas 23, bonded to the azalide scaffold with a propylenamino-linker [49] were prepared to obtain improvement in specific antibacterial activity.

Ethenyl derivatives 24 (Fig. 6) were prepared, with potential antibacterial activity, and with broad possibility for derivatisation [50].

\subsection{O-Substituted Azalide Derivatives (Esters, Ethers and Carbamates)}

8 and its 8a-aza isomer possess five hydroxyl groups, of which two are secondary hydroxyl groups on sugar moieties while one secondary and two tertiary hydroxyl groups are located on the aglycone ring itself. Their presence explains the difficulties in targeted derivatisation. The most reactive hydroxyl group is at the $2^{\prime}$-position on the amino sugar. Initial derivatives targeting the hydroxyl 


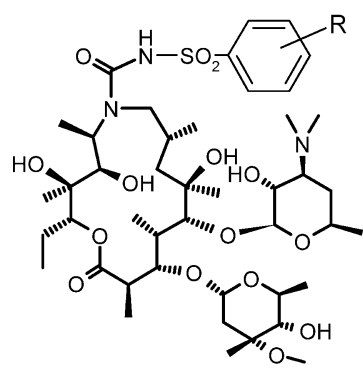

22

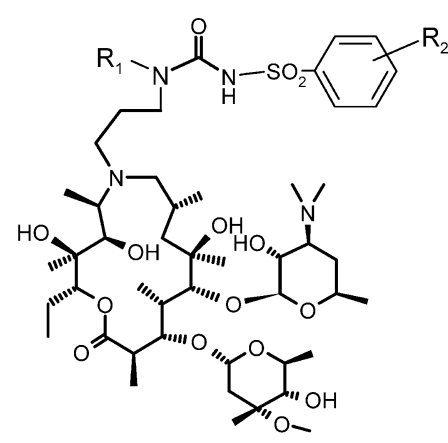

23

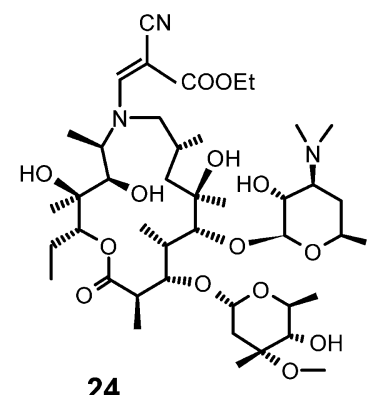

24

Fig. 6 Structures of 9a-sulfonyl-carbamoyl-9-dihydro-9a-aza-9a-homoerythromycins and 9a-ethenyl-9-dihydro-9a-aza-9ahomoerythromycins.

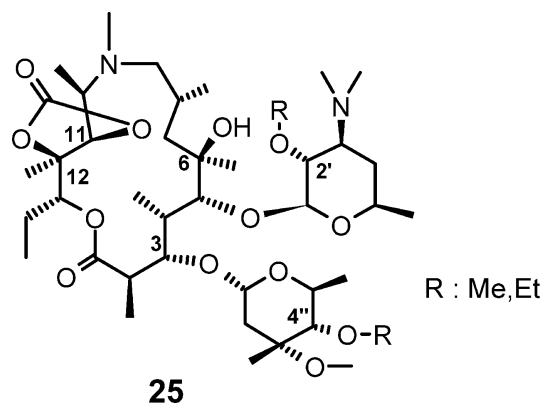

Fig. 7 Structure of azithromycin 11,12-carbonates.

groups were esters: mono-, di- or tri-acetyl on the $2^{\prime}-O-$, 4"-O- and 11-O-hydroxyl groups, which were prepared using acetic anhydride with pyridine [32]. Reaction of $\mathbf{8}$ or its diacetyl derivative with ethylene carbonate and potassium carbonate yielded the corresponding 11,12carbonates (25) or its diacetyl derivatives (Fig. 7). Acetyl groups could be easily removed by hydrolysis in methanol.

All esters and carbonates of free hydroxyl groups failed to show any improvement over $\mathbf{1}$ in antibacterial activity against Gram-positive bacteria, but they were found to exhibit higher activity against Gram-negative strains.

A number of 4"-arylalkyl esters or carbamates (26) have been synthesized on 8a-lactams (Fig. 8). Most esters were prepared using mixed anhydrides of carboxylic acids obtained with pivaloyl chloride. Some of them, such as 4"quinolyl-acryloyl with 6-hydroxy- and 6-O-methyl showed antibacterial activity on azithromycin resistant Streptococcus pneumoniae strains [51,52], but introduction of a second arylalkyl group, such as 6- or 11-quinolylallyl, decreased antibacterial activity. Corresponding derivatives of isomeric 9a-lactam (6) had little antibacterial activity.

Since esters most often are cleaved in biological fluids, formation of ether bonds was performed to generate

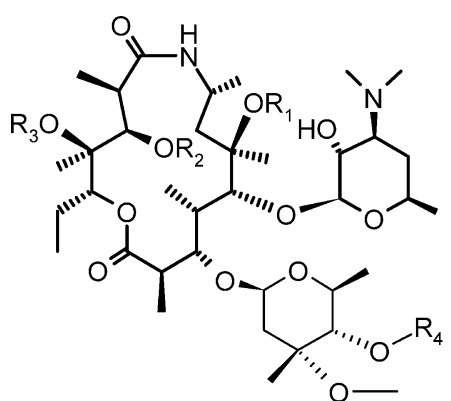

26

$$
\begin{aligned}
& \mathrm{R}_{1}:-\mathrm{H} \text {, -alkyl, -arylalkenyl } \\
& \mathrm{R}_{2}, \mathrm{R}_{3}: \mathrm{H},-\mathrm{CO}- \\
& \mathrm{R}_{2}:-\mathrm{H} \text {, -arylalkenyl or -CO-NH-arylalkyl } \\
& \mathrm{R}_{4} \text { : - } \mathrm{H}, \text {-CO-arylalkyl, -CO-arylalkenyl, } \\
& \text { or -CO-NH-arylalkyl }
\end{aligned}
$$

Fig. 8 Structure of 4"-arylacyl-8a-aza-8a-homoerythromycins (8a-lactams).

stable $O$-substituted derivatives. The first efforts were focused on the synthesis of the 6-O-methyl derivative of $\mathbf{8}$, similar to the synthesis of clarithromycin. Using benzyloxycarbonyl chloride in the presence of sodium bicarbonate, 8 was protected at the $2^{\prime}-\mathrm{O}$ - and $3^{\prime}-\mathrm{N}$ positions to yield the di-benzyloxycarbonyl derivative 27 , which was methylated with methyl iodide and sodium hydride in DMSO-THF or DMF [53]. Unfortunately, only mixtures of 11-O- and 12-O-methyl derivatives with small amounts of di- or tri-methylated products (28) were generated (Scheme 8). These products were hydrogenated using palladium on carbon to yield $\mathbf{2 9}$ and then remethylated on position $3^{\prime}-N$ - with formaldehyde and formic acid. The mixture of mono- and some di- or tri- 
8

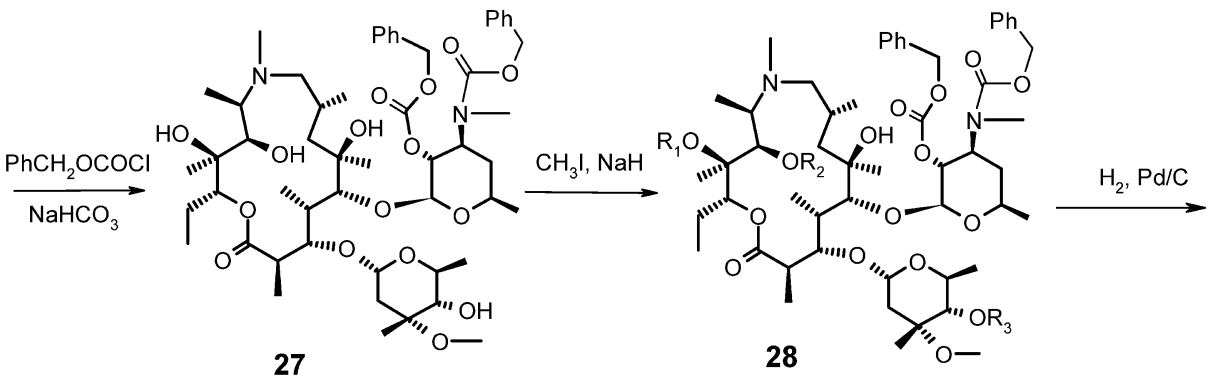

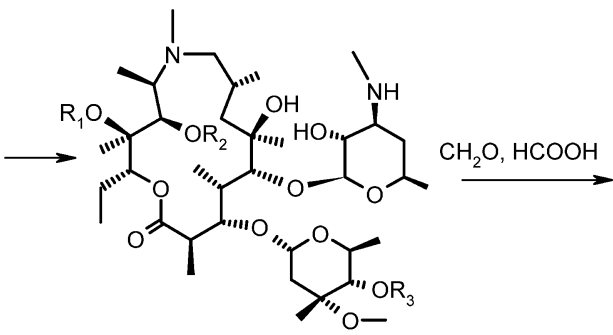

29

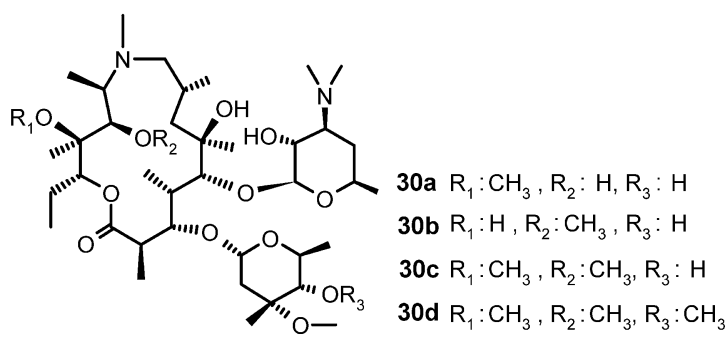

30

Scheme 8 Synthesis of 0 -methyl derivatives of $\mathbf{8}$

methylated azithromycins (30) was difficult to separate.

The structure of $12-O$-methyl derivative 30a was first described as 6-O-methyl azithromycin [53]. This error was corrected later by a publication from Merck [54] and confirmed by PLIVA using X-ray structural analysis of the trimethylated compound 30d [55]. Finally, structureactivity studies using quantum mechanics of azithromycin, revealed that alkylation of the 6-hydroxy group is practically impossible to achieve.

Antibacterial testing of $12-O$-methyl derivative 30a indicated weaker activity than azithromycin, while 11-Omethyl 30b was equally or slightly more active. The antibacterial activities decreased with increasing degree of methylation [53, 55].

Merck published the synthesis of mono-, di-, and trimethyl derivatives of 9-dihydro-9-deoxo-8a-methyl-8aaza-homoerythromycin (31), and the authors established rates of $O$-methylation from $8 \mathrm{a}$-aza- and 9a-azahomoerythromycins: $11-\mathrm{OH}(9 \mathrm{a}) \geq 12-\mathrm{OH}(9 \mathrm{a})>4$ " $-\mathrm{OH}(9 \mathrm{a}) \equiv$ 4 "-OH $(8 \mathrm{a})>12-\mathrm{OH}(8 \mathrm{a})>11-\mathrm{OH}(8 \mathrm{a})$. To methylate the 6hydroxy group, they started with the 11,12-carbonate of $8 \mathrm{a}-$ azalide 13 and obtained the 12-O-methylated 3,6-ether accompanied by removal of cladinose. Direct methylation of the 6-hydroxy group of 8a-azalide was only achieved after removal of cladinose, which yielded the 3,6,11,12tetra- $O$-methyl derivative. Furthermore, the 6-O-methyl-9aazalide 31 and 6-O-methyl-8a-azalide 32, starting from clarithromycin (6-O-methyl-erythromycin A), have been described [56]. The $E$ - and $Z$-oximes were prepared and then converted using the reaction with $\mathrm{TsCl}$ in ether/pyridine to the corresponding 9a-aza-9,11-iminoether or 8a-aza-9,12-iminoether. Beckman reaction of $E$-oxime in aqueous acetone resulted in the 6-O-methyl derivative of 9a-lactam 7. After reduction of imino-ethers and reductive methylation of 9a- and 8a-amines, the desired 6-O-methyl compounds 31 and $\mathbf{3 2}$ were generated (Fig. 9).

In the course of these experiments, PLIVA chemists discovered a new synthetic procedure for selective methylation of position 11- to obtain $\mathbf{3 0 b}$ using diazomethane and catalyst $[57,58]$.

Authors from Hoechst-Marion-Roussel (now SanofiAventis) published comparable results using the same reaction to synthesize the azalide 31 . The 6-O-methyl derivative $\mathbf{3 4}$ of $9 \mathrm{a}$-lactam 7 was generated by reaction of 6-O-methyl-erythromycin- $9(E)$-oxime with $\mathrm{TsCl}$ in aqueous acetone [59].

Antibacterial evaluation of the 6-O-methyl derivatives $\mathbf{3 1}$ and 32 revealed lower activity compared to the 11- or 12$O$-methyl analogues. Generally, $O$-methyl derivatives of 8 aazalides were less active than the corresponding 9a-azalides [56]. 6-O-Methyl derivatives 33, 34 of lactams $\mathbf{6}$ and $\mathbf{1 1}$ were less active than the corresponding methylamines $\mathbf{3 1}$ and 32.

Abbott's researchers reported the introduction of its telithromycin side chain 3-(3-quinolyl)allyloxy group at position 6-O of 8 [60]. Synthesis was carried out starting from protected erythromycin-9-oxime, the intermediate in the preparation of cethromycin, which was alkylated on the 6-hydroxyl with propargyl halide, treated with quinolyl bromide and partially reduced to 6-quinolylallyl- 

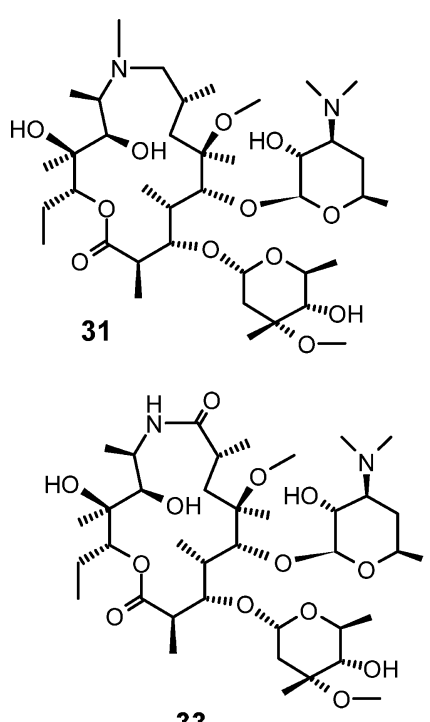

33
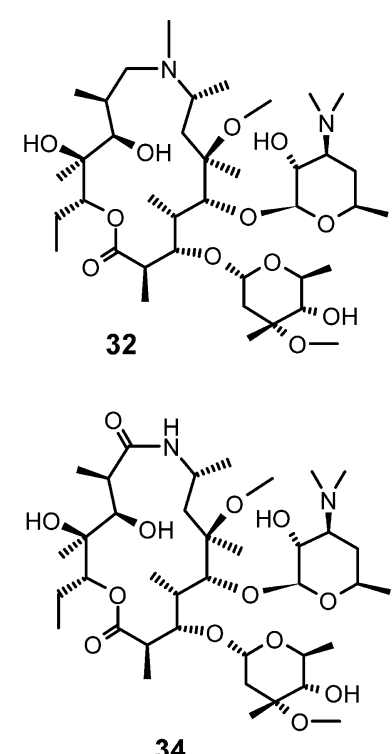

Fig. 9 Structures of 6-O-methyl- 8a- and 9a-aza-homoerythromycins.

erythromycil oxime. Another method for synthesis of the same oxime was given, applying the allyl intermediate under Heck conditions or using tert-butyl carbonate as the active intermediate. Deprotection yielded 6-substituted erythromycin A oxime, which was transformed, via a Beckmann rearrangement, to the imino-ether, then reduced to the azalide and finally methylated at position 9a (Scheme 9).

Some compounds, such as $\mathbf{4 2}$, showed activity against azithromycin-resistant Gram positive bacteria strains.

Starting from 6-O-quinolylallyl-oxime 39 and its $Z$-isomer, scientists in PLIVA have prepared the corresponding 6-O-3-(3-quinolyl)allyl-9a- and 8a-lactam $[51,52]$.

Derivatization of macrolides including azalides at the 4"position have been described by Pfizer chemists to obtain novel 4"-O-(aryl-methyl-amino)alkyl carbamates. These compounds, especially the 9-erythromycylamine analog, showed activity against resistant strains comparable to the ketolide telithromycin (HMR 3647, Ketek). The corresponding azalide derivative $\mathbf{4 3}$ was less active than the 14-membered compounds [61].

Subsequently, a number of carbamate derivatives (Fig. 10) of the 11-hydroxy group of 9a azalides (44) or 8aazalides were prepared [62]. The family comprised carbamoyl substituents with various isomers of pyridyl or dimethoxybenzyl side chains.

Within the collaboration between PLIVA and GSK, a number of 4 "-( $\beta$-ethylendiamino)propionyl esters and carbamates with an alkylendiamino chain and heteroaromatic $\beta$-keto-carboxylic acid as the side chain have been prepared on 8a-lactams, 9a-lactams and $\mathbf{8}$ [63, 64]. 4"-Substituted lactams were prepared by reaction of $2^{\prime}$-acetyl-protected lactams with 3-chloropropionyl-chloride in the presence of sodium carbonate, whereas $4 "$-acryloyl-azithromycin 49 was prepared indirectly from 2-acetyl-azithromycin $\mathbf{4 5}$ using 6-acryloyl-11,12-cyclic carbonate $\mathbf{4 8}$ (Scheme 10) as intermediate.

New $\beta$-amino esters $\mathbf{5 0} \sim \mathbf{5 3}$ (Fig. 11) were prepared applying Michael addition of substituted arylalkyl-amines to 4"-acryloyl precursors. One of the first compounds prepared on 8a lactam was a conjugate based on the fluoroquinolone, ciprofloxacin, which was linked via the piperazine moiety. The new compound $\mathbf{5 0}$ displayed lower antibacterial activity than 8a-lactam linked with an ethylendiamino group to oxoquinolonic acid.

Many of these alkylendiamino-quinolone derivatives $(\mathbf{5 1}, \mathbf{5 2}, \mathbf{5 3})$ showed excellent activity against resistant Streptococcus pneumoniae and Streptococcus pyogenes, but 6- and 4"-disubstituted derivatives with the same side chain didn't show significant antibacterial activity. 4"-OCarbamoyl derivatives were prepared using 4"imidazolylcarbonyl-azithromycin as intermediate.

Later on, antibacterially active $4 "$ "-( $\beta$-ethylendiamino)propionyl esters and carbamates (54) with another second heteroatom (Fig. 12) in linker have been prepared [65, 66], resulting in a profound increase in antibiotic activity.

In one of the latest patent applications, GSK chemists have described [67] 4"-arylheteroalkyl-sulphonates (55).

Using different ligands, 4 "-( $\beta$-ethylendiamino)propionyl esters (56) were prepared by PLIVA (Fig. 13) as potential anti-inflammatory agents [68, 69]. 


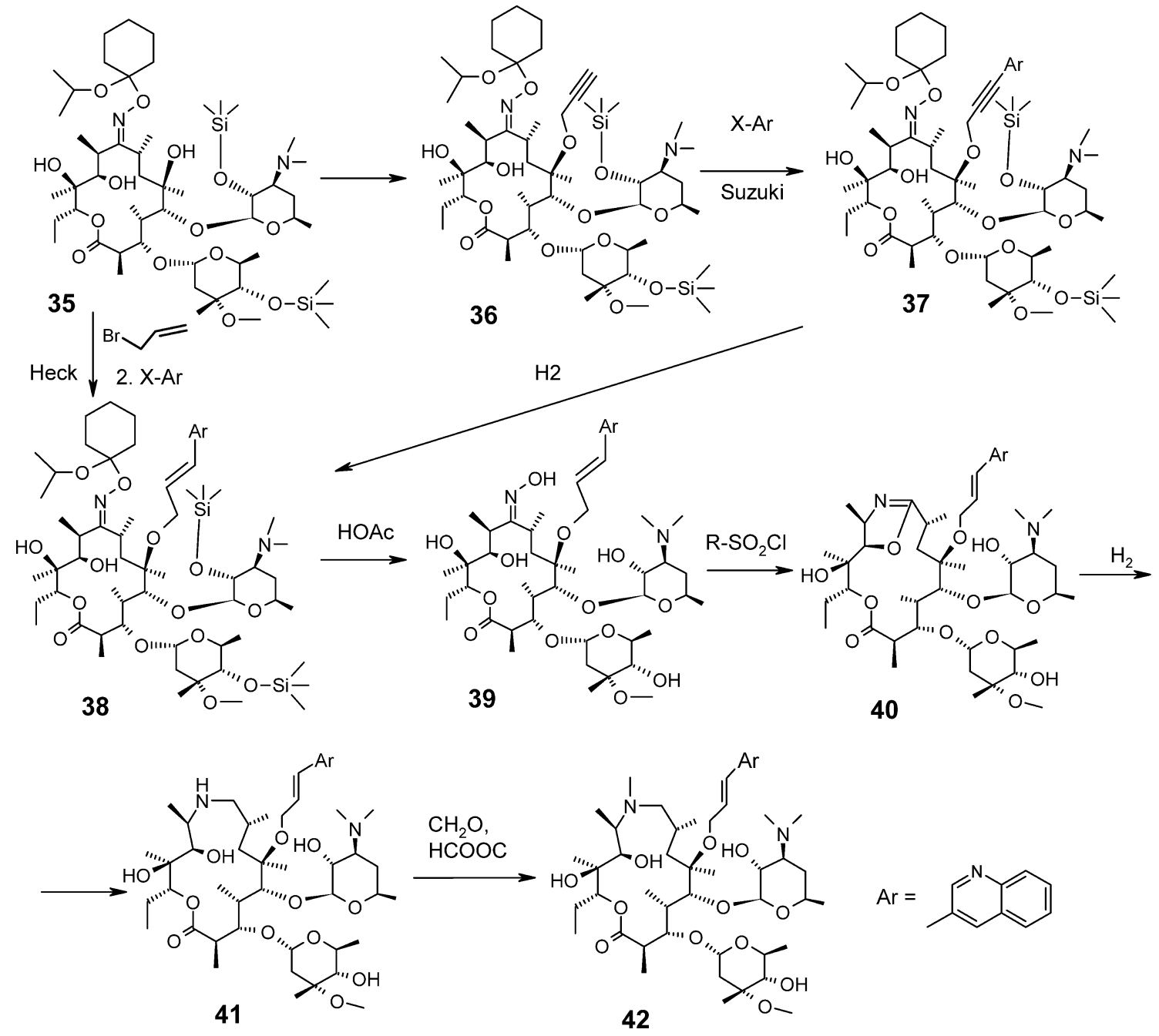

Scheme 9 Synthesis of 6-O-(3-quinolyl)allyl derivative of $\mathbf{8}$.

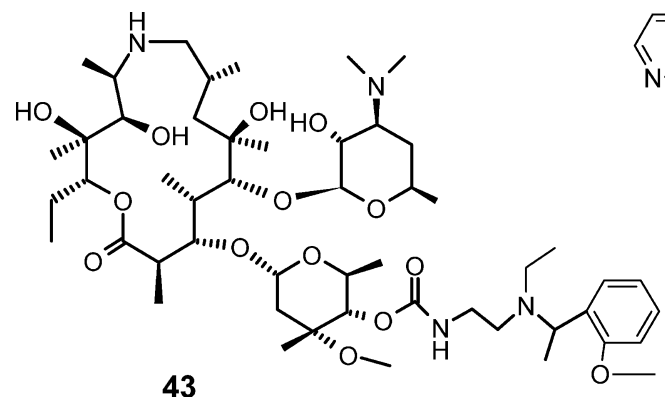<smiles>C/C=C\CCC</smiles>

Fig. 10 Structures of O-carbamoyl derivatives of 9a-aza-9-dihydro-homoerythromycin and 8.

\section{6. $\quad N, O$-Disubstituted Bicyclic Azalides}

It is clear from earlier examples, that most derivatives were made by combination of $N$ - and $O$-substitutions, but in some cases bicyclic compounds were obtained.

In an effort to synthesize $O$-methyl azalides before introducing the $9 \mathrm{a}-\mathrm{N}$-methyl group, 7 was protected as its tris-carbobenzoxy derivative $\mathbf{5 7}$ and treated with methyl iodide in the presence of $\mathrm{NaH}$ in DMF [70]. The reaction resulted in a mixture of $2^{\prime}-O-3^{\prime}-N$-bis-carbobenzoxy-9dihydro-9-deoxo-9a-aza-9a-homoerythromycin-9a,11-cyclic carbamate and its 12-O-methyl derivative. The cyclic carbamates were deprotected using catalytic reduction and 


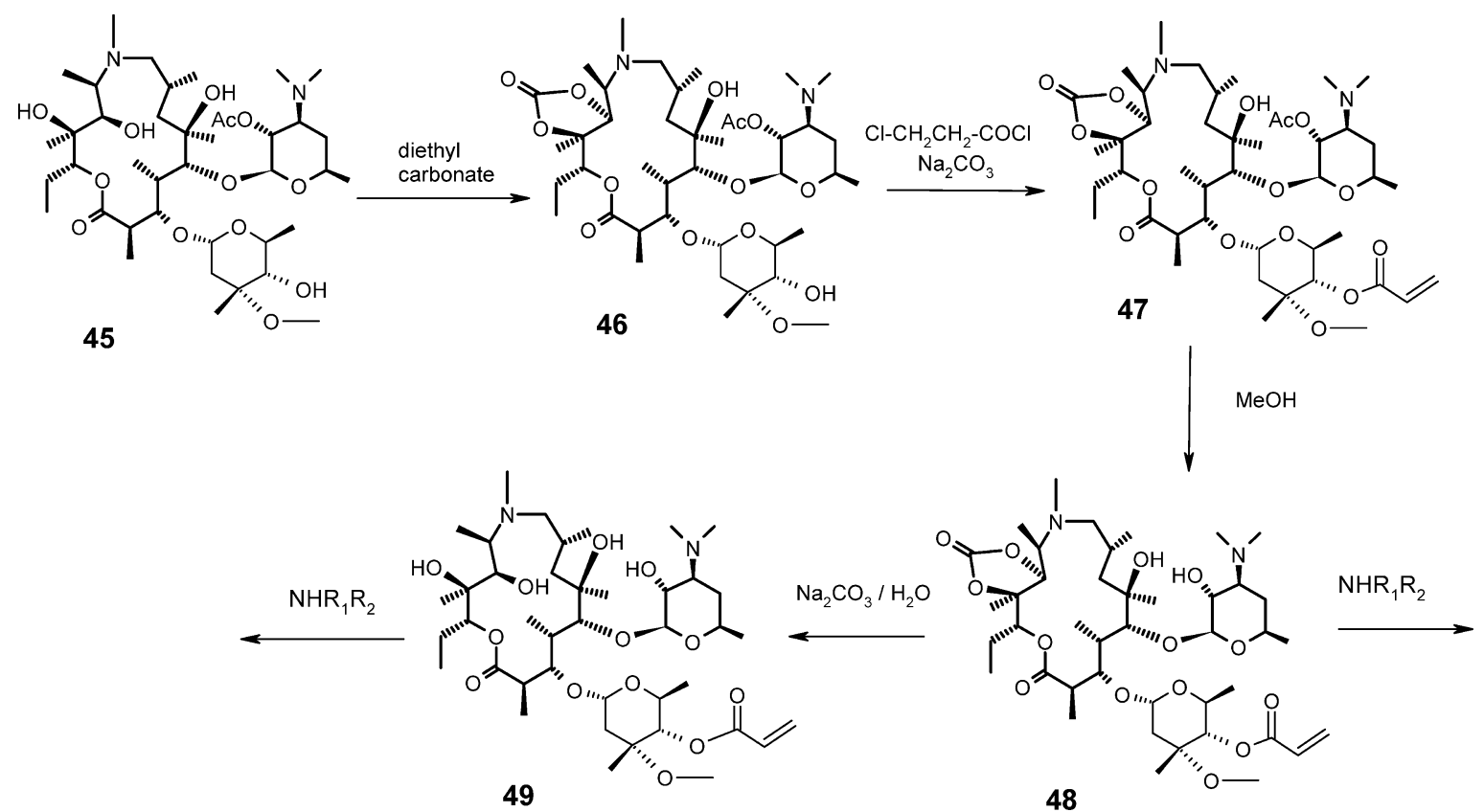

Scheme 10 Synthesis of -4"-O-acryloyl derivatives of $\mathbf{8}$.

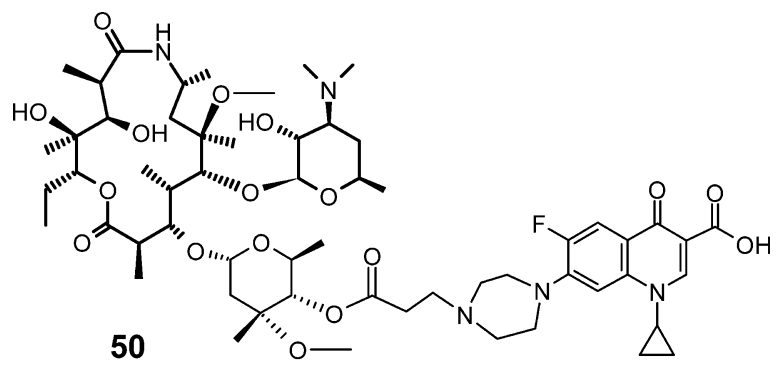

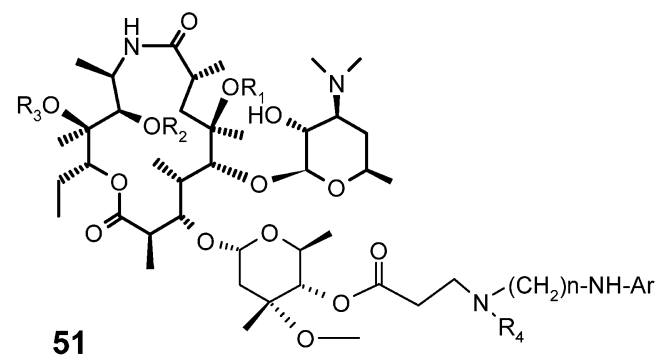

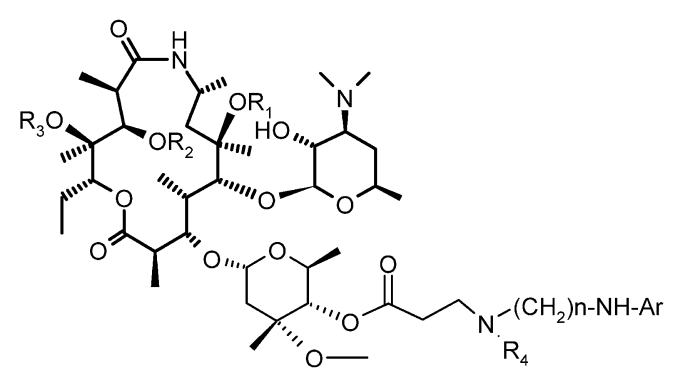

52

$$
\begin{aligned}
& \mathrm{R}_{1}: \mathrm{H} \text {, alkyl, arylalkyl } \\
& \mathrm{R}_{2}, \mathrm{R}_{3}: \mathrm{H},-\mathrm{CO}- \\
& \mathrm{R}_{2}: \mathrm{H},-\mathrm{CO}-\left(\mathrm{CH}_{2}\right) \mathrm{nAr} \text { or }-\mathrm{CO}-\mathrm{NH}\left(\mathrm{CH}_{2}\right) \mathrm{nAr} \\
& \mathrm{R}_{4}: \mathrm{H}, \mathrm{Me} \text { or Et } \\
& \mathrm{R}_{5}: \mathrm{Me}, \mathrm{Et} \text {, cyclopropyl } \quad \mathrm{R}_{6}: \mathrm{H}, \mathrm{Me} \text { or Et }
\end{aligned}
$$

Fig. 11 Structures of heteroaryl substituted 4"-O-( $\beta$-amino)propionyl azalides. 


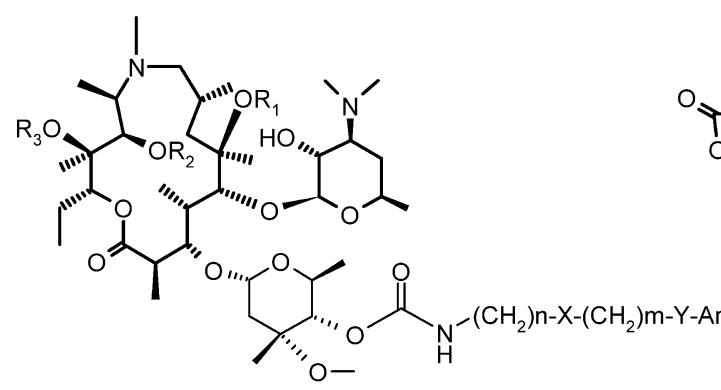

54

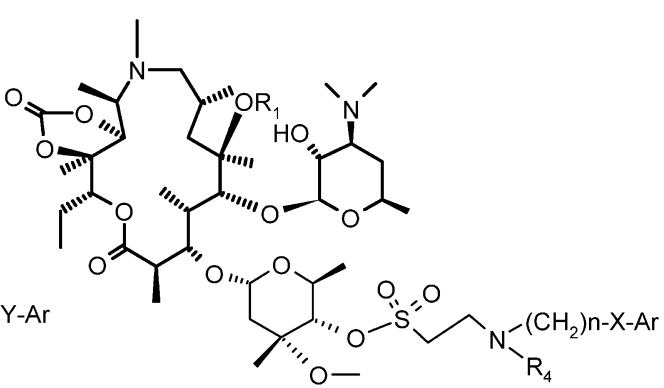

55

$$
\begin{aligned}
& \mathrm{X} \text { and } \mathrm{Y}: \mathrm{N}, \mathrm{O} \text { or } \mathrm{C} \\
& \mathrm{Ar}=\text { substituted heterocycle with keto } \\
& \text { and carboxylic functional group }
\end{aligned}
$$

Fig. 12 Structures of heteroaryl substituted 4"-O-( $\beta$-amino)propyl-carbamate and 4"-O-( $\beta$-amino)propyl-sulfonate azalides.

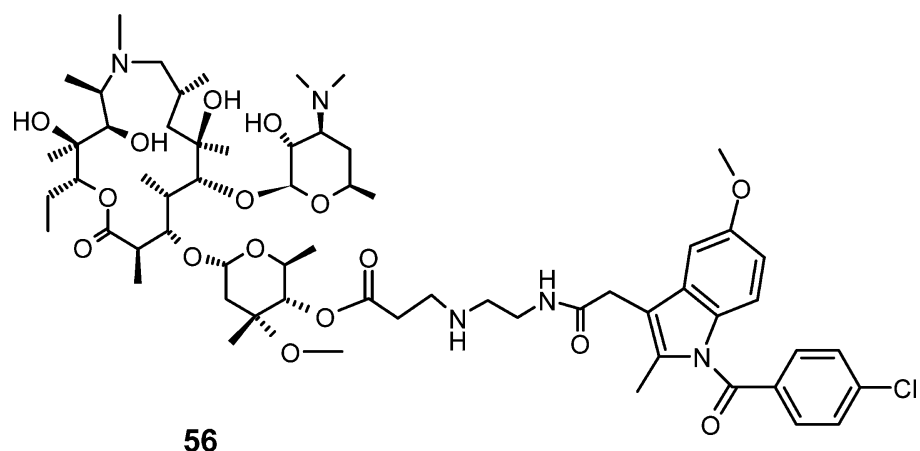

Fig. 13 Structure of potential anti-inflamatory 4"-O-( $\beta$-ethylendiamino)propionyl azalide.
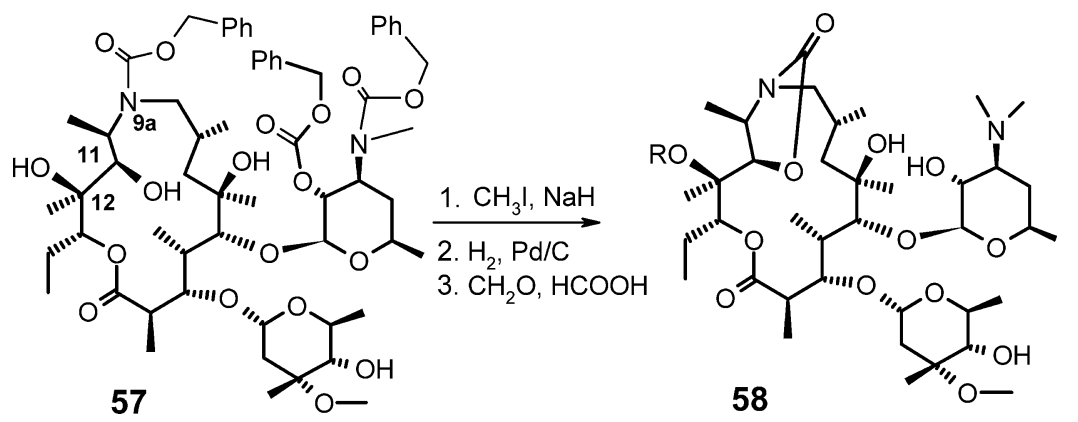

58a R : H

58b $\mathrm{R}: \mathrm{CH}_{3}$

Scheme 11 Synthesis of azithromycin-9a,11-cyclic carbamates.

$3^{\prime}-N$-methylated with formaldehyde and formic acid to reintroduce the dimethylamino group (Scheme 11). Finally, 9-dihydro-9-deoxo-9a-aza-9a-homoerythromycin-9a,11cyclic carbamate (58a) and its 12-O-methyl derivative (58b) were isolated by column chromatography.

In comparison to azithromycin, these novel bicyclic azalides $\mathbf{5 8 a}$ and $\mathbf{5 8 b}$ exhibited substantially decreased antibacterial activities in vitro.

Merck chemists have prepared 6,9a-bicyclic azalide carbamate and methylene derivatives [71, 72] as intermediates for ketolides (Fig. 14) to avoid formation of 3,6-hemiketals (chapter 2.9.2.).

During the last few years, ENANTA Pharm. Inc. entered into the area of macrolide antibiotics. They made many new analogues of 14, 15 and 16-membered macrolides. Starting from desmethyl-azithromycin or 7 and reacting the di-tert-butyl carbonate of the corresponding 2-methylene1,3-propandiol with a palladium catalyst, 9a,11-3C-bicyclic 9a-azalide 62 was obtained (Scheme 12), which was later 


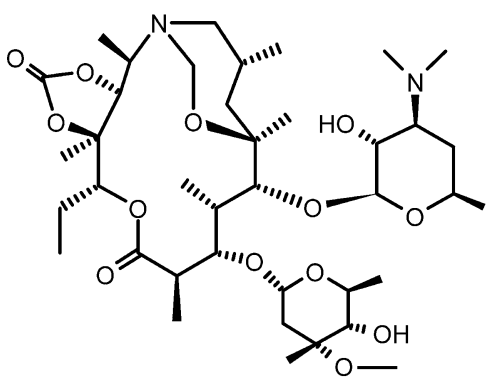

59

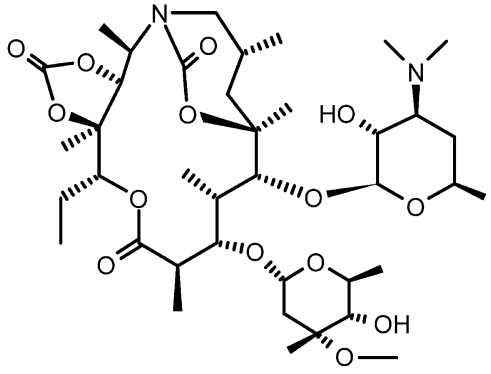

60

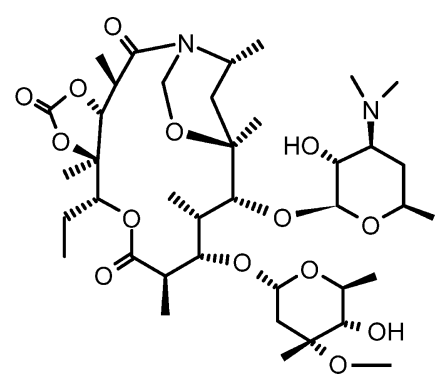

61

Fig. 14 Structures of 6,9a-bridged azalides.

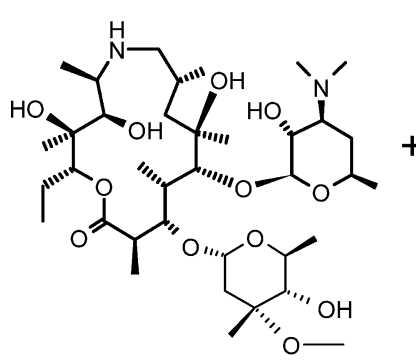

7<smiles>C=C(COC(=O)OC(C)(C)C)COC(=O)OC(C)(C)C</smiles><smiles>CCC</smiles>

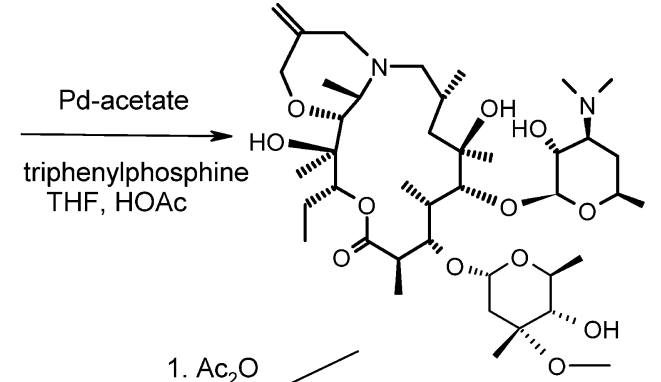

62

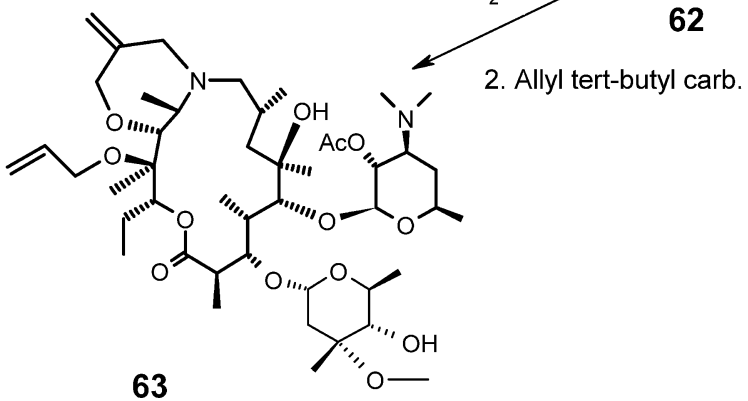

Scheme 12 Synthesis of 9a,11-3C-bicyclic-9-dihydro-9a-aza-9a-homoerythromycins.

derivatized at various positions to as 11-allyl 63 [73].

A bicyclic product was hydrogenated from methylene to give a methyl substituent, or acetylated at position $2^{\prime}$, derivatized and/or further hydrolysed to the descladinosyl analog and finally oxidised to the 3-keto derivative. (Chapter 2.9.2.). 9a,11-Bridged azalides didn't show satisfactory antibacterial activity but 3-keto derivatives were reported to be active against resistant strains [73].

\subsection{Substitution on C-4" Position}

As a further line of derivatization of 9a-azalides [25], starting with $\mathbf{8}$, another amino group was introduced on the cladinose sugar in place of the 4 "-hydroxy group. After protection of the $2^{\prime}$-hydroxyl group as the acetate (45), the 4 "-hydroxyl group was oxidized using Moffat-Pfitzer conditions (Scheme 13) to yield the respective 4 "-oxo derivative 64, which was transformed to 65 and then reduced to a mixture of epimers of the 4"-amine $\mathbf{6 6}$.

In vitro and in vivo antibacterial activity of the amine 66a was better than that of $\mathbf{1}$ and equaled that of $\mathbf{8}$, especially against Gram-negative microorganisms. Similarly, Merck chemists have prepared 4"-oxo, 4"-oxime and epimers of 4 "-amine from the corresponding 9-deoxo9-dihydro-8a-aza-8a-homoerythromycin A [22, 74]. Further, a number of $4 "-N$-acyl derivatives of 8 a-azalides were described $[22,75]$.

Starting from the 9a-aza scaffold (8), each of the epimers of the 4 "-amino compound have been prepared by PLIVA chemists. Amides with heteroalkyl-linked quinolone derivatives were synthesized resulting in compounds with activity against resistant strains [75]. The derivative of the 4 "-amine 67 with the natural $(S)$ stereochemistry (Fig. 15) showed better biological activity than the corresponding $(R)$ epimer. 


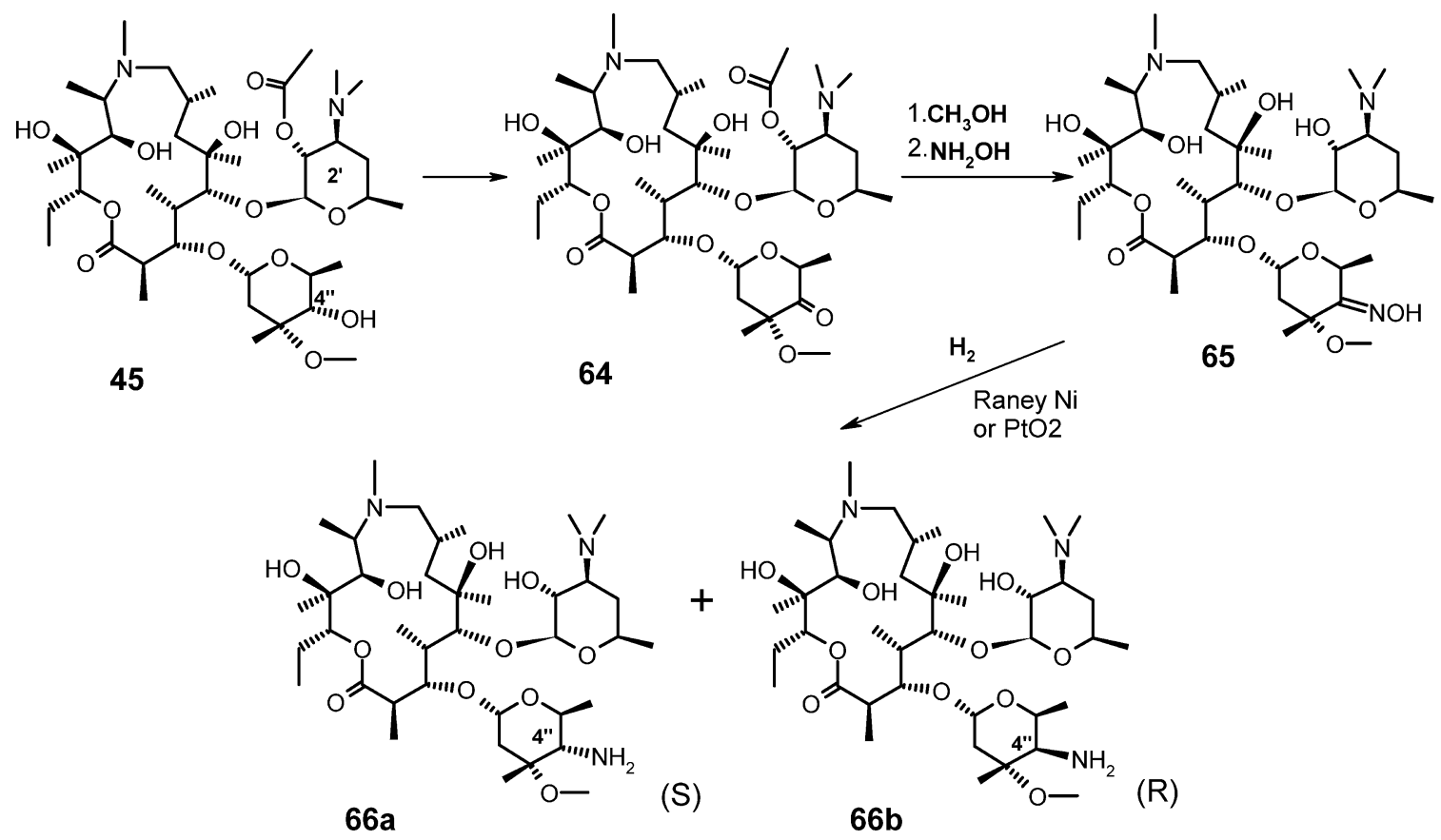

Scheme 13 Synthesis of 4"-oximino- and 4"-amino-9a-methyl-9-dihydro-9a-aza-9a-homoerythromycins.

Chemists at Pfizer [76] have introduced a carbon atom at C-4" applying Grignard reagents in DMF to the 4"-oxo derivative 64. Starting from the $4^{\prime \prime}$-ketone 64, various reagents and reaction conditions were tried, and the epoxide 69 or its epimer were prepared (Scheme 14).

4"Hydroxy-4"carbon substituted compounds showed good antibacterial activity against bacteria in bovine and swine respiratory disease and one of them has been approved for the market as a veterinary drug under the generic name, tulathromycin (70) (Pfizer). Subsequently, the polymorph of the crystalline diphosphate salt was patented [77].

Scientists from PLIVA have attached a steroid moiety to 4"-C-substituted epoxy-azalides $[68,69]$ to obtain antiinflammatory agents (Fig. 16) such as $\mathbf{7 1}$, which acts predominantly at the inflamed site due to enrichment in inflammatory cells, such as granulocytes and macrophages.

\subsection{Substitution on C-3' Position}

The amino group on C-3' is important for antibacterial activity and all described changes on the dimethylamino group resulted in a decrease in antibacterial activity. When $O$-methyl derivatives of azithromycin were synthesized [53], using a benzoyloxycarbonyl group for protection, the $3^{\prime}$ - $N$-demethyl derivative 29 was obtained, which, after removing protecting groups, had to be remethylated with formaldehyde and formic acid. 3'-N-Demethylazithromycin is known as one of the impurities in $\mathbf{8}$

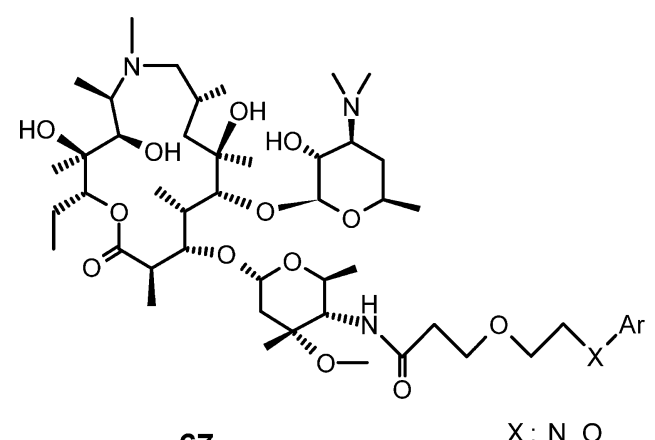

67

Fig. 15 Structure of 4"-deoxy-4"-acylamino derivatives of azithromycin.

synthesis. Scientists from TEVA have studied the degradation products of $\mathbf{8}$ during manufacturing processes, processes that include formulation of the pharmaceutical dosage forms [78]. They have reported structures (Fig. 17) of azithromycin-3'- $N$-oxide 72, $3^{\prime}-N$-didemethyl- $3^{\prime}-N$ formyl $\mathbf{7 3}$ and $3^{\prime}$-de-dimethylamino-3'-oxo derivatives $\mathbf{7 4 .}$

Scientists from Sandoz [79] have reported a process for preparing azithromycin-3'-N-oxide, $3^{\prime}-N$-didemethyl$3^{\prime}-N$-formyl-azithromycin, then $3^{\prime}-N$-demethyl-3' $-N$ formyl (75), and $3^{\prime}$ - $N$-didemethyl-azithromycin $\left(3^{\prime}-\right.$ aminoazithromycin). From this line, $3^{\prime}$-de(dimethylamino)$3^{\prime}$-oxo- and $3^{\prime}$-de(dimethylamino)-3', 4'-didehydroazithromycin (76) derivative (Fig. 17) could be prepared. 


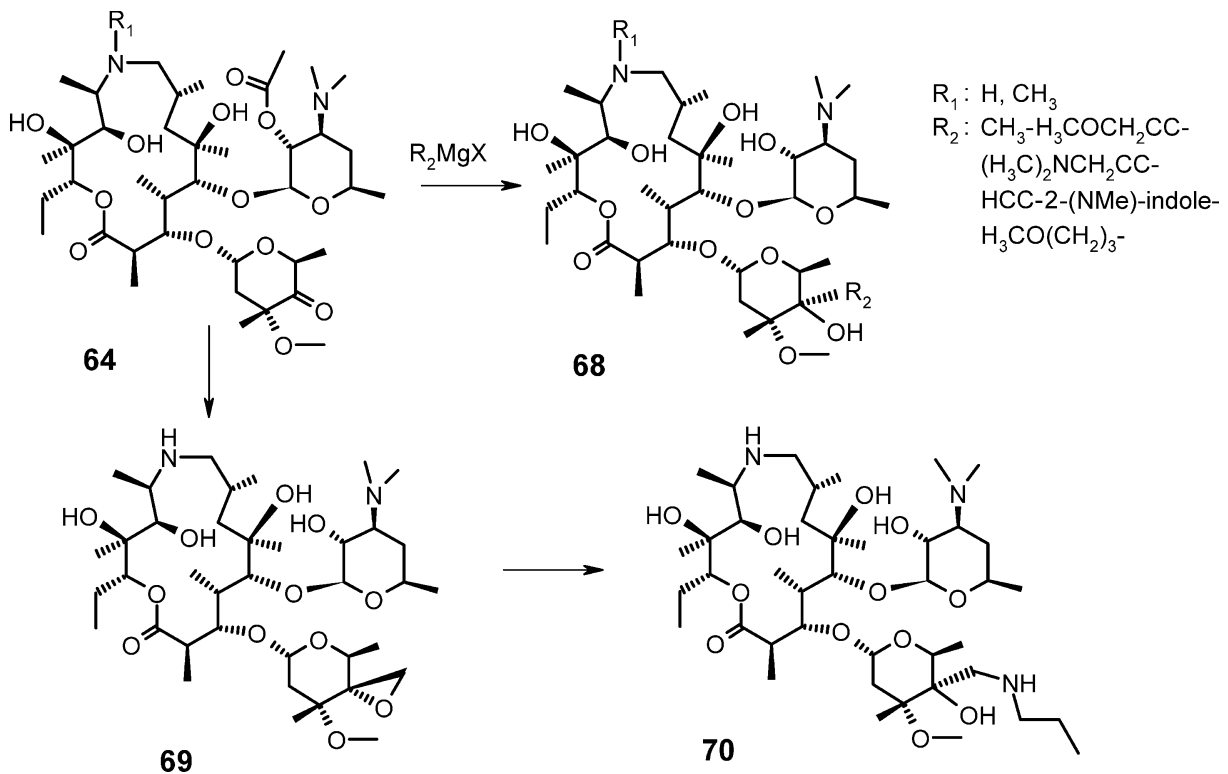

Scheme 14 Synthesis of 4"-C-substituted-9a-methyl-9-deoxo-9-dihydro-9a-aza-9a-homoerythromycins.

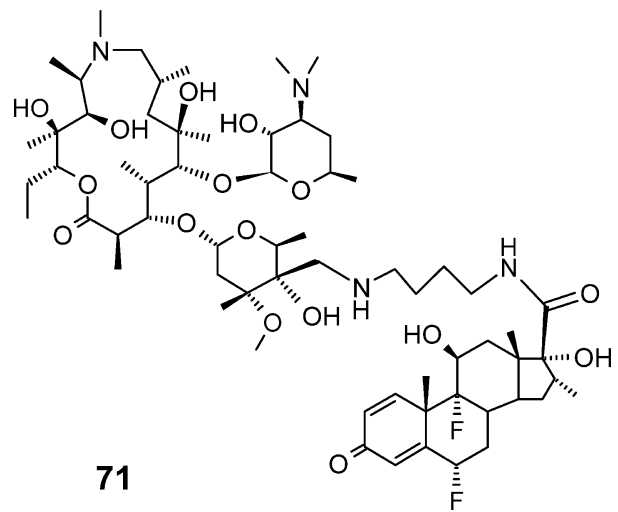

Fig. 16 Structure of potential anti-inflamatory 4 "-Ctetramethylendiamino-steroido-substituted azalide.

Scientists working on anti-inflammatory agents at PLIVA have described in their patent applications the binding of a steroid moiety to $3^{\prime}$-demethyl azithromycin with some suitable linkers $[40,41]$.

\subsection{3-Descladinosyl-3-substituted Azalides-Acylides, Ketolides}

\subsubsection{Acylides}

During the last few years resistance to macrolides has increased worldwide. One of the main mechanisms results from a base-specific mono- and dimethylation of $23 \mathrm{~S}$ ribosomal RNA near or within the macrolide binding site. This decreases significantly the binding of macrolides, lincosamide or streptogramin $[80,81]$.
Macrolides lose antibacterial activity almost completely if the cladinose sugar at position 3 is hydrolyzed to form the 3-hydroxy analogs. However, further conversion to acylides, anhydrolides and ketolides not only restores the activity but overcomes typical macrolide resistance. The synthesis of various 3-O-esters was described by Taisho for different erythromycin derivatives. Especially 3decladinosyl-arylacetyl macrolides demonstrated activity against inducible resistant strains. The 15 -membered macrolides included 3-descladinosyl-3,6-di( $p$-nitrophenyl)acetyl-azithromycin and its 11,12-carbonate 77 [82]. However, biological activity of aza-acylides was not mentioned. A similar 3-O-(3-pyridyl)-acetyl derivative (78) (Fig. 18) of $\mathbf{8}$ was prepared [83], but antibacterial activity against Staphylococcus aureus and Streptococcus pneumoniae was lower than with the corresponding 14membered derivative; only activity against $H$. influaenzae was improved.

Synthesis of 3-descladinosyl-3-arylalkyl-8a-lactams, starting from 8a-lactam 12, has been described by PLIVA chemists [84]. Some of these lactams, such as 3-O-( $p$ nitrophenyl)-acetyl-8a-lactam 79, possess antibacterial activity similar to that of azithromycin but no improvement in activity towards resistant pathogens was observed. 9aLactam derivatives $\mathbf{8 0}$ were antibacterial inactive (Fig. 19).

In a further attempt to improve antibacterial activity of aza-acylides, corresponding 3-O-arylacyl derivatives of azithromycin-9a,11-cyclic carbamate $\mathbf{8 1}$ were prepared [85, 86], but with lower antibacterial activity (Scheme 15).

Chemists at Pfizer reported [87] the synthesis of aryl and 


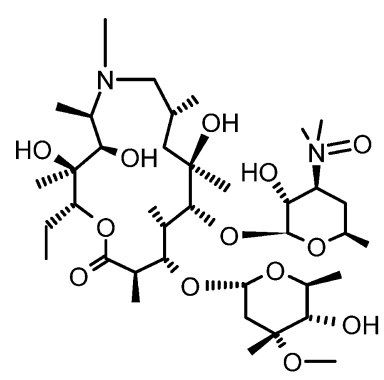

72

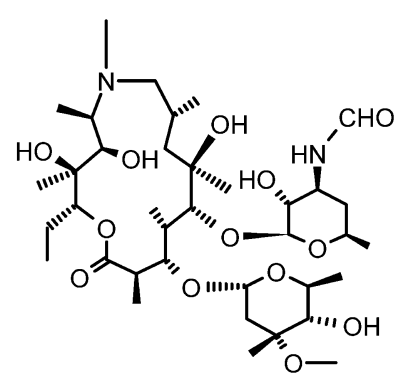

73

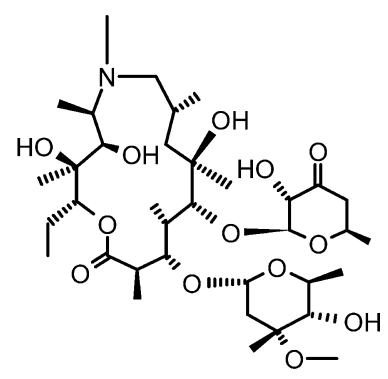

74

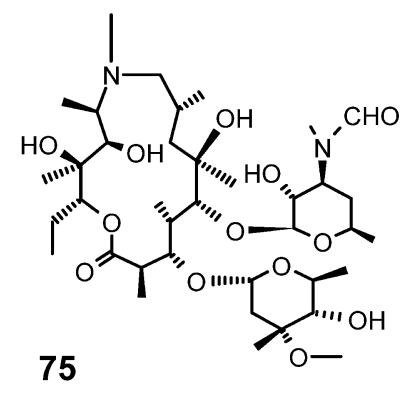

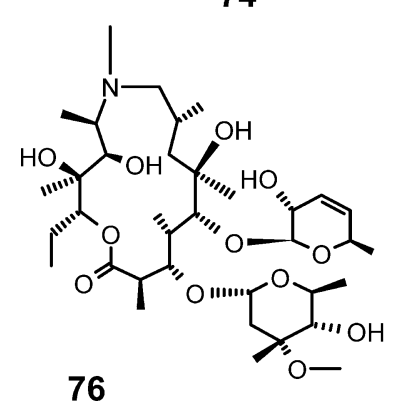

Fig. 17 Structures of 3'-substituted derivatives of azithromycin.
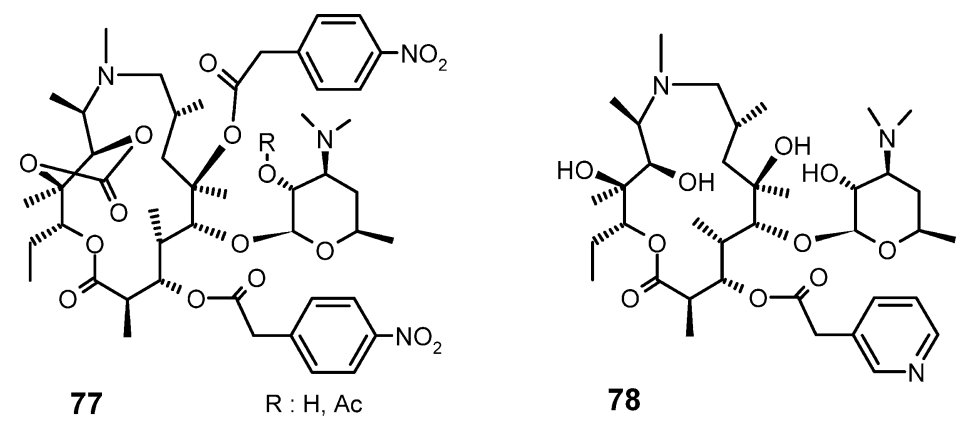

Fig. 18 Structures of various 3-acyl substituted 3-descladinosyl-azalides.

heteroaryl substituted 3,6-ketals of 15-membered azalide analogues 84 (Fig. 20) with in vitro antibacterial activity against veterinary pathogens, including Staphylococcus aureus and Pasteurella multocida.

3-Descladinosyl-3-acyl- derivatives of 9a,11-azalides prepared by ENANTA [73] have shown some antibacterial activity against resistant strains.

At PLIVA, chemists have prepared new descladinosyl compounds 86 with 9a-carbamoyl and thio-carbamoyl groups [88], which were acylated at position 3 to rich antibacterial activity (Fig. 21).

Other descladinosyl derivatives prepared in PLIVA were 9a-sulfonylureas $\mathbf{8 7}$ and 9a-propylamino-sulfonyl-ureas $\mathbf{8 8}$ [48, 49].

Scientists at ZAMBON Group s.p.a. have prepared new descladinosyl-azalides 89, 90 (Fig. 22) macrolides with anti-inflammatory activity [89].

Macrolides and especially azalides possess some antiinflammatory effects [15 18], and PLIVA chemists have prepared new active compounds (Fig. 23) with a steroid linked at positions $2^{\prime}$ - and 3- of 3-descladinosylazithromycin [43]. Another group of azalide conjugates were compounds 91 and 92, comprising binding of the aglycone to a steroid moiety $[40,42,69]$. Both sugars were removed probably to avoid antibacterial activity.

In the same group of patent applications, claims were also made for steroid ester-bonded conjugates at position 2 '- and position 3- of descladinosyl-azithromycin 93 [42, 43].

\subsubsection{Ketoazalides}

Early reports on the 3-keto macrolides, narbomycin [90] 


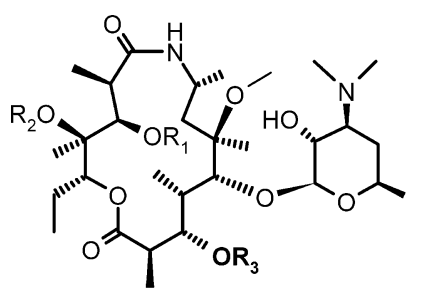

79

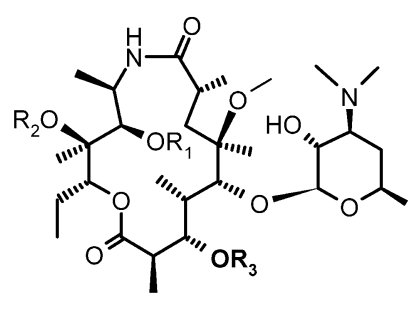

80

$$
\begin{aligned}
& \mathrm{R}_{1}, \mathrm{R}_{2}: \mathrm{H},-\mathrm{CO}- \\
& \mathrm{R}_{3}:-\mathrm{CO}-\mathrm{CH}_{2}-\mathrm{R}_{4}, \\
& \quad \text { or O-CO-NH-R} \mathrm{R}_{4} \\
&
\end{aligned}
$$<smiles>CC(=O)Cc1ccc([N+](=O)[O-])cc1</smiles><smiles>CC(=O)Cc1ccc[nH]1</smiles><smiles>CC(=O)CC=CCc1cnc2ccccc2c1</smiles>

Fig. 19 Structures of various acyl substituted 3-descladinosyl 8a- and 9a-lactams.

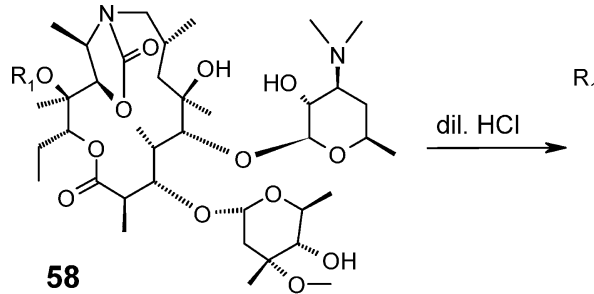

$\mathrm{R}_{1}: \mathrm{H}, \mathrm{Me}, \mathrm{Et}$

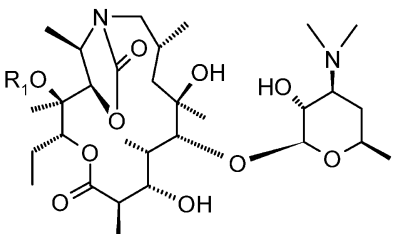

81<smiles>[3H][13CH]=O</smiles>

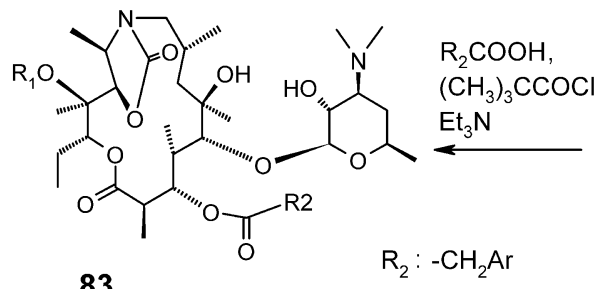

83

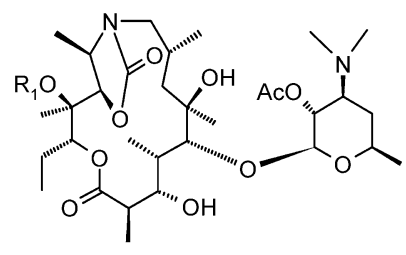

82

Scheme 15 Synthesis of 3-acyl-9-dihydro-9a-aza-9a-homoerythromycin-9a,11-cyclic carbamates.

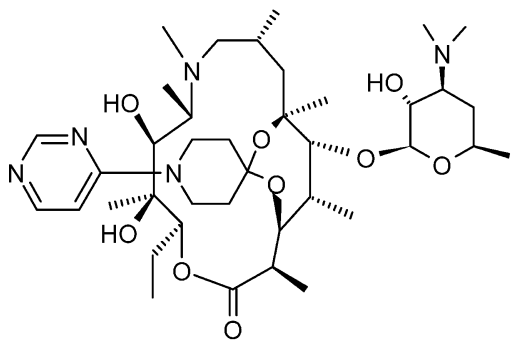

84

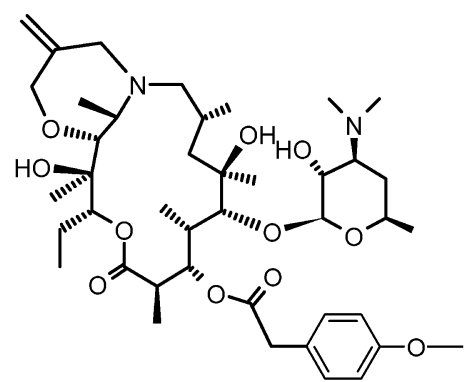

85 or<smiles>O=C(O)c1ccc([N+](=O)[O-])cc1</smiles>

Fig. 20 Structures of 9a,11- and 3,6-bridged-3-descladinosyl-azalide derivatives. 


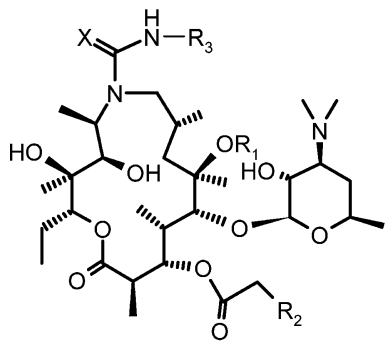

86

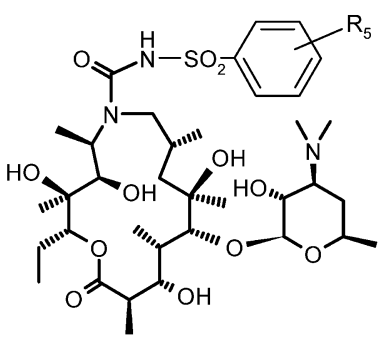

87

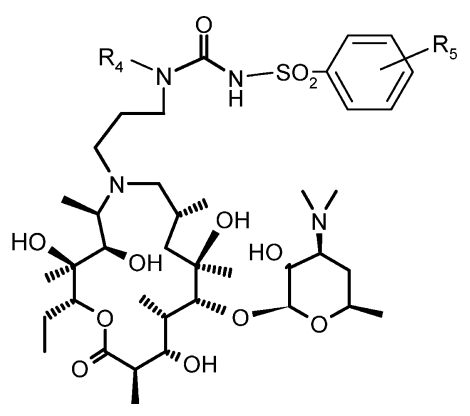

88

$$
\begin{aligned}
& \mathrm{X}: \mathrm{O}, \mathrm{S} \\
& \mathrm{R}_{1}: \mathrm{H},-\mathrm{Me} \\
& \mathrm{R}_{2} \text { arylalkyl or } \\
& \text { arylalkenyl } \\
& \mathrm{R}_{3}: \text { alkyl or Substituted aryl } \mathbf{8 7} \\
& \mathrm{R}_{4}: \mathrm{H}, \text { alkyl } \\
& \mathrm{R}_{5}: \mathrm{H}, p-\mathrm{Me}, o-\mathrm{Me}, p-\mathrm{Cl}, \\
& \quad \text { - } \mathrm{Cl}, p-\mathrm{F}
\end{aligned}
$$

Fig. 21 Structures of 3-descladinosyl-N-carbamoyl derivatives of 9-deoxo-9-dihydro-9a-aza-homoerythromycin.

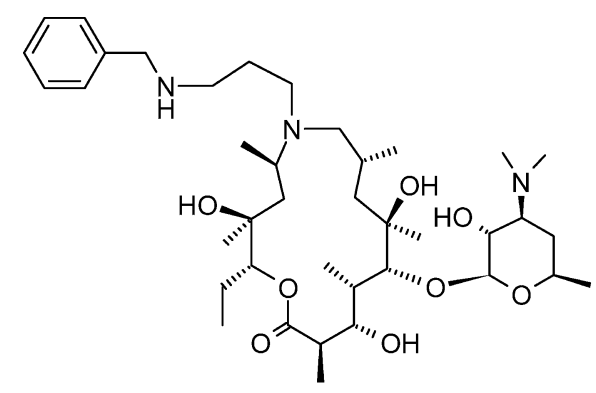

89

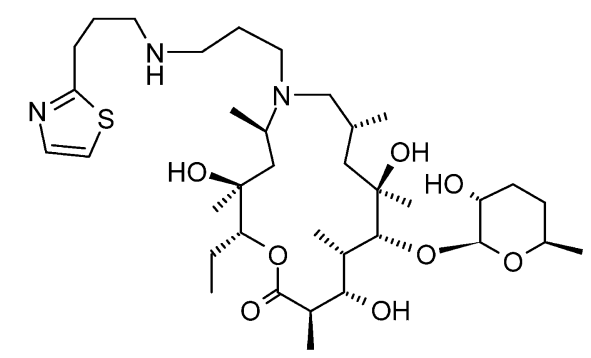

90

Fig. 22 Structures of different 9a-methylenamino-substituted 3-descladinosyl azalides.

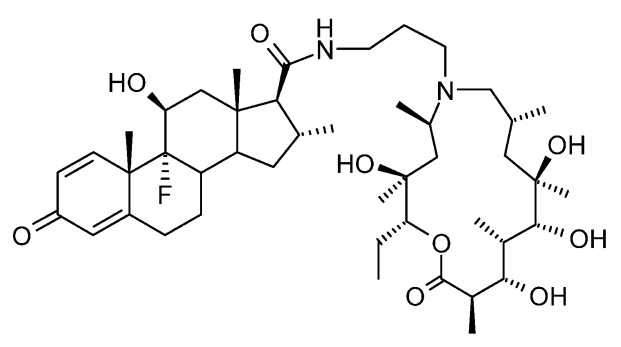

91

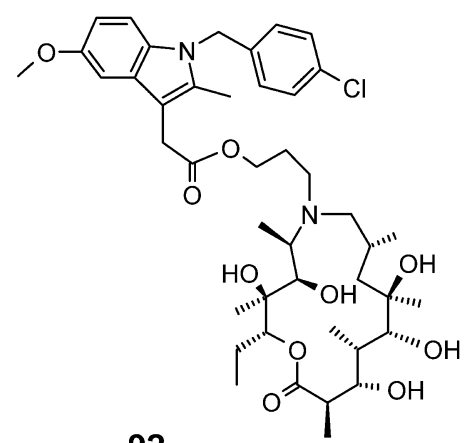

92

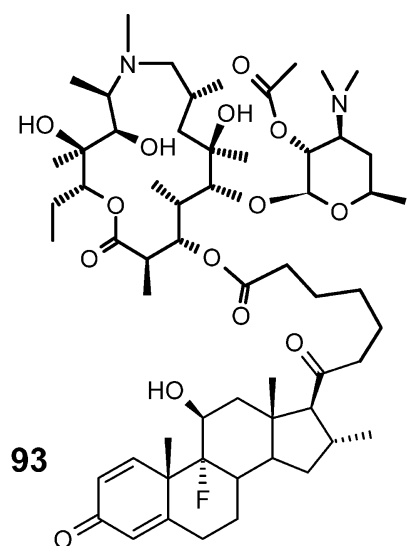

Fig. 23 Structures of complex 9a, $\mathrm{N}$-substituted-aglycone and 3-substituted descladinosyl azalides.

and picromycin [91], which have only weak intrinsic antibacterial properties, indicated the absence of any potential to induce antibacterial resistance, in contrast to other macrolides [92]. This observation was the rationale for transformation of 3-descladinosyl-erythromycin-oxime derivatives to 3-oxo compounds [93]. However, the reaction resulted in the formation of 3,6-hemiketals, if the hydroxyl group at position 6 was not protected e.g. by prior methylation. A comparable hemiketal formation is observed if azalides are used [94]. 
<smiles>CC[C@H](OC(=O)C(C)C(=O)[C@@H](C)[C@H](OC1OC(C)CC(N(C)C)[C@H]1O)[C@](C)(C[C@@H](C)CN(C)C)OC)[C@@H](C)O</smiles>

94

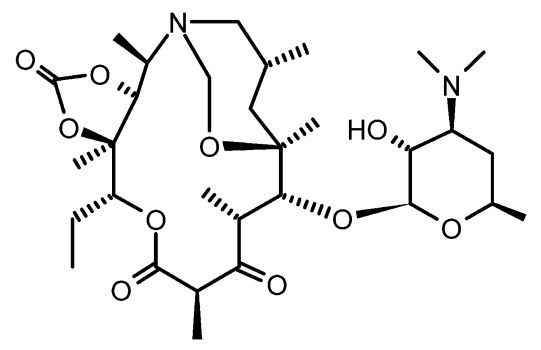

95

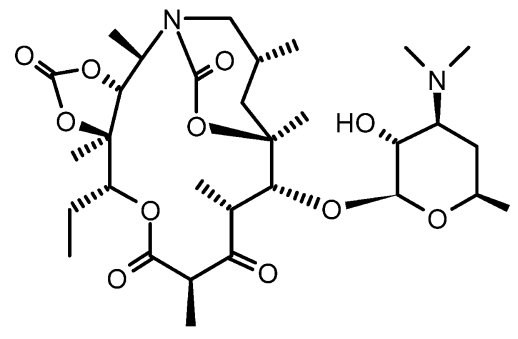

96

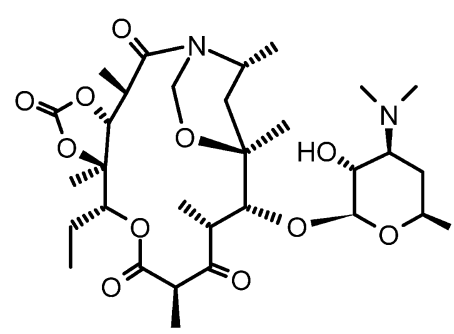

97

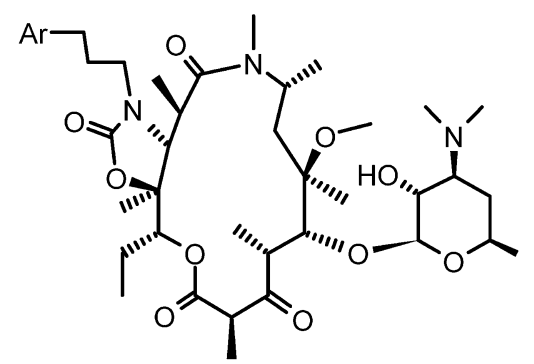

98

Fig. 24 Structures of azaketolides of 9a-aza-9-dihydro-homoerythromycin-11,12-carbonate-6,9a-methylene, bridged carbonyl derivative or 11,12-carbamate.

Recently, 3-decladinosyl-3-oxo-6- $O$-alkyl-erythromycin derivatives were reported to show significantly enhanced activity against resistant bacteria. Preparation of 3-oxo azalides (amines and lactams) requires protection of the 6hydroxyl group, since otherwise inactive 3,6-hemiketals are formed. Starting from 6-O-methyl-azithromycin, however, the corresponding 3-keto-azalide was synthesized. 3-Keto$8 \mathrm{a}$-and 9a-aza-lactams showed some limited antibacterial activity that warrants further derivatization.

3-Keto-9a-azalide was prepared, starting from 6-Omethyl-erythromycin- $9(E)$-oxime, which was converted to the 6-O-methyl derivative of 9,11-imino-ether (5) or, under aqueous conditions, to the corresponding lactam, 34 [59]. The imino-ether 6 was transformed to 6-O-methylazithromycin 31, which after hydrolysis of cladinose, subsequent protection, oxidation and deprotection, yielded the ketoazalide 94.

The antibacterial activity of azalides compared with azithromycin and the ketolide HMR-3647 (Ketek, telithromycin) [95] was decreased, while 94 was significantly less active.

94 was mentioned in a patent applied for by Merck [71], in which the inventors described the synthesis of various 9-dihydro-9a-aza-homoerythromycins and their 3-ketoderivatives (Fig. 24), such as 3-decladinosyl-3-oxo-9aaza 9a- $N$, 6-O-methylene-9a-homo-erythromycin-11,12carbonate (95) and 3-decladinosyl-3-oxo-9a-aza-9ahomoerythromycin-11,12-carbonate-9a,6-carbamate (96).
Also various 11,12-cyclic-carbamates were mentioned, but without any antimicrobial data.

In another patent, chemists at Merck have described broad derivatisation of 8a-lactam 11 [72]. They have prepared 8a-methyl or 8a- $N$, 6-O-methylene-8a-aza-8ahomoerythromycin-11,12-carbonate (61), which was transformed in four steps to its 3-decladinosyl-3-keto derivative (97).

Various combinations of 3-hydroxy-substituted or 3deoxy compounds have been prepared, but none of them showed antibacterial activity.

In the same patent application [72], various 3-oxoarylalkyl-substituted 11,12-cyclic carbamates (98) were claimed (Fig. 24); aryl groups comprised phenyl-, naphthyl-, 4-quinolyl- and pyridyl-imidazolyl group.

Scientists at Abbott have prepared ketoazalides 104 containing 6-O-(3-quinolyl)allyl-azithromycin, with an analogous side chain to that of its ketolide, cethromycin $[60,96]$. The cladinose sugar was removed from $2^{\prime}$-acetyl protected 6-O-(3-quinolyl)allyl-azithromycin or its 9,11iminoether intermediate and oxidized (Scheme 16). Iminoether was reduced with sodium borohydride and methylated at position $9 \mathrm{a}$.

Ketoazalide $\mathbf{1 0 4}$ was active against Staphylococcus aureus, Staphylococcus epidermidis, Escherichia coli and Nocardia asteroides.

Starting from 6-O-methyl-erythromycin $9(E)$ - or $(Z)$ oxime, PLIVA researchers prepared 8a-lactam 33 and $9 \mathrm{a}-$ 


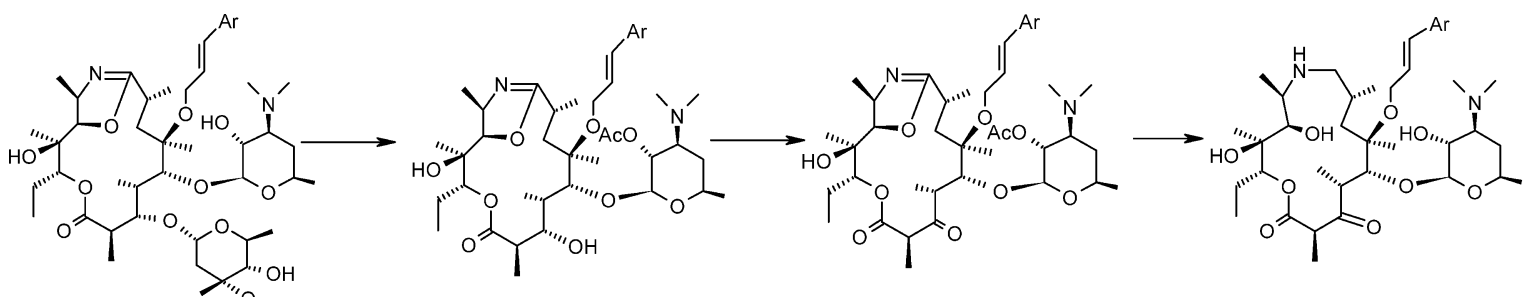

40

99

100

101

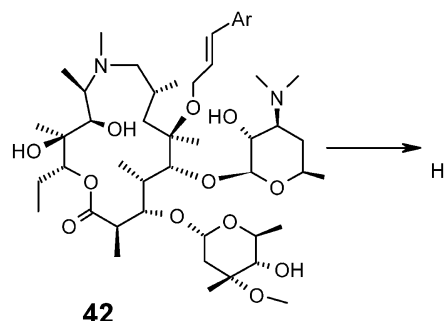

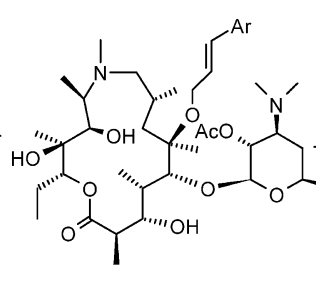

102

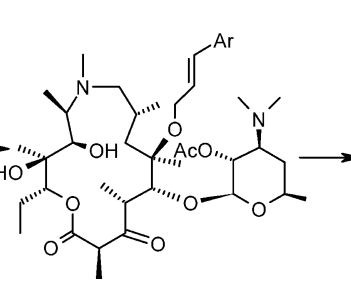

103

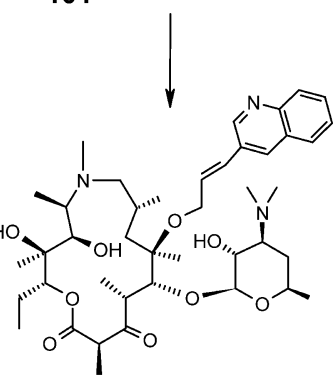

104

Scheme 16 Synthesis of 6-O-quinolylallyl-substituted-azaketolides.

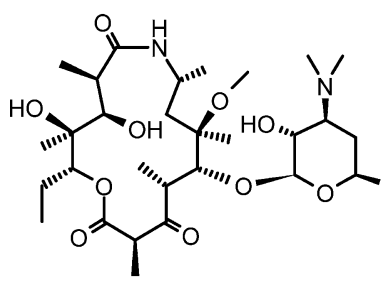

105

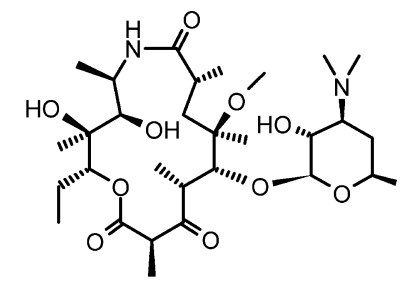

106

Fig. 25 Structures of 3-oxo-6-O-methyl-8a-aza-8a-homoerythromycin (ketolactam) and its 9a-aza-izomer.
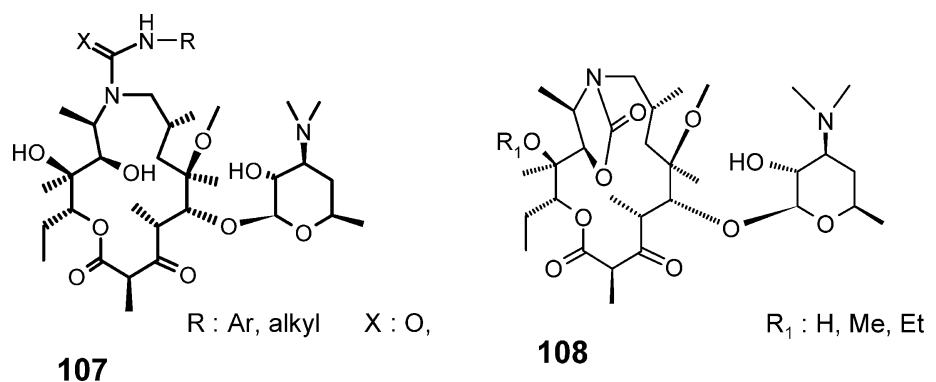

Fig. 26 Structures of 9a-carbamoyl-3-oxo-6-O-methyl-9-deoxo-9-dihydro-9a-aza-9a-homoerythromycin- and 3-oxo-9a,11cyclic carbamates.

lactam 34 by Beckmann rearrangement, which were converted, via the 3-descladinosyl derivatives, to the corresponding (Fig. 25) 8a- and 9a-3-ketolactams 105 and $106[97,84]$.

Antibacterial activity of 8a-lactam 34 was similar to that of 8, while its 9a-isomer 33 was less active. Ketolactam 105 was less active than $\mathbf{5}$ and more active than 106, but showed improved activity against inducible resistant $S$. aureus.

Within PLIVA, a group of descladinosyl compounds was prepared with 9a- carbamoyl and thio-carbamoyl 6-Omethyl-9a-aza-9-dihydro-9-homoerythromycin [88], which were oxidised on position 3 (107). This resulted in a 3,6hemiketal if the hydroxyl group at position 6 was not protected. Similar results were obtained in the case of 


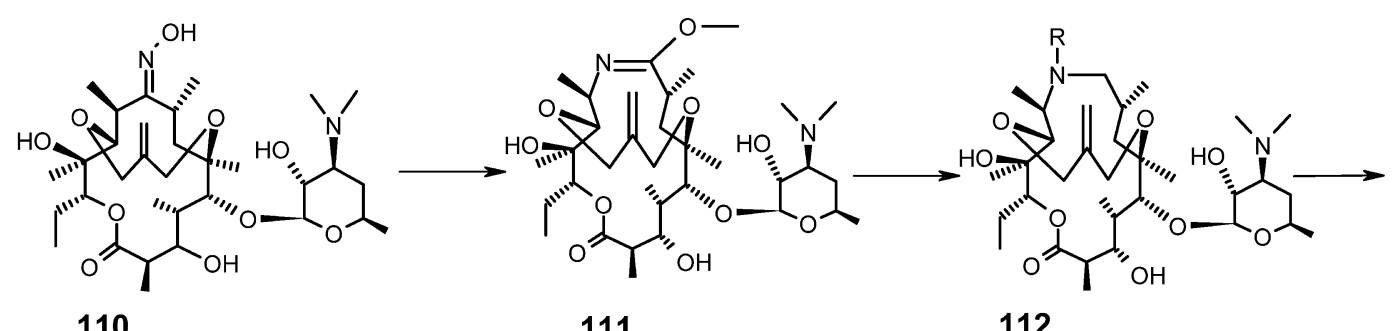

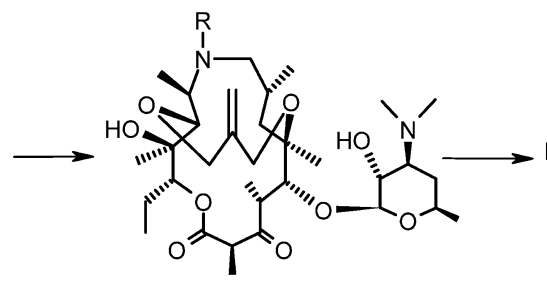

113
111
112

$\mathrm{R}: \mathrm{H}, \mathrm{Me}$

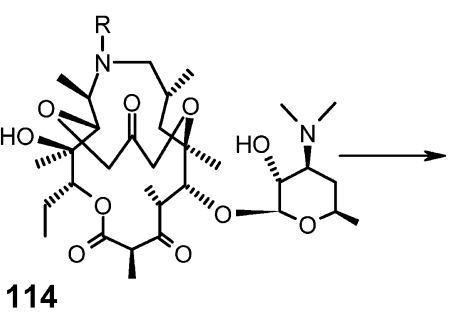

Scheme 17 Synthesis of 3-oxo-6,11-3C-methylene-bridged 9a-aza-9a-homoerythromycin and structure of 3-oxo-6,11-4Cbridged 9a-aza-9a-homoerythromycin.

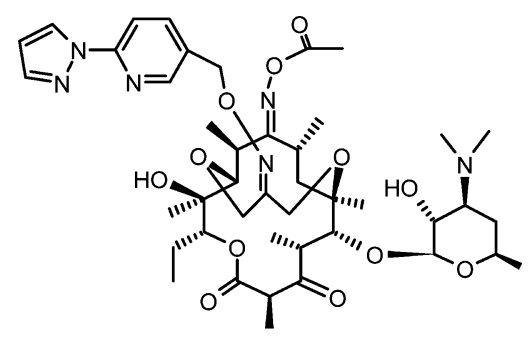

109 EP-13420

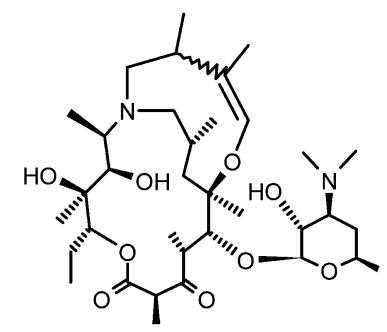

118

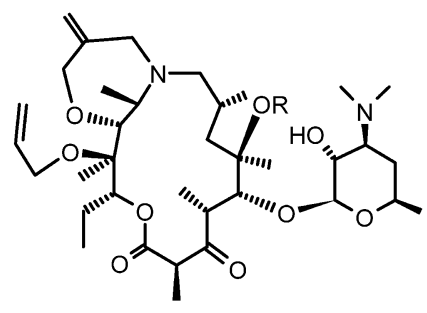

116

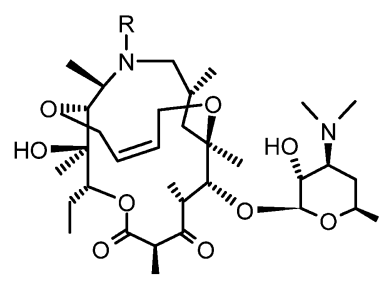

117

$\mathrm{R}: \mathrm{H}, \mathrm{Me}$

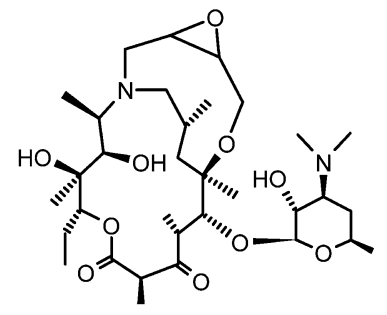

119

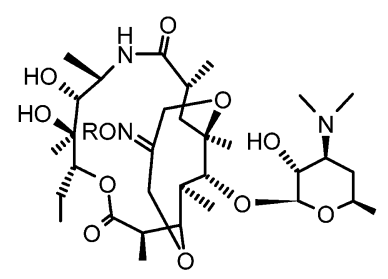

120

Fig. 27 Structures of 6,11-4C-bridged erythromycin-9-oxyme-ketolide and various 3-oxo-3C- and 4C-bicyclic- 9-dihydro-9aaza-9a-homoerythromycins.

9a,11-cyclic carbamates 108 [85], starting with the 6-Omethyl precursor (Fig. 26).

ENANTA Pharm. Inc. has entered the area of macrolide antibiotics with bridged macrolides. The main focus is on ketolides derived from 1. Major line of this research comprises 6,11-ether bridged erythromycin derivatives. 6,9Bridged-3-oxo-erythromycin-9-oxyme (109) EP-13420 [96] was reported as a candidate antibacterial (Fig. 27).

Starting from bridged erythromycin 9-oxime (110), the new 6,11-3C-bicyclic-3-descladinosyl-9a-azalide iminoether
(111), its 9a-amino $\mathbf{1 1 2}$ and finally ketolide $\mathbf{1 1 3}$ were synthesized [98, 99] (Scheme 17).

Applying the reaction ozonolysis, egzo-methylene group was transformed to keto 114, which could be further derivatised by amination or oximation to $\mathbf{1 1 5}$.

New 3-oxo derivatives of -9a,11-3C-bicyclic azalides 116 have been prepared starting from corresponding bicyclic azalide [73]. Other similar new 6,11-4C-bicyclic 9a-azalide derivatives and the 3-oxo analogs $\mathbf{1 1 7}$ have been prepared [100]. The double bond was again transformed to 


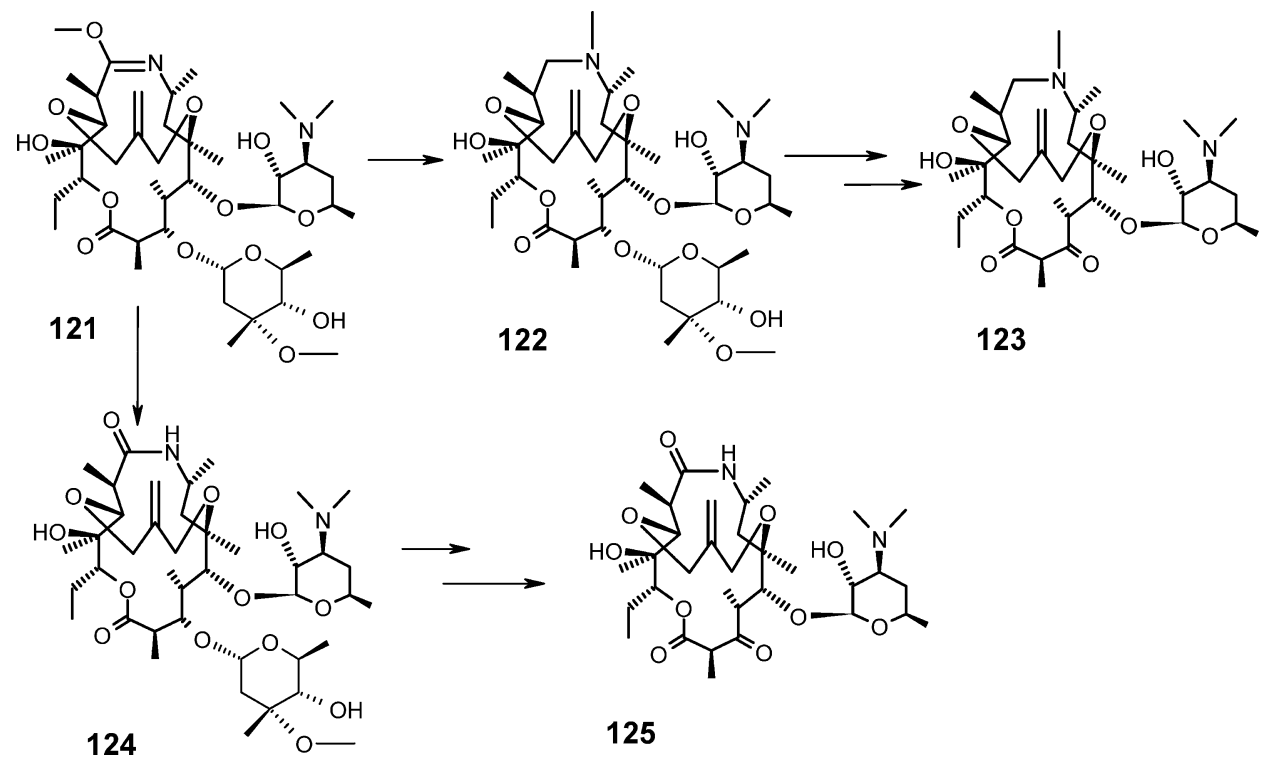

Scheme 18 Synthesis of 3-oxo-6,11-3C-methylene-bridged 8a-aza-8a-homoerythromycins and corresponding 8a-lactams.

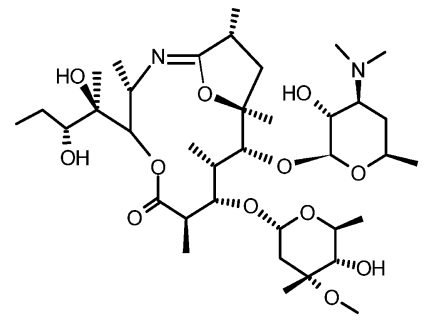

126

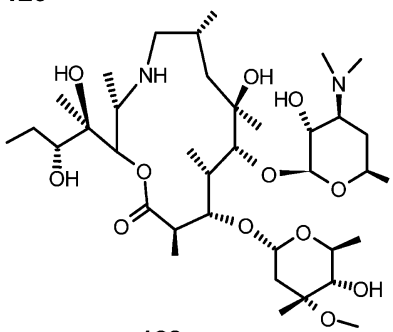

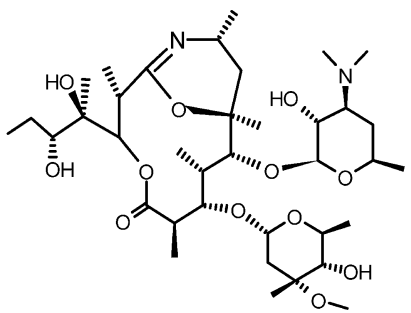

127

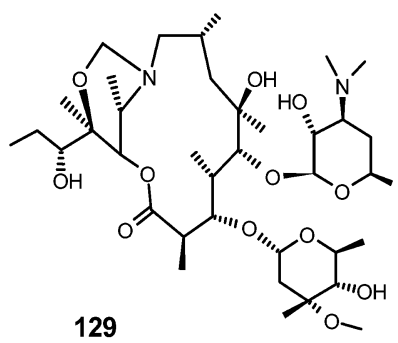

Fig. 28 Structures of 13-membered azalides.

other suitable compounds (Fig. 27).

Later, the same authors [101] have prepared various 3-oxo 6,9a-4C-bicyclic-9-dihydro-9a-aza-9a-homoerythromycins (118 and 119). In the patent application 3,6bycyclic ethers $\mathbf{1 2 0}$ have been protected [102].

Starting from erythromycin Z-oxime, scientists at Merck [103] have prepared the analogous 6,11-bridged oxime, which was transformed into the corresponding 8aiminoether $\mathbf{1 2 1}$ and further to the 8a-azalide 122, finally yielding the ketolide $\mathbf{1 2 3}$ (Scheme 18).

6,11-Bridged 8a-lactams $\mathbf{1 2 4}$ and their ketolides $\mathbf{1 2 5}$ were also prepared, but no data about antibacterial were reported.

\section{Other Azalides}

\subsection{3-Membered Azalides}

Intramolecular rearrangement of azalide imino-ethers yielded 13-membered azalides, as described by Merck [20]. The trans-annular reactions between the aglycone hydroxyl groups and imino-ether and lactone groups of the 9a- (3) and 8a-azalide (9) were investigated. Trans-lactonisation of 4 and $\mathbf{9}$, which included the 11-hydroxy group, resulted in 

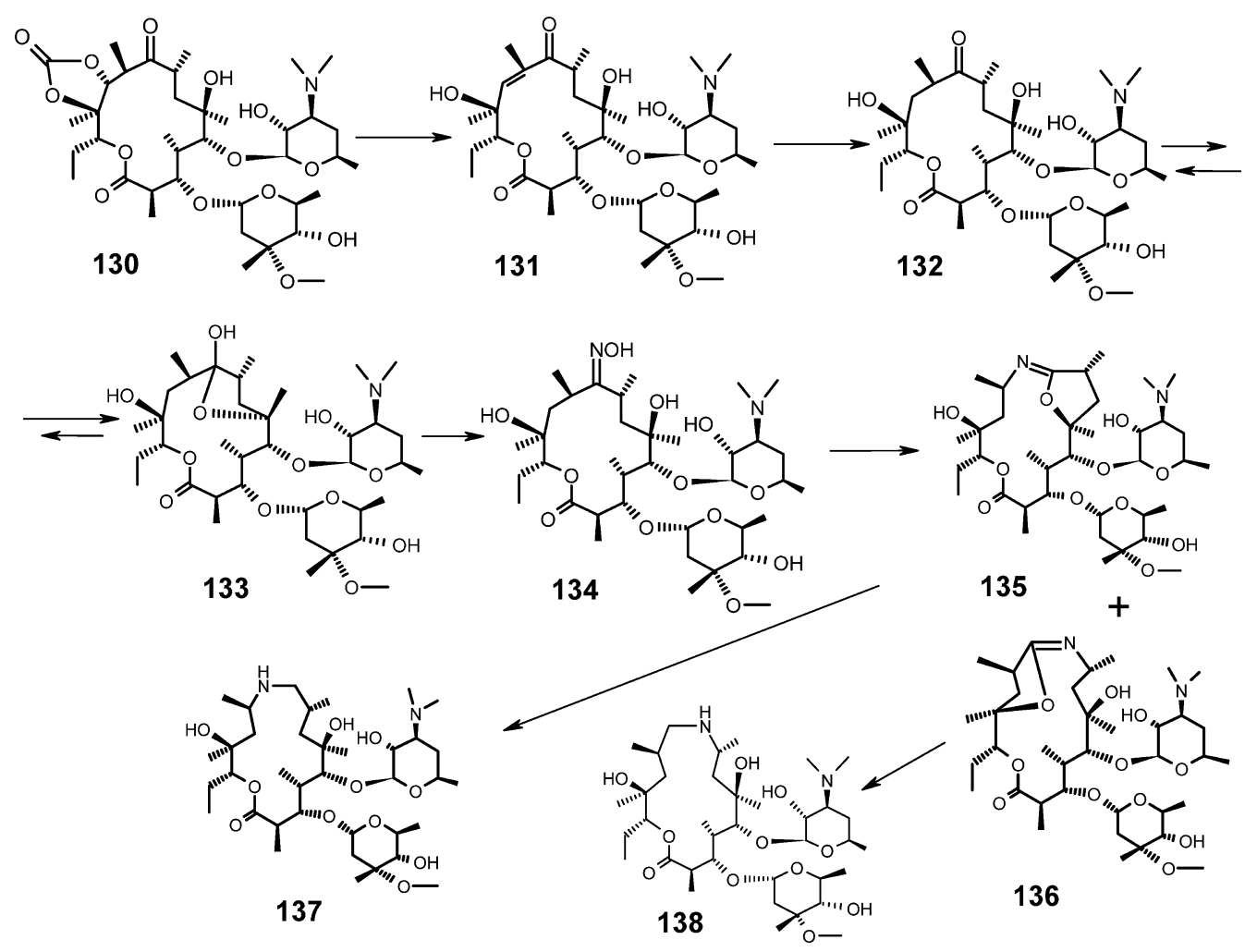

Scheme 19 Synthesis of 11-deoxy-azalides.

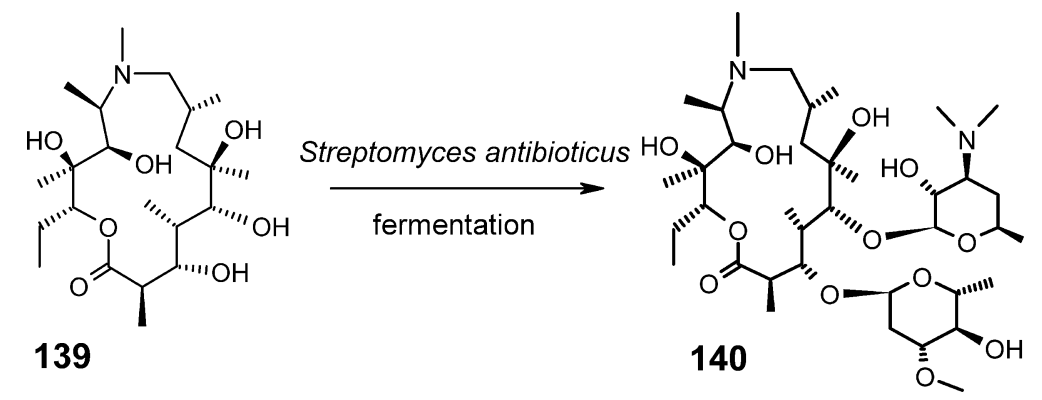

Scheme 20 Microbial transformation of 3-oleandrosyl-azalide.

13-membered imino-ethers $\mathbf{1 2 6}$ and $\mathbf{1 2 7}$ (Fig. 28).

Reductive methylation of 13-membered azalide $\mathbf{1 2 8}$ $(\mathrm{R}=\mathrm{H})$ with formaldehyde and formic acid resulted in the formation of tetrahydro-oxazine $\mathbf{1 2 9}$ (Fig. 28).

Thermal rearrangement of 9a-aza-6,9-imino-ether 4 produced an isomeric mixture of 9a-aza-9,11-imino-ether $\mathbf{6}$ and 8a-aza-9,11-imino-ether 10, which were further transformed to azithromycin and its 8a-methyl isomer. Starting from imino-ether $\mathbf{5}$, in the reaction with acetic acid, a dilactone was formed, which was then transformed to 9 a-aza-lactam 6 by warming in methanol.

13-Membered azalides $\mathbf{1 2 8}$ were prepared at Pfizer by intramolecular translactonisation of 9-dihydro-9-deoxo-9a- aza-9a-homoerythromycin (7). Various azalides were described by derivatisation at positions 13- and 4" [103]. Later, azalide $\mathbf{1 2 8}$ was mentioned as a potential impurity in azithromycin and prepared by chemists at Sandoz [79].

\subsection{Other 15-Membered Azalides}

3.2.1. 11-Deoxy-9a-Aza 15-Membered Azalides

Chemists at Abbott have prepared 9a- and 8a-11-deoxyhomoerythromycins $\mathbf{1 3 7}$ and 138 [104]. Starting from erythromycin-11,12-carbonate (130), 10,11-anhydroerythromycin $\mathbf{1 3 1}$ was made at elevated temperature and after reduction of the double bond to $\mathbf{1 3 2}$, 6,9-hemiketal 133 was formed (Scheme 19). Reaction with hydroxylamine 


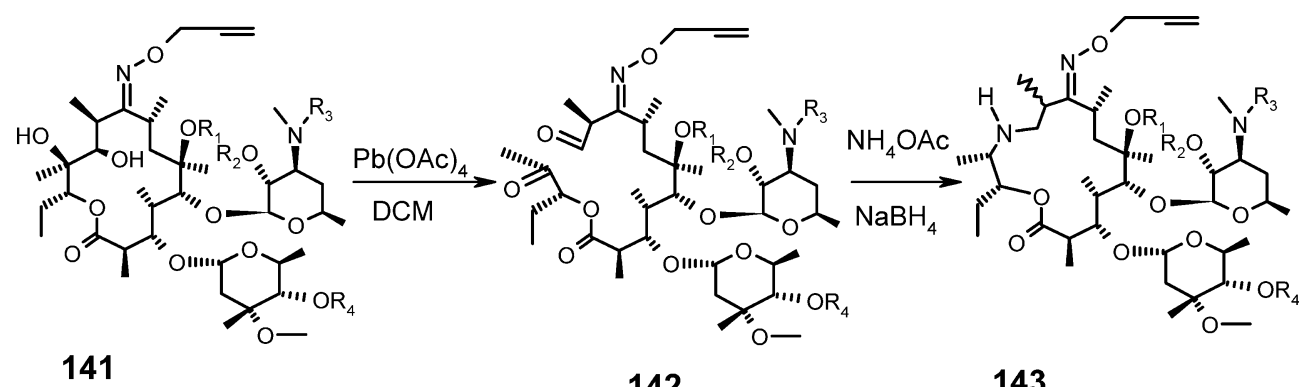

142

143

$\mathrm{R}_{1}, \mathrm{R}_{2}, \mathrm{R}_{3}, \mathrm{R}_{4}$ : protecting groups as benzyl, benzoyl, BOC, TMS, ....

Scheme 21 Synthesis of 11a-azalides.
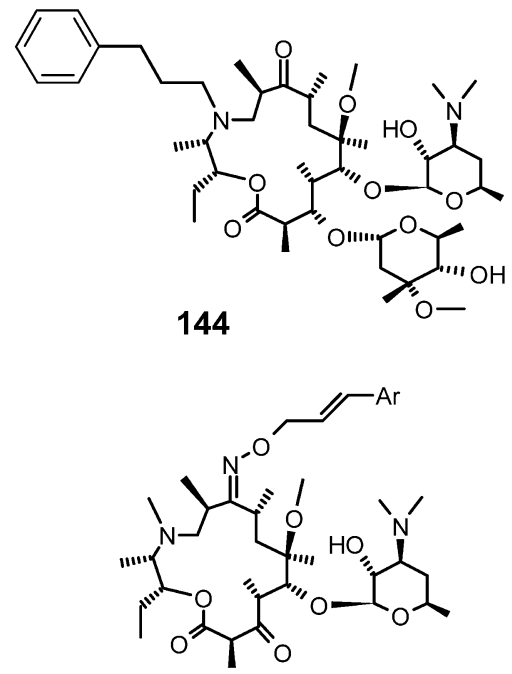

146
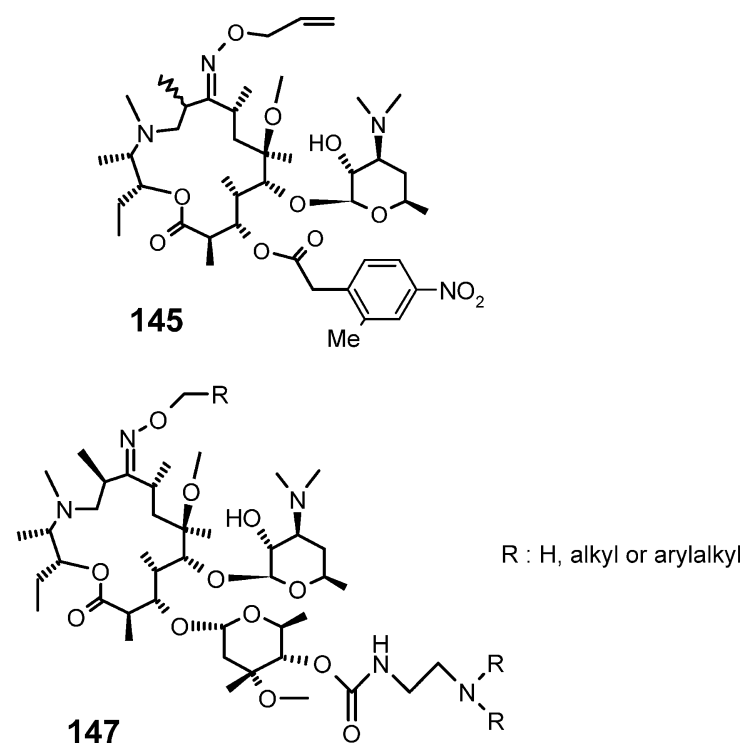

Fig. 29 Examples of various 11a-aza-11a-homoerythromycin derivatives.

resulted in 9-oxime 134, which in the presence of sulphochloride gave 6,9-iminoether $\mathbf{1 3 5}$ and 9,12iminoether 136.

In addition its descladinosyl, 3-ethers, 3-carbonates and 3 -carbamoyl derivatives were prepared. Compounds were described as being useful for prophylaxis or treatment of bacterial infections in fish or mammals.

An unusual derivatisation of the azalide scaffold was made at Pfizer. 3-O-Oleandrosyl-5-O-desosaminylazithromycin was prepared from azithromycin aglycone 139 by microbial transformation using culture with Streptomyces antibioticus ATCC 202189 (Scheme 20). The oleandrose derivatives $\mathbf{1 4 0}$ are more stable under acidic conditions [105].

New compounds have been prepared as potential anticancer and antibacterial agents.

\subsubsection{New 11a-Aza 15-Membered Azalides}

In a new patent application, authors at Wockhard Research Centre have synthesized a new class of 15 -membered azalide at position 11 of the aglycone ring [106]. They oxidized protected erythromycin A oxime (141) with lead tetraacetate to diketone 142. Reductive amination in ammonia or ammonium acetate with sodium borohydride, sodium cyano-borohydride or with hydrogen in the presence of $\mathrm{Pd} / \mathrm{C}$ and ammonia, led to ring closure to form 11a-aza11,12-didehydro-9-oximino-11a-homoerythromycins (143). The reaction (Scheme 21) resulted in a mixture of diastereoisomers, which were separated on chiral columns.

In a further step, nitrogen was alkylated with aldehydes under reductive conditions. Further derivatisation resulted in a number of analogs (Fig. 29) similar to the most active macrolides of the second and third generation, such as $\mathbf{1 4 4}$, 

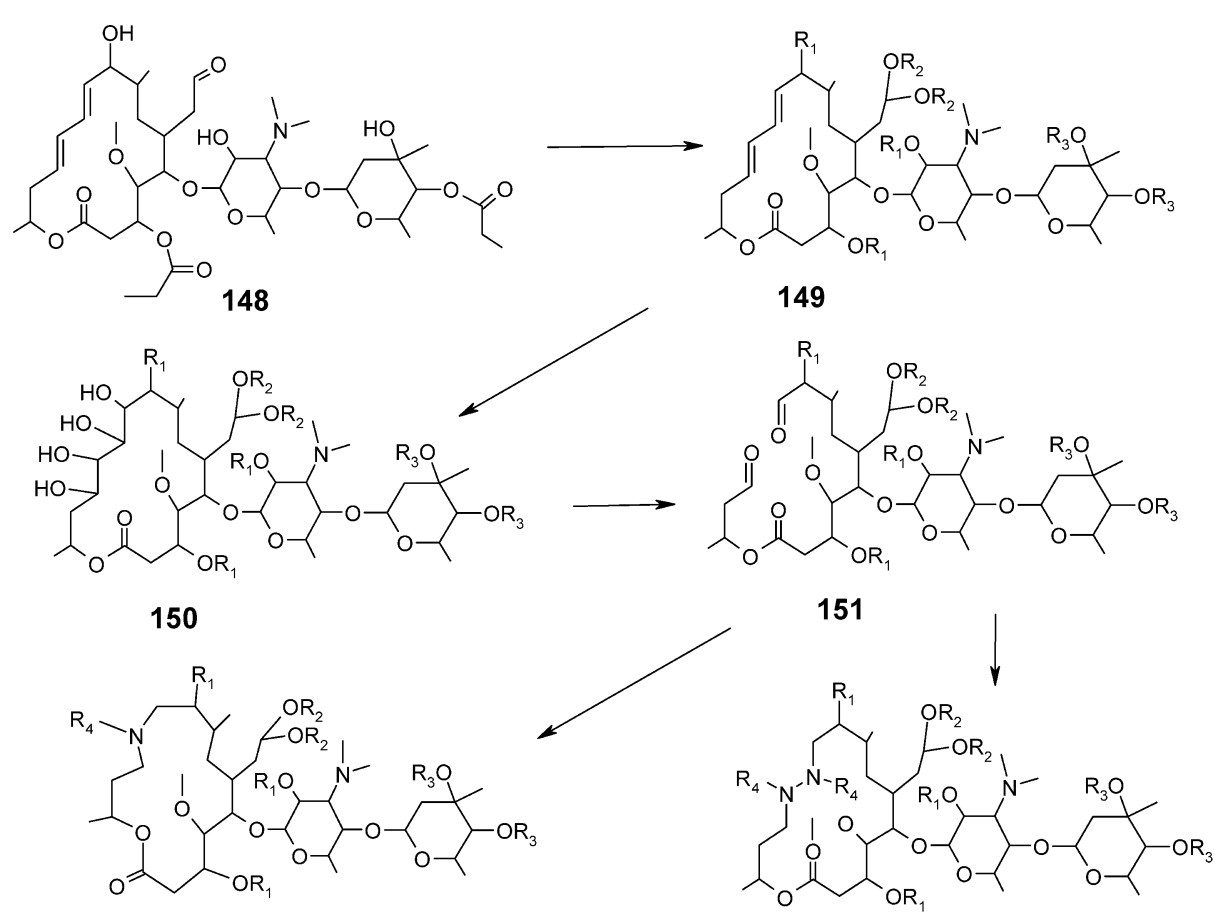

$\mathrm{R}_{1}: \mathrm{H}, \mathrm{Ac}$

$\mathrm{R}_{2}: \mathrm{Me}$

$\mathrm{R}_{3}: \mathrm{H}$, alkyl

$\mathrm{R}_{4}: \mathrm{H}$, acyl
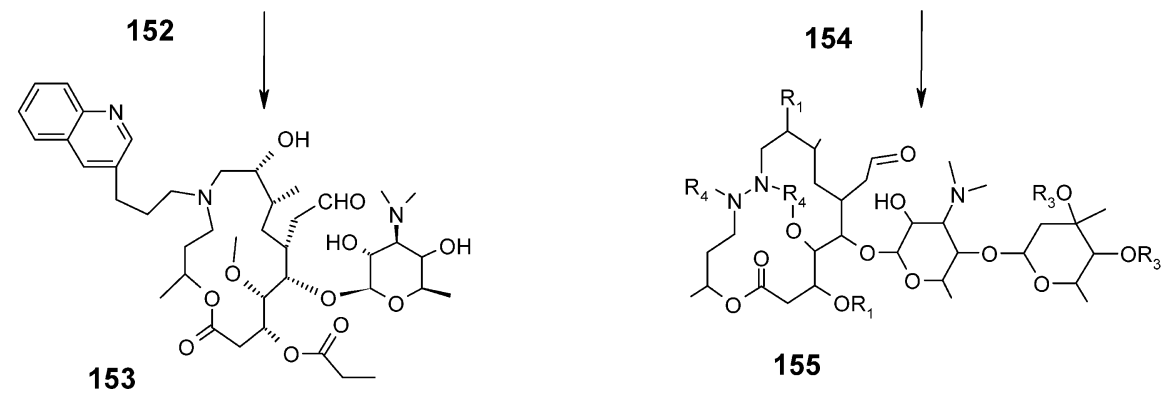

Scheme 22 Transformation of 16-membered macrolides to 15-membered 11a-azalides and 16-membered diazalides.

3-acyl 145, 3-keto 146 and 4"-carbamoyl derivatives (147).

The resulting compounds were reported to be active against common strains of respiratory tract infections including resistant strains, such as Staphylococcus aureus, Streptococcus pneumoniae, Streptococcus pyogenes, Haemophilus influenzae, with MIC's from 0.5 to $32 \mu \mathrm{g} / \mathrm{ml}$.

Another group of 11a-azalides have been prepared by authors at Meiji Seika, starting from 16-membered leucomycin $\mathrm{A}_{3} 148$ [107] (Scheme 22), which was protected and further oxidised to dialdehyde $\mathbf{1 5 1}$ and cyclised to 15-membered 11a-azalides $\mathbf{1 5 2}$ and $\mathbf{1 5 3}$ or 16membered diazalides 154 and 155.

The new synthesized compounds were active against Staphylococcus aureus, Streptococcus pneumoniae and Haemophilus influenzae.

\subsection{7-Membered Azalides}

Various attempts have been undertaken to adapt the key chemical derivatisation step (Beckmann rearrangement) to other macrolide classes or to modify the azalide skeleton further to enhance its activity.

The Beckmann rearrangement was applied to oximes of the 16-membered macrolides tylosin or desmycosin, and corresponding 17-membered 8a- and 9a-lactams were formed.

The 17-membered ring macrolides have been prepared from natural 16-membered macrolides, another large and important family of macrolide antibiotics. These are traditionally divided into sub-families based upon the substitution patterns of their aglycones [2,3]. The principal prototypes of this family are represented by leucomycin, spiramycin and tylosin. Tylosin (156) is a representative of the 16-membered macrolides and possesses a highly substituted aglycone with two double bonds (tylonolide) and a third saccharide substituent ( $\beta$-D-mycinose) in addition to the disaccharide attached to the 5-hydroxyl group. Hydrolytic cleavage of mycarose from the disaccharide yielded desmycarosyl-tylosin (desmycosin, 


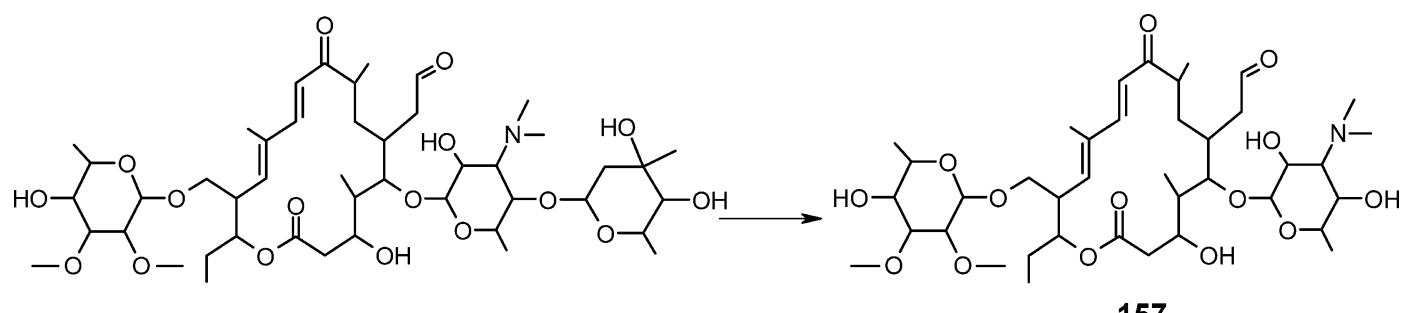

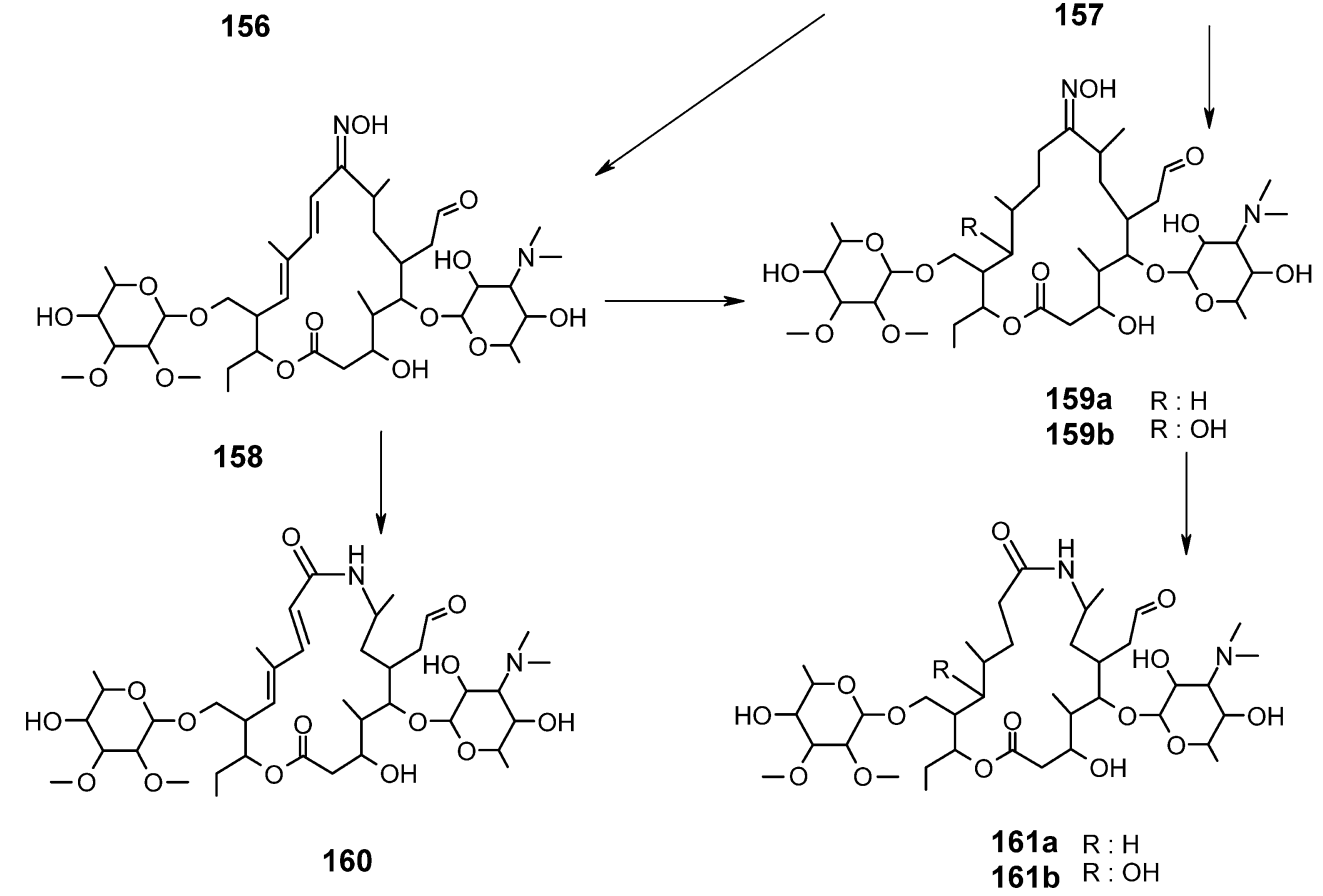

Scheme 23 Synthesis of 8a-aza-homodesmycosins and its di- or tetrahydro derivatives.

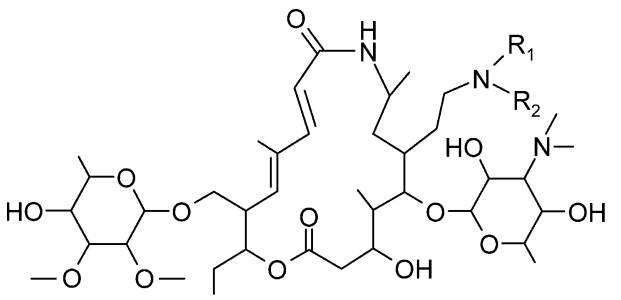

162 162a $\mathrm{R}_{1}: \mathrm{CH}_{3}, \mathrm{R}_{2}: \mathrm{CH}_{2} \mathrm{Ph}$

162b $\mathrm{R}_{1}: \mathrm{H}, \mathrm{R}_{2}:\left(\mathrm{CH}_{2}\right)_{4} \mathrm{Ph}$

162c $R_{1}: H, R_{2}:$ 3-chlorphenyl

162d $R_{1}: H, R_{2}:$ 3,5-dimethylpiperidin

162e $\mathrm{R}_{1}: \mathrm{CH}_{2} \mathrm{Ph}, \mathrm{R}_{2}: \mathrm{CH}_{2} \mathrm{Ph}$

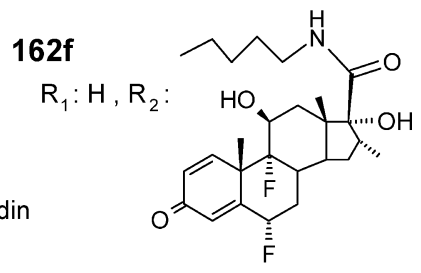

Fig. 30 Structures of 20-deoxo-20-amino-8a-aza-homodesmycosins.

157), which possesses the same antibacterial activity as tylosin.

Other possibilities for tylosin derivatisation comprise transformations of double bonds by catalytic reduction or epoxidation. Researchers at PLIVA have prepared many polyhydro-derivatives of tylosin and desmycosin [108], among them 4'-deoxy-10,11,12,13-tetrahydro-desmycosin, which showed better antibacterial activity than tylosin [109]. Oximes of tylosin, especially desmycosin (158) and their polyhydro-derivatives (159) were prepared [110]. Most of the chemical transformations were made on the desmycosin scaffold (Scheme 23), but without achieving significant improvement in biological activities.

Beckmann rearrangement of these compounds resulted in the corresponding 8a-aza-8a-homodesmycosins (160, 161a) with small amounts of 9a-aza isomers.

In an attempt to prepare 17-membered cyclic amines instead of lactams, 12,13-dihydro-13-hydroxy-desmycosin- 


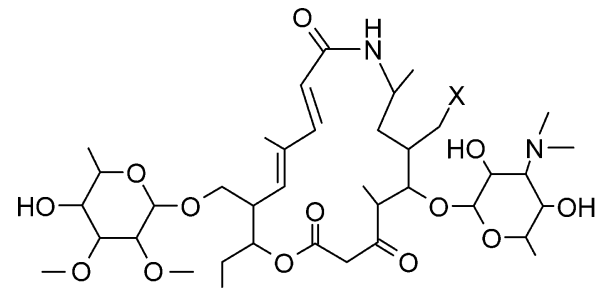

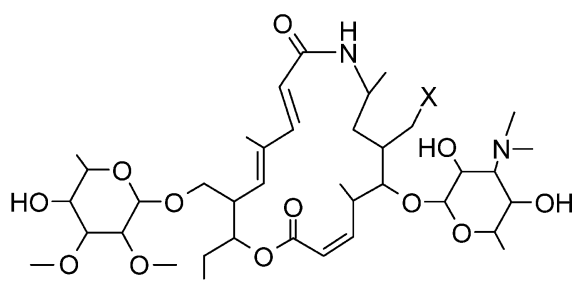

163a $X: \mathrm{CH}=\mathrm{O}$

163b $X: \mathrm{CH}_{2} \mathrm{~N}\left(\mathrm{CH}_{2} \mathrm{Ph}\right)_{2}$

164a $\mathrm{X}: \mathrm{CH}=\mathrm{O}$

$164 b \quad X: \mathrm{CH}_{2} \mathrm{~N}\left(\mathrm{CH}_{2}-\mathrm{Ph}\right)_{2}$

Fig. 31 Structures of 3-oxo- and 2,3-anhydro-20-dibenzylamino-8a-aza-homodesmycosins.
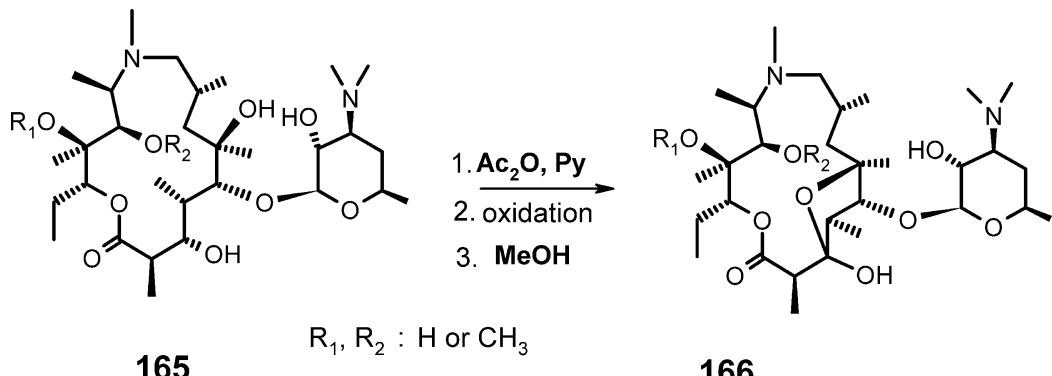

166

Scheme 24 Oxidation of descladinosyl-azithromycin derivatives and formation of 3,6-hemiketals.

oxime and 10,11,12,13-tetrahydro-13-hydroxy-desmycosinoxime (159b) have been synthesized [111]. Beckmann rearrangement did not result in the desired imino-ethers, but in 12,13-dihydro-13-hydroxy-8a-aza-8a-homodesmycosin, 10,11,12,13-tetrahydro-13-hydroxy-8a-aza-8a-homodesmycosin (161b) and its 9a-aza-9a-homo regioisomer [112].

Most 17-membered lactams showed low antibacterial activity. To improve activity, a series of 20-deoxo-20-amino derivatives of 8a-aza-8a-homodesmycosin (161) were prepared by reductive amination of the C-20 aldehyde (Fig. 30).

Only a few newer compounds (162a $\sim \mathbf{e})$ showed slight improvement in activity compared to other 20-deoxo-20amino derivatives.

The activity of the 17-membered azalide, 4'demycarosyl-20-deoxo-20-( $N, N$-dibenzylamino)-8a-aza-8ahomotylosin (162e), was examined in vitro for effects on the proliferation of five different human cell lines [113]. At a concentration of $10^{-4} \mathrm{M}$, these azalides completely inhibited the growth of all cell lines examined and induced morphological changes such as cell shrinkage, condensation and DNA fragmentation. This is typically observed in cells undergoing apoptosis.

Subsequently, new 20-aminosubstituted compounds, such as $\mathbf{1 6 2 f}$, were prepared as potential antinflammatory agents $[42,69]$.

In further synthetic work, 3-oxo-derivatives (163) and 2,3-anhydro-derivatives (164) of 8a-aza-8a-homodesmycosin or its 20-dibenzylamino analogues (Fig. 31) were synthesized [114] as compounds with antibacterial activity.

\section{Intramolecular Rearrangements of Azalides}

\subsection{Hemiketals, Spiroketals and Iminoethers}

Erythromycin has good efficacy, but low oral bioavailability and gastrointestinal side effects. As mentioned earlier, acidic conditions result in the formation of the inactive degradation products, 8,6-anhydroerytromycin-6,9-hemiketal and 6,9;9,12-spiroketal, by intramolecular rearrangement of hydroxy and keto groups.

In a first attempt to prepare a ketolide from protected erythromycin 9-oxime [115], a hemiketal was formed. After oxidation of its 3-decladinosyl derivative, the free 6hydroxy group reacted with the 3-oxo group. 14-Membered erythromycin 3,6-hemiketals didn't show antibacterial activity [93].

Attempts to prepare ketoazalides by oxidation of 3-decladinosyl-3-hydroxy-azithromycin, 3-decladinosyl- 


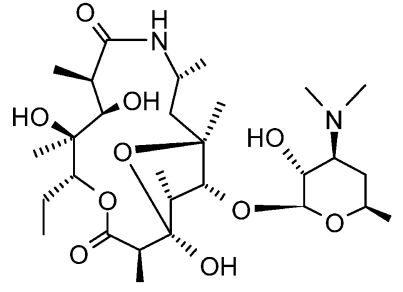

167

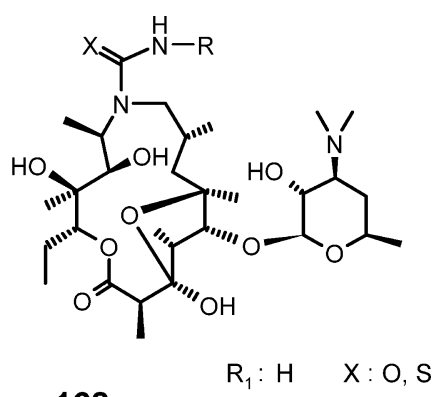

168

Fig. 32 Structures of 8a-lactam and 9a-carbamoyl-azalide 3,6-hemiketals.

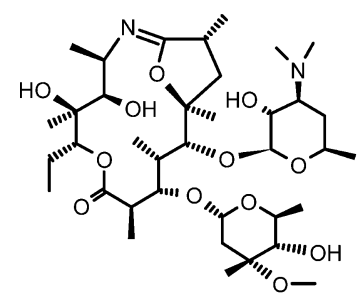

4

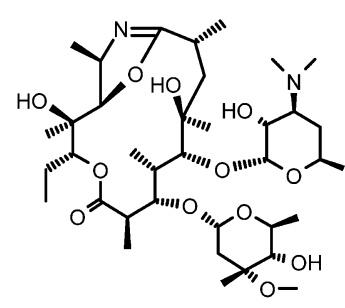

5

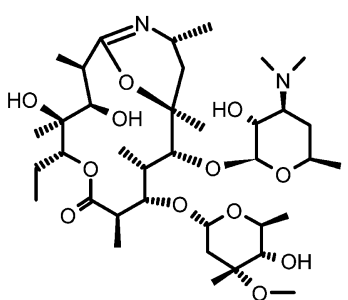

9

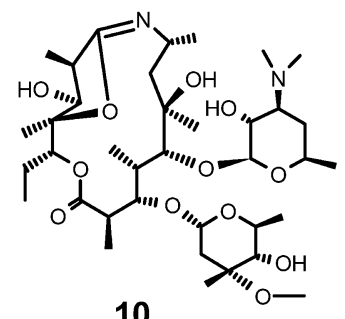

10

Fig. 33 Structures of azalide iminoethers.

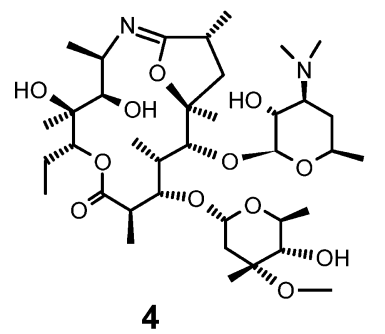

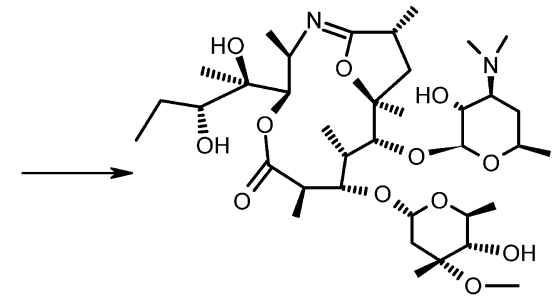

169

Scheme 25 Base induced translactonisation of 9a-aza-9a-homoerythromycin-6,9-imino-ethers.

3-hydroxy-8a-lactam or 3-decladinosyl-3-hydroxyazithromycin-9a,11-cyclic carbamate with 3-oxo groups resulted in the immediate formation of hemiketals with a 6-hydroxy group [85, 94].

Azithromycin (8) and its 11- or 12-O-methyl derivatives (30b or 30a) yielded the corresponding 3-decladinosyl derivatives 165 by acid hydrolysis, which were protected by acylation of the $2^{\prime}$-hydroxyl group, oxidized and deprotected (Scheme 24) to 3-descladinosyl-3-oxo-9amethyl-9-dihydro-9a-aza-9a-homoerythromycin-3,6hemiketals (166).

Similar 3,6-hemiketals (Fig. 32) were formed after oxidation of 3-descladinosyl-8a lactam (167) and 9acarbamoyl- or thiocarbamoyl-9a-aza-9-dihydro-9a-homoerythromycins (168) [88].

New azalide analogs formed by ring reorganization include the group of azalide precursors, such as the iminoethers (Fig. 33) mentioned above.

These compounds have no antibacterial activity.

Researchers at Merck studied transanular rearrangements of azalide iminoethers and obtained 13-membered iminoether (169) by translactonisation of 6,9-iminoether 4 with lithium hydroxide in ethanol $[20,21]$ (Scheme 25).

\subsection{Anhydrolides}

3-Descladinosyl-9a-carbamoyl-6-O-methyl-2,3-anhydro9a-aza-9-dihydro-9-homoerythromycins $\mathbf{1 7 1}$ have been obtained, when 3-descladinosyl-9a-carbamoyl-6-O-methyl9a-aza-9-dihydro-9-homoerythromycins 170 [88] were treated with mesyl-chloride (Scheme 26).

In the case of 3-descladinosyl-9a,11-cyclic carbamates, leaving the hydroxyl group at position 6 unprotected in the 


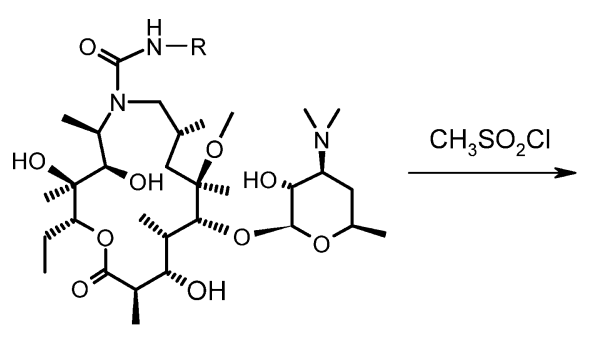

170

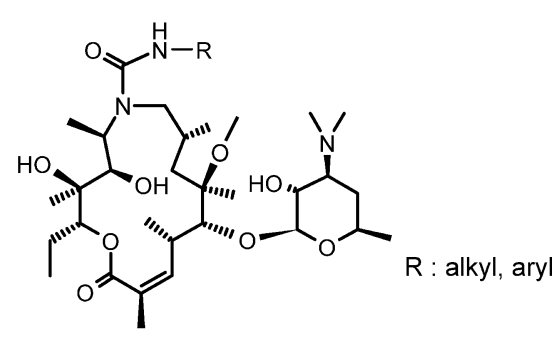

171

Scheme 26 Synthesis of 3-descladinosyl-9a-carbamoyl-2,3-anhydro-6-O-methyl-9a-aza-9-dihydro-9a-homoerythromycin.

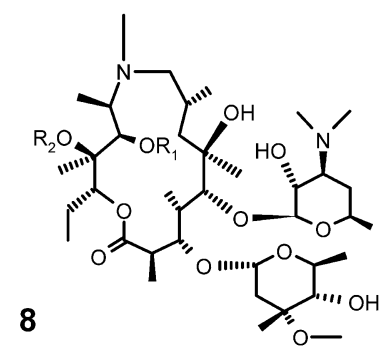<smiles>CC(C)OCCO</smiles>

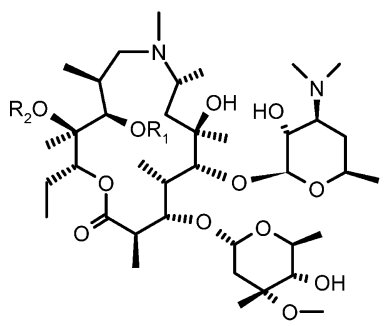

13

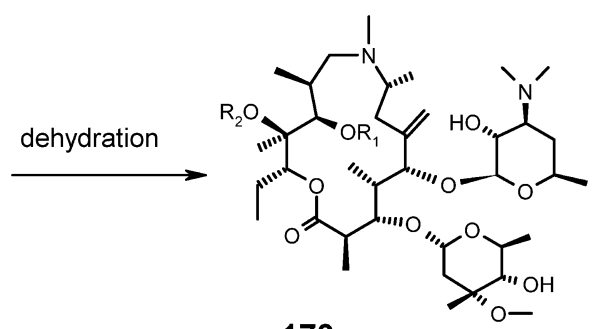

173

Scheme 27 Dehydration of isomeric 15-membered 9a- and 8a-azalides.

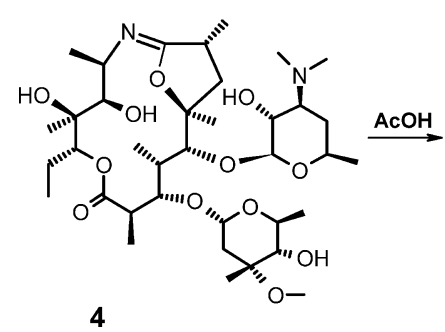

4

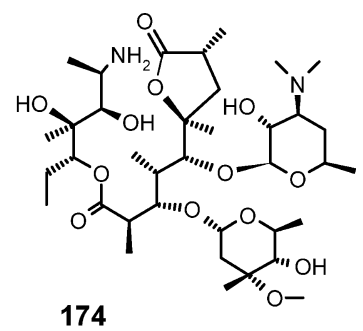

174

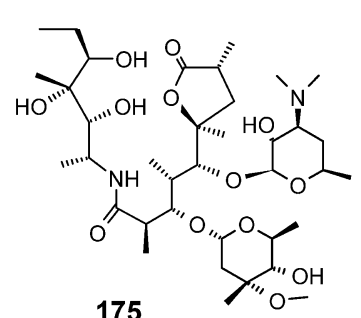

175

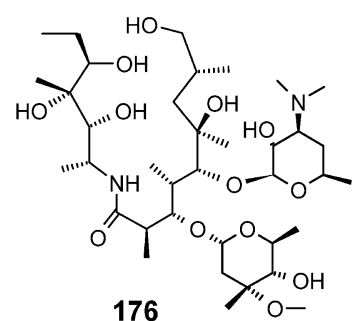

176

Scheme 28 Acid induced degradation of 9a-aza-9a-homoerythromycin-6,9-imino-ethers and formation of secomacrolides and secoazalides.

reaction with mesyl-chloride resulted in the 3,6-ether derivative [85].

Selectivity in the dehydration of 15 -membered azalides was found between 8a- and 9a-isomers (Scheme 27). It shows opposing regioselectivity [116]. Azithromycin (8) favours the $E-\Delta_{6,7}$-isomer 172 while 8a-isomer 13 generates the $-\Delta_{6,18}$-isomer 173 .

\subsection{Open Chain Analogs}

Intramolecular rearrangements by breaking the aglycone ring of some 15-membered azalides yielded corresponding secoazalides or 13-membered azalides.

In recent years, several reports have evidenced a growing interest in ring opening reactions of macrolide antibiotics, which has led to the synthesis of chimeric 9a- and 8a- 


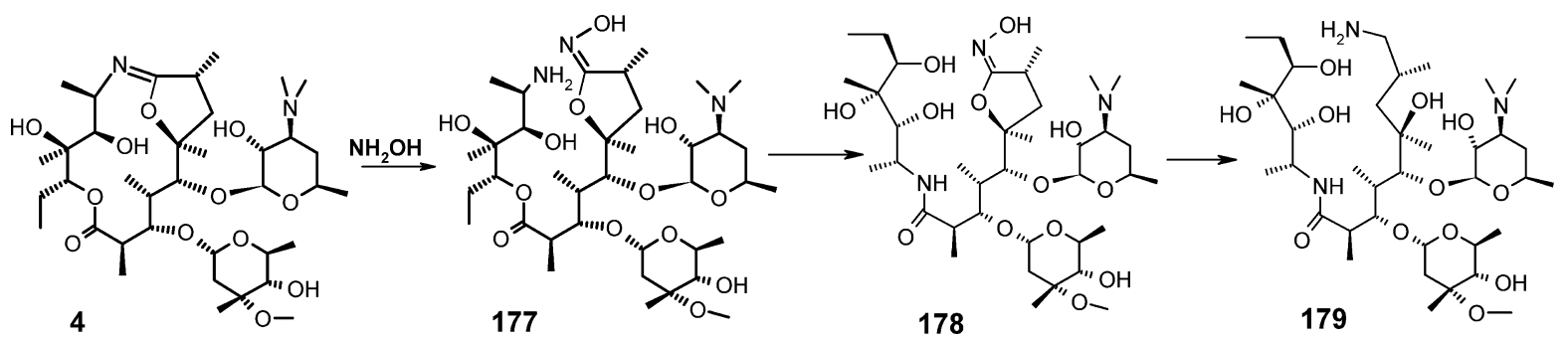

Scheme 29 Reaction of 9a-aza-9a-homoerythromycin-6,9-imino-ether with hydroxylamine and formation of secomacrolides and secoazalides.
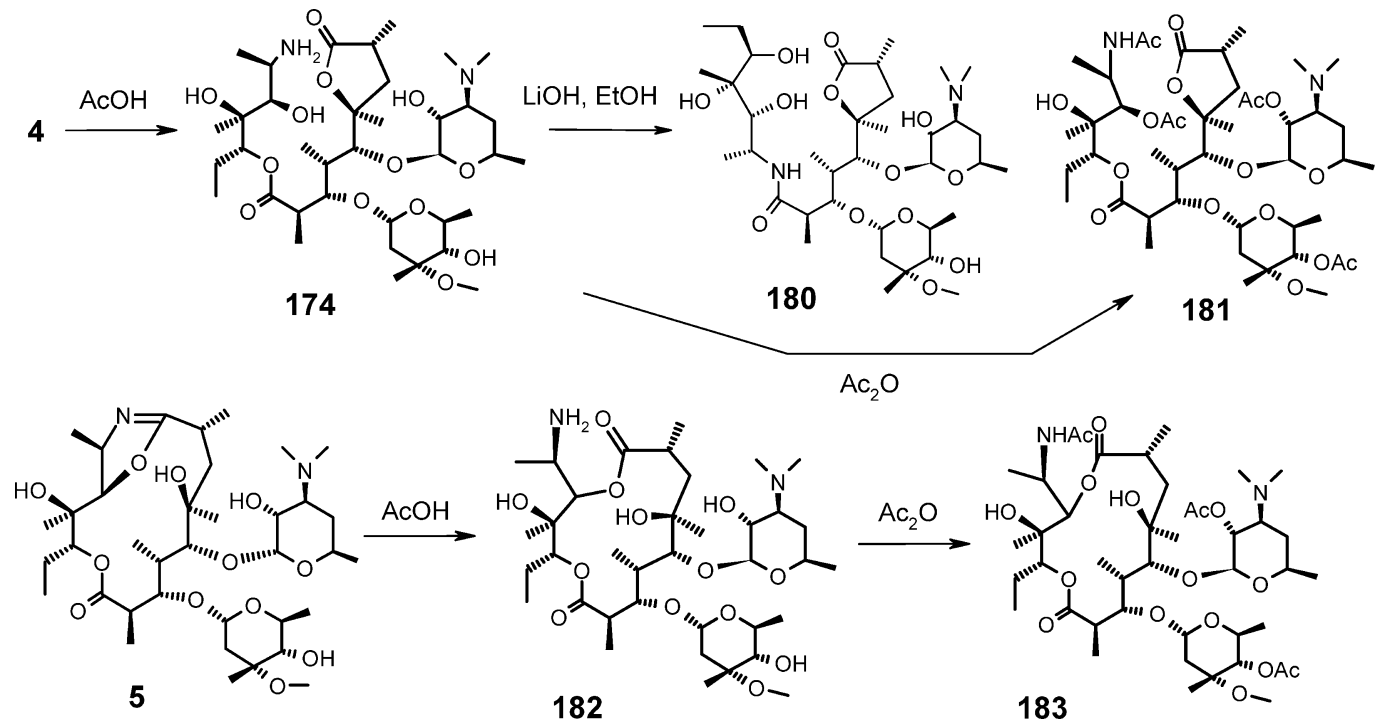

Scheme 30 Reaction of 9a-aza-9a-homoerythromycin-6,9-imino-ether with acetic acid.

azalides [117]. Two different types of base-catalyzed ringopening reactions of azalides have been reported [118, 119].

Compounds containing carbon-nitrogen double bonds are easily hydrolyzed to the corresponding aldehydes or ketones. The key intermediate in the synthesis of azithromycin 6,9-iminoether 4 has a $\mathrm{C}-9 / 9 \mathrm{a}-\mathrm{C}=\mathrm{N}$ (or carbon-nitrogen) double bond, which through acidcatalyzed hydrolysis $(\mathrm{AcOH})$ yielded the amino-lactone 174 [120]. The amino group was acylated or methylated to its corresponding $\mathrm{N}$-acetyl or $\mathrm{N}, \mathrm{N}$-dimethylamino derivative (Scheme 28). If the amino group was not protected during this reaction, amine $\mathbf{1 7 4}$ in acetone/water solution reacted by intermolecular transacylation to yield the amide 175, which was further reduced to its amido-alcohol 176. Various $O$-acetyl derivatives have been prepared. Compounds 174 176 and their acetyl derivatives, named secomacrolides or secoazalides, did not show any antibacterial activity, but are useful as intermediates for novel macrolides or azalides. Another ring-opening reaction was observed if the imino-ether 4 was treated with hydroxylamine hydrochloride [121]. During preparation of the lactam oxime, a simultaneous cleavage of the double bond led to formation of the secooxime 177. The amino-oxime $\mathbf{1 7 7}$ was acetylated to $\mathrm{N}$ - and $O$-acetyl derivatives, or trans-acylated to seco-amide $\mathbf{1 7 8}$. Catalytic reduction of the imino-ether group of amide $\mathbf{1 7 8}$ yielded the amine 179, which was converted to the corresponding $N, N$-dimethylamine (Scheme 29).

Compounds 177 179 and their acetyl or $N, N$-dimethyl derivatives did not show any antibacterial activity.

Similar rearrangements and translactonisation were observed at Merck [20,21], with the formation of novel dilactones 182 and 183 (Scheme 30).

No data on biological activity were provided.

These groups of compounds have the potential to be used as intermediates for new groups of derivatives, a general conclusion that can be applied to all the compound classes described here, due to the unlimited possibilities resulting from imaginative chemistry. 
Acknowledgements Thanks for many suggestions and corrections to Wolfgang Schoenfeld and Gorjana Lazarevski, and for English corrections to Michael Parnham.

\section{References}

1. Ōmura S. Macrolide antibiotics. Chemistry, biology and practice, Second Edition, Academic Press Inc., San Diego, London (2002)

2. Kirst HA. Structural modification of macrolide antibiotics, Recent progress in the chemical synthesis of antibiotics. Springer-Verlag, Berlin-Heidelberg, pp. 39-63 (1990)

3. Kirst HA. Introduction to the macrolide antibiotics, In Macrolide Antibiotics. Ed., Schoenfeld W, Kirst HA, pp. 1-12, Birkhauser Verlag, Basel (2002)

4. Neu HC, Young LS, Zinner SH, Acar JF. New macrolides, azalides and streptogramins in clinical practice. $E d$. Marcel Dekker, New York (1995)

5. Bryskier AJ, Agouridas C, Chantot J-F. New insights into the structure-activity relationship of macrolides and azalides; In: Bryskier AJ, Butzler J-P, Neu HC, Tulkens PM, Macrolides: Chemistry, pharmacology and clinical uses. Ed. Arnette Blackwell, pp. 3-30, Paris (1993)

6. Schoenfeld W, Mutak S. Azithromycin and novel azalides, In Macrolide antibiotics. Ed., Schoenfeld W, Kirst HA, pp. 96 Birkhauser Verlag, Basel (2002)

7. Yang BV, Goldsmith M, Rizzi A. A novel product from Beckmann rearrangement of erythromycin A $9(E)$ oxime. Tetrahedron Lett 55: 3025-3028 (1994)

8. Fattori R, Pelacini F, Romagnano S, Fronza G, Rallo R. Unusual isoxaline formation by intramolecular cyclization of (9E)-erythromycin oxime. J Antibiot 49: 938-940 (1996)

9. Djokic S, Tamburasev Z. Erythromycin study: 9-amino3-O-cladinosyl-6,11,12-trihydroxy-2,4,6,8,10,12-hexamethylpentadecane-13-olide. Tetrahedron Lett 17: 16451647 (1967)

10. Kobrehel G, Djokic S (PLIVA). Nouveaux derives de l'erythromycine A, procede pour leur preparation et leur utilisation comme substances antibacteriennes. BE. 892 357, July 1 (1982)

11. Kobrehel G, Djokic S (PLIVA). 11-Methyl-11-aza-4-Ocladinosyl-6-O-desosaminyl-15-ethyl-7,13,14-trihydroxy3,5,7,9,12,14-hexamethyl-oxacyclopentadecane-2-one and derivatives thereof. US 4517 359, May 14 (1985)

12. Kobrehel G, Radobolja G, Tamburasev Z, Dokic S. (PLIVA). 11-Aza-10-deoxo-10-dihydroerythromycin A and derivatives thereof as well a process for their preparation. US 4328334 (1982)

13. Djokic S, Kobrehel G, Lazarevski G, Lopotar N, Tamburasev Z, Kamenar B, Nagl A, Vickovic I. Erythromycin series. Part 11. Ring expansion of erythromycin A oxime by the Beckmann rearrangement. J Chem Soc Perkin Trans I
1881-1990 (1986)

14. Djokic S, Kobrehel G, Lopotar N, Kamenar B, Nagl A, Mrvos D. Erythromycin series. Part 13. Synthesis and structure elucidation of 10-dihydro-10-deoxo-11-methyl11-azaerythromycin A. J Chem Research (S): 152-153 (1988)

15. Labro MT. Anti-inflamatory activity of macrolides: a new therapeutic potential? J Antimicrob Chemother 41 (Suppl. B): 37-46 (1998)

16. Labro MT. Macrolide antibiotics: current and future uses, Expert Opin. Pharmacother 5(3): 541-550 (2004)

17. Amsden GW. Anti-inflamatory effects of macrolidesan underappreciated benefit in the treatment of community-aquired respiratory tract infections and chronic inflammatory pulmonary conditions? J Antimicrob Chemother 55: 10-21 (2005)

18. Culic O, Erakovic V, Parnham MJ. Anti-inflammatory effects of macrolide antibiotics. Eur J Pharmacol 429: 209-229 (2001)

19. Sassa K, Mizushima Y, Fujishita T, Oosaki R, Kobayashi M. Therapeutic effect of clarithromycin on a transplanted tumor in rats. J Antimicrob Chemother 43: 67-72 (1999)

20. Wilkening RR, Ratcliffe RW, Doss GA, Mosley RT, Ball RG. Novel transanular rearrangements of azalide iminoethers. Tetrahedron 53: 16923-16944 (1997)

21. Wilkening RR, Ratcliffe RW, Doss GA, Bartizal KF, Graham AC, Herbert CM. The synthesis of novel-8a-aza8a-homoerythromycin derivatives via the Beckmann rearrangement of (9Z)-erythromycin A oxime. Bioorg Med Chem Lett 3: 1287-1292 (1993)

22. Heck JV, Leanza WJ, Ratcliffe RW, Salzmann TN, Wilkening RR, Szymonifka MJ, Shankaran K. (Merck \& Co). 9-Deoxo-8a-aza-8a-homoerythromycin a derivatives modified at 4"- and 8a-positions. Eur Pat. 0508699 A1, Oct. 14 (1992)

23. Lazarevski G, Vinkovic M, Kobrehel G, Djokic S, Metelko B. Conformational analysis of 9-deoxo-9a-aza-9a- and 9deoxo-8a-aza-8a-homoerythromycin A 6,9-cyclic iminoethers. Tetrahedron 50: 12201-12210 (1994)

24. Bright GM (Pfizer). Antibacterial $N$-methyl 11-aza-10deoxo-10-dihydro-erythromycin A and pharmaceutically acceptable acid addition salts thereof, intermediates therefore, and processes for their preparation. USP 4474 768, Oct. 2 (1984)

25. Bright GM, Nagel AA, Bordner J, Desai KA, Dibrino JN, Nowakowska J, Vincent L, Watrous RM, Sciavolino FC, English AR, Retsema JA, Anderson MR, Brennan LA, Borovoy RJ, Cimochowski CR, Faiella JA, Girard AE, Girard D, Herbert C, Manousos M, Mason R. Synthesis, in vitro and in vivo activity of novel 9-deoxo-9a-aza-9ahomoerythromycin A derivatives; a new class of macrolide antibiotics, the azalides. J Antibiot 41: 1029-1047 (1988)

26. Allen DJM, Nepveux KM (Pfizer). Non-hygroscopic, azithromycin (9-deoxo-9a-aza-9a-methyl-9a-homoerythromycin) dihydrate and a process therefor. US 8701612 , 
Jan. 26 (1989)

27. Kamenar B, Nagl A, Mrvos D. Structural investigations of 11-methylaza-10-deoxo-10-dihydroerythromycin A $\left(\mathrm{DCH}_{3}\right)$. 10th Meeting of chemists of Croatia, Feb. 16 18, Zagreb, Croatia, Abstr. p. 29 (1987)

28. Djokic S, Kobrehel G, Lazarevski G. Erythromycin series XII. Antibacterial in vitro evaluation of 10-dihydro-10deoxo-11-azaerythromycin A: synthesis and structure activity relationship of its acyl derivatives. J Antibiot 40: 1006-1015 (1987)

29. Bucar D, Cincic D, Danilovski A, Dumbovic A, Dumic M, Filic D, Knezevic Z, Lazarevski G, Lazaric K, Mestrovic E, Oresic M, Vinkovic M. (PLIVA). Novel amorphous 9deoxo9a-aza-9a-methyl-9a-homoerythromycin A. Process for preparing the same, and use thereof. WO 2004/009608, Jan. 29 (2004)

30. Djokic S, Vajtner Z, Lopotar N, Mrvos-Sermek D, Kamenar D, Nagl A. Complexes of azithromycin with some divalent metal ions. Croatica Chemica Acta 68: 375-381 (1995)

31. Retsema J, Girard A, Schelkly W, Manousos M, Anderson M, Bright G, Borovoy R, Brenan L, Mason R. Spectrum and mode of action of azithromycin (CP-62,993), a new 15-membered-ring macrolide with improved potency against Gram-negative organisms. Antimicrob Agent Chemother 31: 1939-1947 (1987)

32. Fiese EF, Steffen SH. Comparism of the acid stability of azithromycin and erythromycin A. J Antimicrob Chemother 25: 39-47 (1990)

33. Girard AE, Girard D, English AR, Gotz TD, Cimochowski CR, Faiella JA, Haskell SL, Retsema JA. Pharmacokinetic and in vivo studies with azithromycin (CP-62,993), a new macrolide with an extended half life and excellent tissue distribution. Antimicrob Agent Chemother 31: 1948-1954 (1987)

34. Foulds G, Shepard RM, Johnson RB. The pharmacokinetics of azithromycin in human serum and tissues. $\mathrm{J}$ Antimicrob Chemother 25: 73-82 (1990)

35. Schonwald S, Skerk V, Petricevic I, Car V, Majerus-Misic L, Gunjaca M. Comparism of three-day and five-day courses of azithromycin in the treatment of atypical pneumonia. Eur J Clin Microbiol Infect Dis 10: 877-880 (1991)

36. Lazarevski G, Vinkovic M, Kobrehel G, Djokic S, Metelko B, Vikic-Topic D. Conformational analysis of azithromycin by nuclear magnetic resonance spectroscopy and molecular modelling. Tetrahedron 49: 721-730 (1993)

37. Schlutzen F, Harms JM, Franceschi F, Hansen AS, Bartels $\mathrm{H}$, Zarivach R, Yonath A. Structural basis for the antibiotic activity of ketolides and azalides. Structure 11: 329-338 (2003)

38. Jones AB, Herbert CM. Assessment of the biological value of the 11-hydroxy group of the azalides. Bioorg Med Chem Lett 3: 1999-2004 (1993)

39. Kamenar B, Mrvos-Sermek D. Nagl A. Crystal structure of 9-deoxo-9-dihydro-9a-(n-propyl)-9a-aza-9a-homo-erythronolide $\mathrm{A}, \mathrm{C}_{24} \mathrm{H}_{47} \mathrm{NO}_{7}$. Zeitschrift für Kristallographie 211: 415-417 (1996)

40. Markovic S, Mercep M, Mesic M, Tomaskovic L (PLIVA). Novel compounds, compositions as carriers for steroid/ non-steroid anti-inflammatory, antineoplastic and antiviral active molecules. WO 2004/005313, January 15 (2004)

41. Makaruha O, Markovic S, Mercep M, Mesic M, Poljak V, Tomaskovic L. (PLIVA). New compounds, compositions and methods for treatment of inflammatory diseases and conditions. WO 2004/005310 A2, January 15 (2004)

42. Mercep M, Mesic M, Hrvacic B, Elenkov IJ, Malnar I, Markovic S, Simicic L, Cempuh-Klonkay A, Filipovic A (PLIVA). Substituted furochromene compounds of antiinflammatory action. US2006148890, July 6 (2006)

43. Mercep M, Mesic M, Tomaskovic L, Komac M, Hrvacic B, Markovic S (PLIVA). Conjugates of immune cell specific macrolide compounds with anti-inflammatory compounds for improved cellular targeting of anti-inflamatory therapy. WO 02/055531, July 18 (2002)

44. Kujundzic N, Kobrehel G, Banic Z, Kelneric Z, KojicProdic B. Azalides: Synthesis and antibacterial activity of novel $9 \mathrm{a}-N$ - $\left(N^{\prime}\right.$-substituted carbamoyl and thiocarbamoyl) derivatives of 9-deoxo-9a-aza-9a-homoerythromycin A. Eur J Med Chem 30: 455-462 (1995)

45. Sheldrick GM, Kojic-Prodic B, Banic Z, Kobrehel G, Kujundzic N. Structure of 9-deoxo-9a- $N$-( $N^{\prime}-\left(4^{\prime}\right.$-pyridyl)carbamoyl)-9a-aza-9a-homoerythromycin A and conformational analysis of analogous 9a-aza 15-membered azalides in solid state. Acta Cryst B51: 358-366 (1995)

46. Marusic-Istuk Z, Kujundzic N, Kobrehel G, Mutak S, Marsic N (PLIVA). Halo derivatives of 9-deoxo-9a-aza-9ahomoerythromycin A. WO 00/66603, Nov. 9 (2000)

47. Brajsa K., Bukvic Krajacic M. Kujundzic N (PLIVA). Substituted 9a- $N-\left(N^{\prime}\right.$-(4-(sulfonyl)phenylcarbamoyl derivatives of 9-deoxo-9-dihydro-9a-aza-9a-homoerythromycin A and 5-O-desosaminyl-9-deoxo-9-dihydro-9a-aza-9a-homoerythronolide A. WO 2004/043985, May 27 (2004)

48. Kujundzic N, Bukvic Krajacic M, Dumic M, Hasenohrl A (PLIVA). 9a- $N$-[N'-(Phenylsulfonyl)carbamoyl] derivatives of 9-deoxo-9-dihydro-9a-aza-9a-homoerythromycin A and of 5-O-desosaminyl-9-deoxo-9-dihydro-9a-aza-homoerythronolide A. US 2004/0077558, April 22 (2004)

49. Bukvic Krajacic M, Kujundzic N, Dumic M, Cindric M, Brajsa K, Metelko B, Novak P. Synthesis, characterization and in vitro antimicrobial activity of novel sulfonylureas of 15-membered azalides, J Antibiot 58: 380-389 (2005)

50. Kujundzic N, Pavlovic D, Kobrehel G, Lazarevski G, Kelneric Z (PLIVA). Beta,beta-disubstituted derivatives of 9-deoxo-9a- $N$-ethenyl-9a-aza-9a-homoerythromycin A. EP 0927722 B1, March 12 (2003)

51. Alihodzic S, Lazarevski G, Derek M, Mutak S, Stimac V, Marusic-Istuk Z, Berdik A, Marsic N, Rusic-Pavletic J, Erakovic V, Schoenfeld W, Petrone M. Synthesis and antibacterial activity of $4 "$ - $O$-substituted 8 a-aza-8a-homo- 
erythromycins. 43rd Intersci Conf on Antimicrob Agents Chemother, ICAAC, Chicago, USA, September 14 17, 2001, F-1185 (2003).

52. Stimac V, Alihodzic S, Lazarevski G, Pavlovic D, Berdik A, Mutak S, Marsic N, Rusic-Pavletic J, Dominis Kramaric M, Erakovic V. Sinteza i antibakterijska aktivnost 6-Oalkil-4"-O-substituiranih 8a-aza-8a-homoeritromicina i 6$O$-alkileritromicin 9(E)- i 9(Z)-oksima. V. Susret mladih kemijskih inzenjera, Febr. 19 20, Zagreb, Croatia, Abstr. p. 85 (2004)

53. Kobrehel G, Lazarevski G, Djokic S, Kolacni-Babic L, Kucisec-Tepes N, Cvrlje M. Synthesis and antibacterial activity of $O$-methylazithromycin derivatives. J Antibiot 45: 527-534 (1992)

54. Waddell ST, Santorelli GM, Blizzard TA, Graham A, Occi J. Synthesis and antibacterial activity of $O$-methyl derivatives of azalide antibiotics: I. 4", 11 and 12-O-Me derivatives via direct methylation. Bioorg Med Chem Lett 8: 549-554 (1998)

55. Kamenar B, Kosutic-Hulita N, Vickovic I, Kobrehel G, Lazarevski G. 11,12,4"-Tri-O-methylazythromycin monohydrate. Acta Cryst C52: 2566-2568 (1996)

56. Waddell ST, Santorelli GM, Blizzard TA, Graham A, Occi J. Synthesis and antibacterial activity of $O$-methyl derivatives of azalide antibiotics: II: 6-O-Me derivatives via clarithromycin. Bioorg Med Chem Lett 8: 1321-1326 (1998)

57. Derek M, Kidemet D, Leljak M (PLIVA). Selective alkylation of macrolide and azalide derivatives comprises reacting an macrolide or azalide derivative having a vicinal hydroxyl system with diazoalkane in the presence of transition-metal halides and of boric acid. WO 2004/106353, Sept. 12 (2004)

58. Derek M, Kidemet D, Lazarevski G, Leljak M (PLIVA). Preparation of 11-alkoxy compounds useful as antibacterial agents involves reacting macrolide or azalide having vicinal hydroxyl system with diazoalkane in the presence of transition-metal halide or boric acid in inert organic solvent. WO 2004/106354, Sept. 12 (2004)

59. Denis A, Agouridas C. Synthesis of 6-O-methylazithromycin and its ketolide analogue via Beckmann rearrangement of 9(E)-6-O-methyl-erythromycin oxime. Bioorg Med Chem Lett 8: 2427-2432 (1998)

60. Keyes RF, Ma Z, Or YS (Abbott). 9a-Azalides with antibacterial activity. US 6764996, July 20 (2004)

61. Wu YJ, Wons R, Durkin D, Goldsmith M, and others. Synthesis and in vitro activity of novel C-4 carbamates of 14- and 15-membered macrolides. 38th Interscience conference of antimicrobial agents and chemotheraphy, San Diego, California, Abstract F-123 (1998)

62. Cheng H, Letavic MA, Ziegler CB, Dutra JK, Bertinato P, Bronk BS (Pfizer). C11 Carbamates of macrolide antibacterials. EP 0984019 A1, Mar. 8 (2000)

63. Alihodzic S, Andreotti D, Berdik A, Biondi S, Ciraco, Damiani F, Derek M, Dumic M, Erakovic V, Hutinec A,
Lazarevski G, Lociuro S, Marsic N, Mutak S, Paio A, Pavlovic D, Quaglia, Schoenfeld W, Stimac V, Tibasco J. (PLIVA \& GSK). Macrolides. WO 03/042228 A1, May 22 (2003)

64. Hutinec A, Derek M, Stimac V, Alihodzic S, Mutak S, Erakovic V, Biondi S, Paio A. Synthesis and antibacterial activity of 4 "-O-beta-aminopropionyl-8a- and 9a-aza-homo erythromycins. 2nd Brazilian Symposium on Medicinal Chemistry, Nov. 22 25, Rio de Janeiro, Brazil, SA-06 (2004)

65. Alihodzic S, Jarvest RL, Palej I (PLIVA \& GSK). Novel 14 and 15-membered ring compounds. WO 2004101588, November 25 (2004)

66. Alihodzic S, Berdik A, Berge JM, Jarvest RL, Mutak S. (PLIVA \& GSK). Macrolides substituted at 4"-position. WO 2004101585, November 25 (2004)

67. Berge JM, Forrest AK, Jarvest RL (GSK). Novel 14 and 15 membered-ring compounds. WO 2004101589, November 25 (2004)

68. Mercep M, Mesic M, Tomaskovic L, Markovic S (PLIVA). Novel nonsteroidal antiinflamatory subtrances, composition and methods for their use. WO 2004005309, April 22 (2004)

69. Mercep M, Mesic M, Tomaskovic L, Markovic S, Makaruha O, Poljak V (PLIVA). New compounds, compositions and methods for treatment of inflammatory diseases and conditions. US 2004014685, January 22 (2004)

70. Kobrehel G, Lazarevski G, Kelneric Z, Djokic S. 9a,11Cyclic carbamates of 15-membered azalides. J Antibiot 46: 1239-1245 (1993)

71. Blizzard TA, Waddell ST, Santorelli GM (Merck). 9a-Aza3-ketolides, compositions containing such compounds and methods of treatment. WO 99/00125, Jan. 7 (1999)

72. Blizzard TA, Santorelli GM (Merck). 8a-Azalides, compositions containing such compounds and methods of treatment. WO 99/19331, Apr. 22 (1999)

73. Wang G, Peng Y, Wang Y, Phan LT, Or YS (ENANTA). 9a,11-3C-Bicyclic 9a-azalide derivatives, WO 2005/ 030227, April 7 (2005)

74. Shankaran K, Wilkening RR, Blizzard TA, Bartizal KF, Ratcliffe RW, Heck JV, Graham AC, Herbert CM. Preparation and activities of 4 "-epi and 4 "-deoxy- $\alpha$-amino analogs derived from 9-deoxo-8a-aza-8a-homoerythromycin A. Bioorg Med Chem Lett 4: 1111-1116 (1994)

75. Alihodzic S, Berdik A, Jarvest RL, Lazarevski G (PLIVA \& GSK). Novel 14 and 15 membered-ring compounds. WO 2004/101590, May 11 (2004)

76. Bronk BS, Letavic MA, Bertsche CD, George DM, Hayashi SF, Kamicker BJ, Kolosko NL, Norcia LJ, Rushing MA, Santoro SL, Yang BV. Synthesis, stereochemical assignment and biological activity of a novel series of C-4" modified aza-macrolides. Bioorg Med Chem Lett 13: 1955-1958 (2003)

77. Rafka RJ, Ragan CB, Allen DJM (Pfizer). New crystalline 
diphosphate salt of antibacterial and antiprotozoal agent, for parenteral administration to livestock. WO 200102414, Jan. 12 (2005)

78. Pesachovic M, Isaacs S, Singer C, Schwartz E, Berger E (TEVA). Degradation products of azithromycin and methods for their identification. WO 04/0087729, October 14 (2004)

79. Codony A, Diago J, Garcia R, Rifa J (Sandoz). Derivatives of azithromycin. WO 2004/09276, October 28 (2004)

80. Leclercq R, Courvalin P. Bacterial resistance to macrolide, lincosamide and streptogramin antibiotics in bacteria. Antimicrob Agents Chemother 35: 1267-1272 (1991)

81. Weisblum B. Erythromycin resistance by ribosome modification. Antimicrob Agents Chemother 39: 577-585 (1995)

82. Asaka TT, Misawa YT, Kashimura MT, Morimoto ST, Hatayama KT (Taisho). 5-O-Desosaminylerythronolide derivative. EP 0619 320, Oct. 12 (1994)

83. Tanikawa T, Asaka T, Kashimura M, Suzuki K, Sugiyama H, Sato M, Kameo K, Morimoto S, Nishida A. Synthesis and antibacterial activity of a novel series of acylides: 3-O(3-pyridyl)acetyl-erythromycin A derivatives. J Med Chem 46: 2706-2715 (2003)

84. Alihodzic S, Kobrehel G, Lazarevski G, Mutak S, Marsic N, Dominis-Kramaric M, Erakovic V, Schoenfeld W. Synthesis and antibacterial activity of isomeric 15membered azalides. 41st Interscience conference of antimicrobial agents and chemotheraphy, ICAAC, September 22 25, Chicago, USA, F-1177 (2001)

85. Berdik-Fajdetic A, Kobrehel G, Lazarevski G, Stimac V, Mutak S. 3-O-Acyl derivatives of bridged-15-membered azalides: Synthesis, structural determination and antibacterial activity. Croatica Chemica Acta 78: 301-312 (2005)

86. Berdik A, Kobrehel G, Lazarevski G, Mutak S (PLIVA). New 3-decladinosyl derivatives of 9-deoxo-9a-aza-9ahomoerythromycin A 9a-11-cyclic carbamate useful for treating bacterial infections. WO-200429067, Apr. 29 (2004)

87. Sakya SM, Bertinato P, Prat B, Suarez-Contreras M, Lundy KM, Minich ML, Cheng H, Ziegler CB, Kamicker BJ, Haxashi SF, Santoro SL, George DM, Bertsche CD. Azalide 3,6-ketals: antibacterial activity and structureactiivity relationships of aryl and hetero aryl substituted analogues. Bioorg Med Chem Lett 13: 1373-1375 (2003)

88. Kujundzic N, Mutak S, Marusic-Istuk Z (PLIVA). New 3decladinosyl derivatives of $9 \mathrm{a}, \mathrm{N}$-(thio)carbamoyl-9-deoxo9-dihydro-9a-aza-9a-homoerythromycin A useful in the treatment of bacterial infections. WO 2004/101591, 25.11.2004, prior. HR 14.05.2003 (2004)

89. Mereu A, Morazzoni G, Moriggi E, Napoletano M, Ornaghi F, Pellacini F. New 9a-azalide derivatives having anti-inflammatory activity useful for the treatment of e.g. inflammatory pathologies and respiratory pathologies. WO 2004/039821, October 28 (2003)
90. Corbaz L, Ettlinger L, Gauman E, Keller W, Kradolfer F, Kyburz E, Neipp L, Prelog V, Reusser R, Zahner H. Stoffwechselprodukte von Actinomyceten. Narbomycin. Helv Chim Acta 35: 935-942 (1955)

91. Brockmann H, Henkel W. Picromycin, ein bitter schmeckendes Antibioticum aus Actinomyceten. Chem Ber 84: 284-288 (1951)

92. Allen N. Macrolide resistance in Staphylococcus aureus: inducers of macrolide resistance. Antimicrob Agents Chemother 11: 669-674 (1977)

93. Agouridas C, Denis A, Auger J-M, Beneddeti Y, Bonnefoy A, Bretin F, Chantot J-F, Dussarat A, Fromentin C, D’Ambriéres SG, Lachaud S, P.Laurin, Le Martret O, Loyau V, Tessot N. Synthesis and antibacterial activity of ketolides (6-O-methyl-3-oxoerythromycin derivatives): A new class of antibacterials highly potent against macrolideresistant and -susceptible respiratory pathogens. J Med Chem 41: 4080 (1998)

94. Kobrehel G, Lazarevski G, Vinkovic M (PLIVA). Novel 3,6-hemiketals from the class of 9a-azalides. WO09920639, Apr. 29 (1999)

95. Denis A, Agouridas C, Auer J-M, Beneddeti Y, Bonnefoy A, Bretin F, Chantot J-F, Dussarat A, Fromentin C, D’Ambrieres SG, Lashaud S, Laurin P, Le Martret O, Loyau V, Tessot N, Pejac J-M, Perron S. Synthesis and antibacterial activity of HMR 3647, a new ketolide highly potent against erythromycin-resistant and susceptible pathogens. Bioorg Med Chem Lett 9: 3075-3080 (1999)

96. Ma Z, Nemoto PA. Discovery and development of ketolides as a new generation of macrolide antimicrobial agents. Curr Med Chem-Anti-infective Agents 1: 15-34 (2002)

97. Lazarevski G, Kobrehel G, Kelneric Z (PLIVA). 15Membered lactams ketolides with antibacterial activity. WO 99/51616, Oct. 14 (1999)

98. Niu D, Wang G, Vo NH, Kim H, Xu G, Peng Y, Wang Y, Busuyek M, Amsler K, Polemeropoulos A, Scorneaux B, Phan LT, Or YS. Synthesis and antibacterial activities of novel 2-fluoro-6,11-bridged oxime ketolides. 43rd Interscience conference of antimicrobial agents and chemotheraphy, September 14 17, Chicago, USA, F-1196 (2003)

99. Busuyek M, Or JS, Phan LT, Wang G (ENANTA). 6,113C-Bicyclic 9A-azalide derivatives. US 6645941 B1, Nov. 11 (2003)

100. Phan LT, Wang G, Or JS (ENANTA). 6,11-4C-Bicyclic 9aazalide derivatives of erythromycin useful for controlling bacterial infection. US. 6764998 B1, July 20 (2004)

101. Or YS, Qiu YL, Wang G, Niu D, Phan LT. Novel bicyclic 9a-azalide derivatives. US 2006/0069048 A1, March 30 (2006)

102. Rafka RJ, Morton BJ, Ragan CB, Bertinato P, Dirlam JP, Blize AE, Ziegler CB (Pfizer). 13-Membered azalides and their use as antibiotic agents. WO 00/31097, June 2 (2000)

103. Bartizal KF, Hammond ML, Schmatz DM, Wilkening RR. 
(Merck). 6,11-3C-Bicyclic 8a-azalide derivatives. WO 2005/072204, November 8 (2005)

104. Clark R, Djuric SMZ, Wang Z (Abbott). 11-Deoxy azalide antibacterials. WO 03/090679 A2, November 6 (2003)

105. O'Connell TN, Morse BK, McArthur HAI, Dirlam JP (Pfizer). Azalides and methods of making same. US 6,270,768, Aug. 7 (2001)

106. Deshpande P, Sindkhedkar MD, Desai V, Gupte SV, Yeole RD, Patel MV, De Souza NJ (Wockhard Chem. Centre). Azalides and azaketolides having antimicrobial activity. WO 2004/108744 A2, December 16 (2004)

107. Ajito K, Kurihara K, Miura T, Yoshida T (Meji Seika). Novel 15-membered cyclic azalide, novel 16-membered cyclic diazalide derivative, and process for production these. WO 03/072589 A1, Febr. 25 (2003)

108. Naranda A, Suskovic B, Kelneric Z, Djokic S. Structureactivity relationship among polyhydro derivatives of tylosin. J Antibiot 47: 581-587 (1994)

109. Naranda A, Kelneric Z, Kolacni-Babic L, Djokic S. 10,11,12,13-Tetrahydro derivatives of tylosin. Synthesis, antibacterial activity and tissue distribution of $4^{\prime}$-deoxy10,11,12,13-tetrahydrodesmycosin. J Antibiot 48: 248-253 (1995)

110. Lopotar N, Djokic S (PLIVA). Tylosine derivatives. EP 0410433B1, Febr. 28 (1996)

111. Naranda A, Lopotar N, Kelneric Z. Synthesis of novel dihydro and tetrahydro desmycosin derivatives. Fourth International Conference on the Macrolides, Azalides, Streptogramins and Ketolides, ICMASK 4, Barcelona, Spain, Abstr. 1.29 (1998)

112. Lopotar N, Naranda A, Vela V, Derek M, Marsic N. Synthesis and microbiological activity of 17-membered azalides. Fifth International Conference on the Macrolides, Azalides, Streptogramins, Ketolides and Oxazolidinones, Seville, Spain, Abstr. 1.01 (2000)

113. Grdisa M, Lopotar N, Pavelic K. Effect of a 17-member azalide on tumor cell growth. Chemotherapy 44: 331 (1998)

114. Lopotar N, Narandja A, Mutak S. Derivatives of 4'demycarosyl-8a-aza-8a-homotylosin. WO 00/77016, Dec. 12 (2000)

115. LeMahieu RA, Carson M, Kerstead RW, Fern LM, Grundberg DE. Glycoside cleavage on erythromycin A. Preparation of erythronolide A. J Med Chem 17: 953-956 (1974)

116. Jones AB, ActionIII JJ, Doss GA. Selectivity in the dehydration of 15-membered azalides. Tetrahedron Lett 31: 4913-4916 (1993)

117. Waddell ST, Blizard. Chimeric azalides with simplified western portions. Tetrahedron Lett 34: 5385-5388 (1993)

118. Waddell ST, Blizard. Base catalysed ring opening reactions of erythromycin A. Tetrahedron Lett 33: 7827-7830 (1992)

119. Waddell ST, Blizard. Semisynthesis of linear fragments corresponding to the eastern portion of azalide antibiotics. Bioorg Med Chem Lett 3: 1757-1760 (1993)

120. Lazarevski G, Kobrehel G, Naranda A, Banic-Tomisic Z, Metelko B. Acid catalyzed ring opening reactions of 6deoxy-9-deoxo-9a-aza-9a-homoerythromycin 6,9-cyclic imino ether. J Antibiot 51: 893-896 (1998)

121. Lazarevski G, Kobrehel G, Metelko B, Duddeck H. Ring opening reactions of 6-deoxy-9-deoxo-9a-aza-9ahomoerythromycin 6,9-cyclic imino ether. J Antibiot 49: 1066-1069 (1996) 